\title{
Updated Draft ASME Boiler and Pressure Vessel Code Case for Use of Alloy 617 for Construction of Nuclear Components for Section III, Division 5
}

R. N. Wright

September 2018

The INL is a

U.S. Department of Energy

National Laboratory

operated by

Battelle Energy Alliance

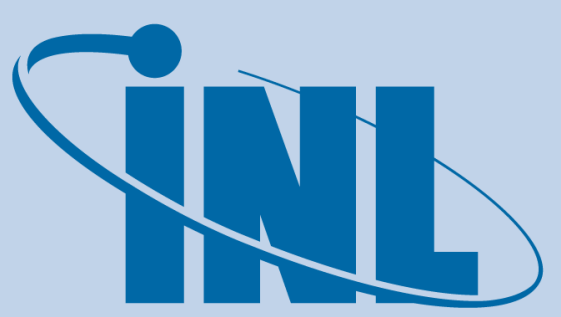

Idaho National Laboratory 


\section{DISCLAIMER}

This information was prepared as an account of work sponsored by an agency of the U.S. Government. Neither the U.S. Government nor any agency thereof, nor any of their employees, makes any warranty, expressed or implied, or assumes any legal liability or responsibility for the accuracy, completeness, or usefulness, of any information, apparatus, product, or process disclosed, or represents that its use would not infringe privately owned rights. References herein to any specific commercial product, process, or service by trade name, trade mark, manufacturer, or otherwise, does not necessarily constitute or imply its endorsement, recommendation, or favoring by the U.S. Government or any agency thereof. The views and opinions of authors expressed herein do not necessarily state or reflect those of the U.S. Government or any agency thereof. 
INL/EXT-17-42999

Revision 1

\title{
Updated Draft ASME Boiler and Pressure Vessel Code Case for Use of Alloy 617 for Construction of Nuclear Components for Section III, Division 5
}

\author{
R. N. Wright
}

September 2018

Idaho National Laboratory

INL ART Program

Idaho Falls, Idaho 83415

http://www.inl.gov

Prepared for the

U.S. Department of Energy

Office of Nuclear Energy

Under DOE Idaho Operations Office

Contract DE-AC07-05ID14517 



\title{
Updated Draft ASME Boiler and Pressure Vessel Code Case for Use of Alloy 617 for Construction of Nuclear Components for Section III, Division 5
}

\author{
INL/EXT-17-42999 \\ Revision 1
}
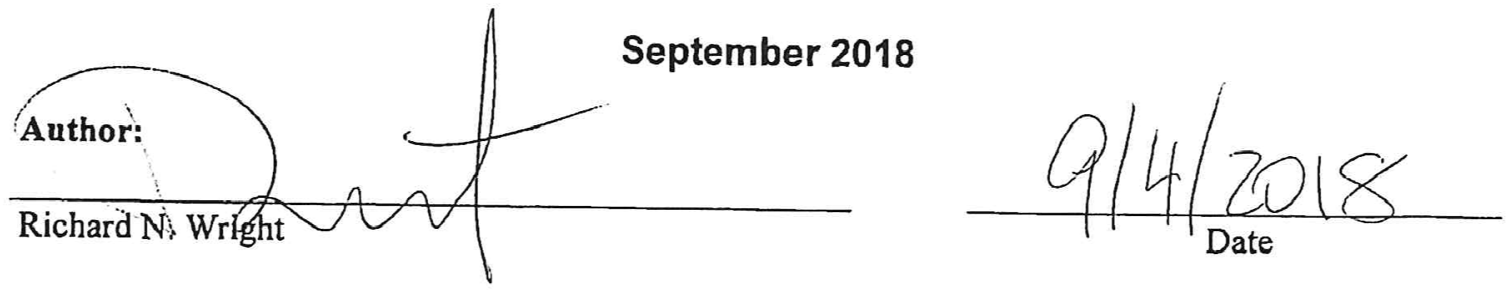

Peer Reviewer: (Confirmation of mathematical accuracy, and correctness of data and appropriateness of assumptions.)

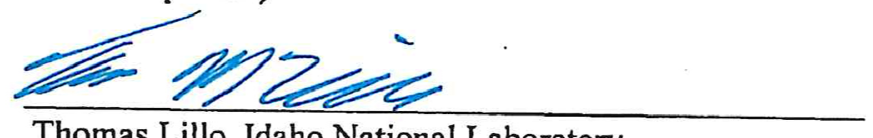

Thomas Lillo, Idaho National Laboratory Peer Reviewer

Corsee Copeesn

Mark Messner, Argonne National Laboratory

Peer Reviewer

Approved by:

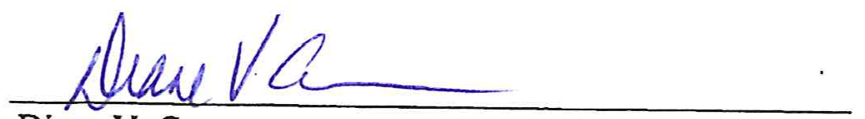

Diane V. Croson

INL ART Deputy Director

$\frac{h y \text { j \& harpe }}{\text { Michelle T. Sharp }}$

INL Quality Assurance

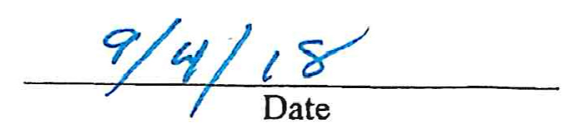

$9 / 4 / 18$

Date
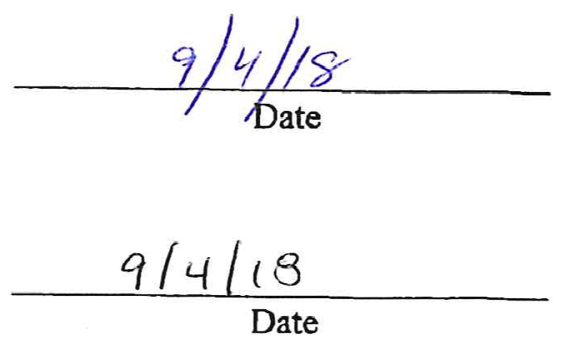



\section{REVISION LOG}

\begin{tabular}{|c|c|c|c|}
\hline Rev. & Date & Affected Pages & Revision Description \\
\hline 0 & 08/15/2017 & All & Newly issued document. \\
\hline \multirow[t]{2}{*}{1} & \multirow[t]{2}{*}{$09 / 05 / 2018$} & Page 3 & $\begin{array}{l}\text { Progress on Code Case balloting has been updated and } \\
\text { the response to comments and editorial issues identified } \\
\text { during balloting noted }\end{array}$ \\
\hline & & Page 24 & $\begin{array}{l}\text { Editorial correction to Table HBB-I- } 14.3 \text { to correct } \\
\text { transposed numbers at } 1 \text { and } 10 \text { hours for temperatures of } \\
1,400 \text { and } 1450^{\circ} \mathrm{F} \text { and } 775^{\circ} \mathrm{C}\end{array}$ \\
\hline & & & \\
\hline & & & \\
\hline & & & \\
\hline & & & \\
\hline & & & \\
\hline & & & \\
\hline & & & \\
\hline & & & \\
\hline & & & \\
\hline & & & \\
\hline & & & \\
\hline & & & \\
\hline & & & \\
\hline & & & \\
\hline & & & \\
\hline & & & \\
\hline
\end{tabular}





\begin{abstract}
The American Society of Mechanical Engineers (ASME) Boiler and Pressure Vessel Code currently only allows five materials for use in construction of nuclear components for high temperature service. Since 2005, the United States high temperature gas-cooled reactor program has been characterizing elevated temperature mechanical properties of Alloy 617 as the leading candidate material for the intermediate heat exchanger. After analysis of these experimental results, along with historical data and additional results available through the Generation IV International Forum Very High Temperature Reactor Materials Program Management Board Materials Handbook, a draft ASME Code Case to allow nuclear construction with Alloy 617 has been developed.

This report contains the Code Case for Low Temperature Service Construction Section III, Division 5, Section HB, Subpart A, Class A and Subsection HC, Subpart A, Class B components, which has been approved by the Board of Nuclear Codes and Standards. This Code Case allows use of Alloy 617 up to $800^{\circ} \mathrm{F}\left(425^{\circ} \mathrm{C}\right)$.

This report also contains an updated draft of a Section III, Division 5, Section HB, Subsection B, Code Case for Alloy 617 to qualify it for use in construction of nuclear components up to $1750^{\circ} \mathrm{F}\left(950^{\circ} \mathrm{C}\right)$ for service life up to 100,000 hours. The draft is in the balloting process by the appropriate ASME Committees.
\end{abstract}




\section{ACKNOWLEDGEMENTS}

The author gratefully acknowledges the contributions of Sam Sham at Oak Ridge National Laboratory for planning, testing, and analysis of the data that support the draft Code Case. The ASME Special Task Group on Alloy 617 Code Qualification made substantial contributions to defining the process for obtaining Code allowable stresses; active participants include, Michael Swindeman, Peter Carter, Tai Asayama, Jim Nestell, Mainak Sengupta, and Weiju Ren, and in particular the contributions of Bob Swindeman and Keith Morton. Bob Jetter developed the detailed template for the Code Case and made innumerable suggestions for how the authors should approach determination of many of the stress allowable values. His deep historical understanding of the high temperature design methods played a key role in guiding the special Task Group.

At Idaho National Laboratory, Laura Carroll (formerly of INL) directed much of the fatigue and creep-fatigue testing and analysis that were carried out in the laboratory by Joel Simpson, Randy Lloyd, Julian Benz, and Tim Yoder. Mark Carroll, Todd Morris, and Tammy Trowbridge conducted important

microstructural analysis on deformation mechanisms that support the background to the Code Case. Tom Lillo performed TEM analysis that was critical to developing a fundamental understanding of creep and onset of tertiary creep. The authors are particularly grateful to Nancy Lybeck for her efficient, careful, and responsive support of the statistical data analysis and archiving. Jill Wright developed the allowable stresses contained in this report using ASME developed analysis tools. 


\section{CONTENTS}

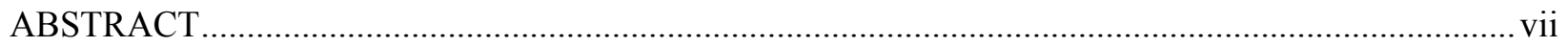

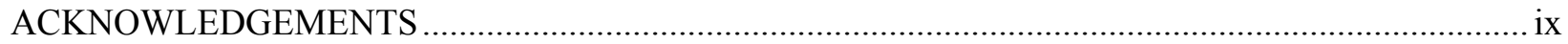

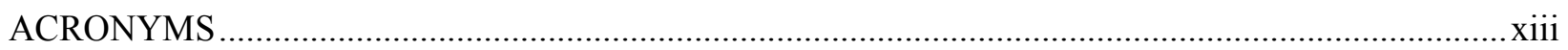

Appendix A Case N-XXX: Use of Alloy 617 (UNS N06617) for Low Temperature Service

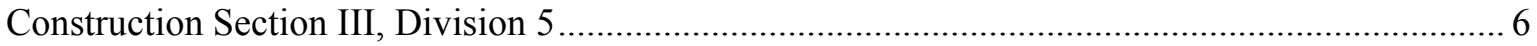

Appendix B Case N-XXX: Use of Alloy 617 (UNS N06617) for Class A Elevated Temperature Service Construction Section III, Division 5 ........................................................................ 16 


\section{ACRONYMS}

ART

ASME

BPV

INL

SC-D

SG-ETD

SG-ExtPress

SG-HTR

SG-MF\&E

SG-NFA

SG-PhysProp

SG-StrengthWeld

WG-AM

WG-ASC

WG-CFNC
Advanced Reactor Technologies

American Society of Mechanical Engineers

Boiler and Pressure Vessel

Idaho National Laboratory

Subcommittee Design

Subgroup Elevated Temperature Design

Subgroup External Pressure

Subgroup High Temperature Reactors

Subgroup Materials, Fabrication and Evaluation

Subgroup Nonferrous Alloys

Subgroup Physical Properties

Subgroup Strength of Weldments

Working Group Analysis Methods

Working Group Allowable Stress Criteria

Working Group Creep-Fatigue and Negligible Creep 


\section{Updated Draft ASME Boiler and Pressure Vessel Code Case for Use of Alloy 617 for Construction of Nuclear Components for Section III, Division 5}

Early in the United States' very high temperature reactor program, several candidate nickel alloys were considered for use in construction of the intermediate heat exchanger. Based primarily on technical maturity, a down-selection was made to focus on Alloy 617. After this down-selection, the primary goal of the research and development program was to develop sufficient information on the high temperature properties of the material to qualify it for construction of high temperature nuclear components in the American Society of Mechanical Engineers (ASME) Boiler and Pressure Vessel (BPV) Code.

Alloy 617 is a solid-solution strengthened material with nominal Ni-Cr-Co-Mo composition, originally developed for aerospace applications such as burner can liners for turbine engines by Huntington Alloys. (Huntington Alloys is now Special Metals Division of Precision Castparts, Inc.) The ASME BPV Code allows use of Alloy 617 for construction of non-nuclear pressure vessels, and Alloy 617 is used in fossil fired power plants.

Section III, Division 1, Subsection NB of the ASME BPV Code was developed for construction of nuclear components in light water reactors and allows use of ferritic materials up to $700^{\circ} \mathrm{F}$ and austenitic alloys up to $800^{\circ} \mathrm{F}$. Subsection $\mathrm{NH}$ of Section III Division 1 was written to allow higher temperature construction with a primary focus on sodium cooled reactors. Recently, a new Division 5 of Section III was published specifically for high temperature reactors (regardless of the primary working fluid) and incorporates both Subsections NB and NH.

There are only five alloys currently allowed for use in high temperature nuclear components: 2.25Cr-1 Mo and V modified 9Cr-1Mo steels, Types 304 and 316 stainless steels, and the high nickel austenitic Alloy $800 \mathrm{H}$. This very sparse set of allowed materials is in contrast with the collection of more than 150 materials that are allowed for use in non-nuclear pressure vessel construction. A draft Code Case to add Alloy 617 to the list of qualified alloys for use in high temperature nuclear design was submitted to ASME in the early 1990s, but it was withdrawn prior to formal Code action.

A great deal of experimental characterization of high temperature properties required for Code qualification has been performed under the Advanced Reactor Technologies (ART) High Temperature Materials program (and its predecessors). Several additional requirements exist for qualification of materials for use in high temperature nuclear construction, compared to conventional pressure vessels. For non-nuclear pressure vessel construction, creep rupture data for 10,000 hours can be used to support qualification up to 100,000 hours of service. For high temperature nuclear construction, extrapolation of rupture life beyond the longest experimental rupture lives is restricted to a factor of 3 to 5 . High temperature nuclear construction is also the only area of the Code that requires creep-fatigue characterization.

A Code Case to qualify Alloy 617 for use in nuclear construction under Section III, Division 5, Subsection HB, Subpart A, Class A and Subsection HC, Subpart A, Class B for components designed for use up to $800^{\circ} \mathrm{F}\left(427^{\circ} \mathrm{C}\right)$ was developed under the ART program. This Code Case was approved by the Board of Nuclear Codes and Standards in late 2016. This Code Case for Low Temperature Service Construction is presented in Appendix A.

A draft of a Section III, Division 5, Section HB, Subsection B, Code Case for Alloy 617 to qualify it for use in construction of nuclear components up to $1750^{\circ} \mathrm{F}\left(950^{\circ} \mathrm{C}\right)$ for service life up to 100,000 hours is under development and major sections are currently being balloted. A detailed balloting plan has been developed for approval by letter ballot of the high temperature Alloy 617 Code Case, as shown in Figure 1. Record numbers have been established in the ASME information managements system, C\&S 
Connect, for sections of the Code Case that are related topically. These records contain detailed background files and related data tables to enable working groups and subgroups to evaluate those sections of the Code Case that are relevant to their area of expertise. For example, Record RC-16-994 contains details of eight sections of the Draft Code Case that relate to allowable stresses. This record must be balloted within Section III first by the Working Group Allowable Stress Criteria (WG-ASC). After the record is approved by the working group, it is sent (with revisions as required) to the Subgroup Elevated Temperature Design (SG-ETD). Upon passage by this subgroup, the record is balloted concurrently by the Subgroups High Temperature Reactors (SG-HTR), and Materials, Fabrication and Evaluation (SG-MF\&E). Record RC-16-994 also requires approval by Section II Subgroups Nonferrous Alloys (SG-NFA) and Strength of Weldments (SG-StrengthWeld). After approval by the subgroups, the draft will be balloted by the Section II Committee (BPV II). In addition to this specific record, each of the working groups and subgroups that are balloted in both Section II and III receive the entire Draft Code Case (RC-16-1001) for review and comment. After RC-16-994 through RC-16-1000 are approved by the lower tier committees and BPV II, the complete Draft Code Case must be balloted by the Section III Committee (BPV III).

\begin{tabular}{|c|c|c|c|c|c|}
\hline no. & $\begin{array}{l}\text { Record/ } \\
\text { Project } \\
\text { Manager }\end{array}$ & $\begin{array}{l}\text { Alloy } 617 \text { Code Case Topics (dry run } \\
\text { presentations in TG-A617CC) }\end{array}$ & $\begin{array}{l}\text { Section III, for approval (order } \\
\text { of balloting indicated by } \\
\text { numbers) }\end{array}$ & $\begin{array}{l}\text { Section II, for approval } \\
\text { (order of balloting } \\
\text { indicated by numbers) }\end{array}$ & $\begin{array}{l}\text { Review and Comment, } \\
\text { accompanying each } \\
\text { sub-record }\end{array}$ \\
\hline 1 & \multirow{8}{*}{$\begin{array}{c}\text { RC-16-994 } \\
\text { R. Wright }\end{array}$} & Permissible base materials & \multirow{8}{*}{$\begin{array}{ll}\text { 1. } & \text { WG-ASC } \\
\text { 2. } & \text { SG-ETD } \\
\text { 3. } & \text { (SG-HTR, SG-MF\&E) }\end{array}$} & \multirow{8}{*}{$\begin{array}{l}\text { 4. (SG-NFA, SG- } \\
\text { StrengthWeld) } \\
\text { 5. BPV II }\end{array}$} & \multirow[t]{8}{*}{ RC-16-1001 } \\
\hline 2 & & Permissible weld materials & & & \\
\hline 3 & & Yield and ultimate $\left(S_{y}, S_{u}\right)$ & & & \\
\hline 4 & & Allowable stresses $\left(\mathrm{S}_{0}, \mathrm{~S}_{\mathrm{m}}, \mathrm{S}_{\mathrm{r}}, \mathrm{S}_{\mathrm{t}}, \mathrm{S}_{\mathrm{mt}}\right)$ & & & \\
\hline 5 & & Stress rupture factor & & & \\
\hline 6 & & Relaxation cracking & & & \\
\hline 7 & & Aging factor & & & \\
\hline 8 & & Cold work and annealing & & & \\
\hline 9 & \multirow[t]{2}{*}{$\begin{array}{c}\text { RC-16-995 } \\
\text { R. Wright }\end{array}$} & $\begin{array}{l}\text { Extension of modulus values to higher } \\
\text { temperatures }\end{array}$ & \multirow{2}{*}{$\begin{array}{ll}\text { 1. } & \text { WG-ASC } \\
\text { 2. } & \text { SG-ETD } \\
\text { 3. } & (S G-H T R, S G-M F \& E)\end{array}$} & \multirow{2}{*}{$\begin{array}{l}\text { 4. (SG-PhyProp, SG- } \\
\text { NFA) } \\
\text { 5. BPV II }\end{array}$} & \multirow[t]{2}{*}{ RC-16-1001 } \\
\hline 10 & & $\begin{array}{l}\text { Thermophysical properties (CTE, } \\
\text { diffusivity, conductivity) }\end{array}$ & & & \\
\hline 11 & $\begin{array}{c}\text { RC-16-996 } \\
\text { Jetter }\end{array}$ & Temp/time limits for buckling charts & $\begin{array}{l}\text { 1. WG-AM 2. SG-ETD } \\
\text { 3. (SG-HTR, SG-MF\&E) }\end{array}$ & $\begin{array}{l}\text { 4. (SG-ExtPress, SG- } \\
\text { NFA) } \\
\text { 5. BPV II } \\
\end{array}$ & RC-16-1001 \\
\hline 12 & \multirow{2}{*}{$\begin{array}{c}\text { RC-16-997 } \\
\text { Jetter }\end{array}$} & Huddleston parameters & \multirow{2}{*}{$\begin{array}{ll}\text { 1. } & \text { WG-ASC } \\
\text { 2. } & \text { SG-ETD } \\
\text { 3. } & \text { (SG-HTR, SC-D) }\end{array}$} & & \multirow[t]{2}{*}{ RC-16-1001 } \\
\hline 13 & & Isochronous stress-strain curves & & & \\
\hline 14 & \multirow{3}{*}{$\begin{array}{c}\text { RC-16-998 } \\
\text { Jetter }\end{array}$} & Negligible creep & \multirow{3}{*}{\begin{tabular}{|ll} 
1. & WG-CFNC \\
2. & SG-ETD \\
3. & (SG-HTR, SC-D)
\end{tabular}} & & \multirow[t]{3}{*}{ RC-16-1001 } \\
\hline 15 & & Creep-fatigue D-diagram & & & \\
\hline 16 & & EPP creep-fatigue damage evaluations & & & \\
\hline 17 & $\begin{array}{c}\text { RC-16-999 } \\
\text { Jetter }\end{array}$ & EPP strain limits evaluations & $\begin{array}{l}\text { 1. WG-AM 2. SG-ETD } \\
\text { 3. (SG-HTR, SC-D) }\end{array}$ & & RC-16-1001 \\
\hline 18 & $\begin{array}{c}\text { RC- } 16-1000 \\
\text { Jetter }\end{array}$ & Fatigue curves & 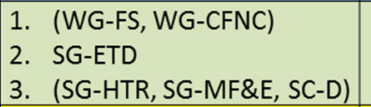 & & RC-16-1001 \\
\hline 19 & $\begin{array}{c}\text { RC-16-1001 } \\
\text { Jetter }\end{array}$ & Overall Alloy 617 Code Case & 1. BPV III & & \\
\hline
\end{tabular}

Figure 1. Balloting plan for approval of the high temperature Alloy 617 Code Case. 
The balloting procedure for the high temperature Code Case began in fiscal year 2017. The status of the balloting process is given below. The updated draft Code Case, reflecting changes resulting from balloting, is shown in Appendix B.

- 16-994 Allowable stress criteria: approved WG-ASC, SG-ETD, SG-HTR, Sg-MF\&E, SG-NFA and SG-Strength of Weldments; awaiting ballot by Section II Committee

- 16-995 Physical properties: approved WG-ASC, SG-ETD, SG-HTR, SG-MF\&E, SG-Physical Properties and SG-NFA; awaiting ballot by Section II Committee

- 16-996 Buckling Charts: verbal approval WG-ASC; awaiting formal ballot

- 16-997 Isochronous Stress Strain Curves and Huddleston parameters: verbal approval WG-ASC; awaiting formal ballot

- 16-998 Creep-fatigue: approved WG-CFNC, SG-HTR, SG-ETD and SC-D

- 16-999 PP strain limits: approved WG-AM, SG-HTR, SG-ETD and SC-D

- 16-1000 Design fatigue curves: approved WG-FS, WG-CFNC, SG-ETD; out for ballot SG-HTR and SG-MFE

As a result of comments during balloting an editorial change has been made to Table HBB-I14.3F $\mathrm{S}_{\mathrm{mt}}-$ Allowable Stress Intensity Values in the high temperature Code Case for both the customary and metric tables. For the customary table, for allowable stress at 1,400 and $1,450^{\circ} \mathrm{F}$ the values at 1 and 10 hours were transposed. That editorial error has been corrected. A similar correction was made in the metric table for $775^{\circ} \mathrm{C}$.

During development of this Code Case it was determined in discussion with the Section II Subgroup Non-Ferrous alloys that existing values for Alloy 617 allowable stresses that are published in Section II D "Materials Properties" would be incorporated into the Code Case where appropriate. Table HBB-I-14.2 "S $\mathrm{S}_{\mathrm{o}}$ - Maximum Allowable Stress Intensity" values in this Code Case were directly incorporated from the time dependent allowable stress values in Table 1B from Section II D. The origin of the values in Table 1B is uncertain, but likely derive from the database developed by Huntington Alloys when Alloy 617 was originally code qualified for non-nuclear construction. It has recently been noted that the Table $1 \mathrm{~B}$ values are not consistent with values that would be derived from the more current and expanded data set used elsewhere in this Code Case. This issue has been discussed with Section II Subgroup Non-Ferrous Alloys and it was determined that it is appropriate to continue using the Table 1B values until a complete analysis is carried out. If it is determined that Table 1B is in need of modification an official ballot item to make the necessary changes to Section II D Table 1B will be taken out and the Code Case can be amended subsequent to that action to reflect the revised values.

Provisional buckling charts and isochronous stress-strain curves are included for completeness. This information has received review and verbal approval from Section III Working Group Allowable Stress Criteria, but the figures have not yet been formally balloted and may be subject to revision as balloting proceeds. 
Appendix A

\section{Case N-XXX: Use of Alloy 617 (UNS N06617) for Low Temperature Service Construction Section III, Division 5}




\section{Appendix A}

\section{Case N-XXX: Use of Alloy 617 (UNS N06617) for Low Temperature Service Construction Section III, Division 5}

Inquiry: May 52Ni-22Cr-13Co-9Mo Alloy 617 (UNS N06617) in the solution annealed condition be used in the construction of components conforming to the requirements of Section III, Division 5, Subsection HB, Subpart A, Class A and Subsection HC, Subpart A, Class B?

Reply: It is the opinion of the Committee that 52Ni-22Cr-13Co-9Mo Alloy 617 (UNS N06617) conforming to the product specifications shown in Table A-1 may be used in the construction of Section III, Division 5, Subsection HB, Subpart A, Class A and Subsection HC, Subpart A, Class B components provided the following requirements are met:

(a) The maximum use temperature shall not exceed $800^{\circ} \mathrm{F}\left(425^{\circ} \mathrm{C}\right)$.

(b) The design stress intensity values and yield and tensile strength values for Class A shall be as shown in Table A-2.

(c) The maximum allowable stress values and yield and tensile strength values for Class B shall be as shown in Table A-3.

(d) The moduli of elasticity shown in Section II, Part D, Table TM-4 shall apply.

(e) The values of Poisson's ratio and density shown in Section II, Part D, Table PRD shall apply.

(f) The coefficients of thermal expansion shown in Table A-6 shall apply.

(g) The nominal coefficients of thermal conductivity and thermal diffusivity shown in Table A-8 shall apply.

(h) All other requirements of Section III, Division 5, Subsection HB, Subpart A for Class A components, and Subsection HC, Subpart A for Class B components shall be met.

(i) The design fatigue curve shown in Section III Appendices, Mandatory Appendix I, Figure I-9.5 and Table I-9.5 shall apply.

(j) External pressure chart Figure NFN-4 and values in Table NFN-4 of Section II, Part D shall apply.

(k) This Case number shall be listed on the Data Report Form for the component. 
Table A-1. Product specifications.

\begin{tabular}{|l|c|}
\hline Product Form & Spec. No. \\
\hline Rod, bar and wire & SB-166 \\
\hline Seamless pipe and tube & SB-167 \\
\hline Plate, sheet and strip & SB-168 \\
\hline Forgings & SB-564 \\
\hline
\end{tabular}

Table A-2. Design stress intensity values and yield and tensile strength values for Section III, Division 5, Class A.

\begin{tabular}{|c|c|c|c|}
\hline $\begin{array}{c}\text { For Metal } \\
\text { Temperature Not } \\
\text { Exceeding, }{ }^{\circ} \mathbf{F} \\
\end{array}$ & $\begin{array}{c}\text { Design Stress Intensity } \\
S_{m}, \text { ksi (Note a) }\end{array}$ & $\begin{array}{c}\text { Yield Strength } \\
S_{y}, \text { ksi } \\
\end{array}$ & $\begin{array}{c}\text { Tensile Strength } \\
S_{u}, \text { ksi } \\
\end{array}$ \\
\hline 100 & 23.3 & 35.0 & 95.0 \\
\hline 200 & 23.3 & 31.1 & 95.0 \\
\hline 300 & 23.3 & 28.9 & 95.0 \\
\hline 400 & 23.3 & 27.1 & 95.0 \\
\hline 500 & 23.3 & 25.9 & 95.0 \\
\hline 600 & 22.5 & 25.0 & 93.2 \\
\hline 650 & 22.1 & 24.6 & 92.3 \\
\hline 700 & 21.9 & 24.3 & 91.4 \\
\hline 750 & 21.7 & 24.1 & 90.6 \\
\hline 800 & 21.5 & 23.8 & 89.9 \\
\hline \multicolumn{4}{|c|}{$\begin{array}{l}\text { a. Due to the relatively low yield strength of this material, the higher stress values were established at temperatures where the } \\
\text { short-time tensile properties govern to permit the use of these alloys where slightly greater deformation is acceptable. The } \\
\text { stress values in this range exceed } 66^{2} / 3 \% \text { but do not exceed } 90 \% \text { of the yield strength at temperature. Use of these stresses } \\
\text { may result in dimensional changes due to permanent strain. These stress values are not recommended for the flanges of } \\
\text { gasketed joints or other applications where slight amounts of distortion can cause leakage or malfunction. For Section III } \\
\text { applications, Table Y-2 lists multiplying factors that, when applied to the yield strength values shown in Table A-2 above, } \\
\text { will give allowable stress values that will result in lower levels of permanent strain. }\end{array}$} \\
\hline
\end{tabular}


Table A-3. Design stress intensity values and yield and tensile strength values for Section III, Division 5, Class A.

\begin{tabular}{|c|c|c|c|}
\hline $\begin{array}{c}\text { For Metal } \\
\text { Temperature Not } \\
\text { Exceeding, }{ }^{\circ} \mathrm{C}\end{array}$ & $\begin{array}{c}\text { Design Stress Intensity } \\
S_{m}, \mathrm{MPa} \text { (Note a) }\end{array}$ & $\begin{array}{c}\text { Yield Strength } \\
S_{y}, \mathrm{MPa}\end{array}$ & $\begin{array}{c}\text { Tensile Strength } \\
S_{u}, \mathrm{MPa}\end{array}$ \\
\hline 40 & 161 & 241 & 655 \\
\hline 65 & 161 & 227 & 655 \\
\hline 100 & 161 & 212 & 655 \\
\hline 125 & 161 & 205 & 655 \\
\hline 150 & 161 & 199 & 655 \\
\hline 175 & 161 & 193 & 655 \\
\hline 200 & 161 & 188 & 655 \\
\hline 225 & 161 & 183 & 655 \\
\hline 250 & 161 & 180 & 655 \\
\hline 275 & 160 & 177 & 651 \\
\hline 300 & 157 & 174 & 647 \\
\hline 325 & 154 & 171 & 640 \\
\hline 350 & 152 & 169 & 635 \\
\hline 375 & 151 & 167 & 629 \\
\hline 400 & 150 & 166 & 624 \\
\hline 425 & 148 & 164 & 620 \\
\hline \multicolumn{4}{|c|}{$\begin{array}{l}\text { a. Due to the relatively low yield strength of this material, the higher stress values were established at temperatures where the } \\
\text { short-time tensile properties govern to permit the use of these alloys where slightly greater deformation is acceptable. The } \\
\text { stress values in this range exceed } 66^{2} / 3 \% \text { but do not exceed } 90 \% \text { of the yield strength at temperature. Use of these stresses } \\
\text { may result in dimensional changes due to permanent strain. These stress values are not recommended for the flanges of } \\
\text { gasketed joints or other applications where slight amounts of distortion can cause leakage or malfunction. For Section III } \\
\text { applications, Table Y-2 lists multiplying factors that, when applied to the yield strength values shown in Table A-3 above, } \\
\text { will give allowable stress values that will result in lower levels of permanent strain. }\end{array}$} \\
\hline
\end{tabular}


Table A-4. Maximum allowable stress values and yield and tensile strength values for Section III, Division 5, Class B.

\begin{tabular}{|c|c|c|c|c|}
\hline $\begin{array}{c}\text { For Metal } \\
\begin{array}{c}\text { Temperature Not } \\
\text { Exceeding, }{ }^{\circ} \mathbf{F}\end{array}\end{array}$ & \multicolumn{2}{c|}{$\begin{array}{c}\text { Maximum Allowable Stress } \\
\text { Ssi }\end{array}$} & $\begin{array}{c}\text { Yield Strength } \\
\boldsymbol{S}_{\boldsymbol{y}}, \mathbf{k s i}\end{array}$ & $\begin{array}{c}\text { Tensile Strength } \\
\boldsymbol{S}_{\boldsymbol{u}}, \mathbf{k s i}\end{array}$ \\
\hline 100 & 23.3 & 23.3 & 35.0 & 95.0 \\
\hline 200 & 20.8 & 23.3 & 31.1 & 95.0 \\
\hline 300 & 19.2 & 23.3 & 28.9 & 95.0 \\
\hline 400 & 18.1 & 23.3 & 27.1 & 95.0 \\
\hline 500 & 17.2 & 23.3 & 25.9 & 95.0 \\
\hline 600 & 16.6 & 22.5 & 25.0 & 93.2 \\
\hline 650 & 16.4 & 22.1 & 24.6 & 92.3 \\
\hline 700 & 16.2 & 21.9 & 24.3 & 91.4 \\
\hline 750 & 16.0 & 21.7 & 24.1 & 90.6 \\
\hline 800 & 15.9 & 21.5 & 23.8 & 89.9 \\
\hline
\end{tabular}

a. Due to the relatively low yield strength of this material, the higher stress values were established at temperatures where the short-time tensile properties govern to permit the use of these alloys where slightly greater deformation is acceptable. The stress values in this range exceed $66^{2} / 3 \%$ but do not exceed $90 \%$ of the yield strength at temperature. Use of these stresses may result in dimensional changes due to permanent strain. These stress values are not recommended for the flanges of gasketed joints or other applications where slight amounts of distortion can cause leakage or malfunction. For Section III applications, Table Y-2 lists multiplying factors that, when applied to the yield strength values shown in Table A-4 above, will give allowable stress values that will result in lower levels of permanent strain. 
Table A-5. Maximum allowable stress values and yield and tensile strength values for Section III, Division 5, Class B.

\begin{tabular}{|c|c|c|c|c|}
\hline $\begin{array}{c}\text { For Metal } \\
\text { Temperature Not } \\
\text { Exceeding, }{ }^{\circ} \mathbf{C}\end{array}$ & \multicolumn{2}{|c|}{$\begin{array}{c}\text { Maximum Allowable Stress } \\
\text { (Note a) }\end{array}$} & $\begin{array}{c}\text { Yield Strength } \\
\boldsymbol{S}_{\boldsymbol{y}}, \mathbf{M P a}\end{array}$ & $\begin{array}{c}\text { Tensile Strength } \\
\boldsymbol{S}_{\boldsymbol{u}}, \mathbf{M P a}\end{array}$ \\
\hline 40 & 161 & 161 & 241 & 655 \\
\hline 65 & 152 & 161 & 227 & 655 \\
\hline 100 & 142 & 161 & 212 & 655 \\
\hline 125 & 136 & 161 & 205 & 655 \\
\hline 150 & 132 & 161 & 199 & 655 \\
\hline 175 & 129 & 161 & 193 & 655 \\
\hline 200 & 125 & 161 & 188 & 655 \\
\hline 225 & 122 & 161 & 183 & 655 \\
\hline 250 & 120 & 161 & 180 & 655 \\
\hline 275 & 117 & 160 & 177 & 651 \\
\hline 300 & 115 & 157 & 174 & 647 \\
\hline 325 & 114 & 154 & 171 & 635 \\
\hline 350 & 113 & 152 & 169 & 629 \\
\hline 375 & 111 & 151 & 167 & 624 \\
\hline 400 & 110 & 150 & 166 & 620 \\
\hline 425 & 110 & 148 & 164 & \\
\hline
\end{tabular}

a. Due to the relatively low yield strength of this material, the higher stress values were established at temperatures where the short-time tensile properties govern to permit the use of these alloys where slightly greater deformation is acceptable. The stress values in this range exceed $66^{2} / 3 \%$ but do not exceed $90 \%$ of the yield strength at temperature. Use of these stresses may result in dimensional changes due to permanent strain. These stress values are not recommended for the flanges of gasketed joints or other applications where slight amounts of distortion can cause leakage or malfunction. For Section III applications, Table Y-2 lists multiplying factors that, when applied to the yield strength values shown in Table A-5 above, will give allowable stress values that will result in lower levels of permanent strain. 
Table A-6. Thermal expansion for Alloy 617.

\begin{tabular}{|c|c|c|c|}
\hline \multirow{2}{*}{$\begin{array}{c}\text { Temperature, } \\
{ }^{\circ} \mathbf{F}\end{array}$} & \multicolumn{3}{|c|}{ Coefficients for N06617 } \\
\hline & $\mathbf{A}$ & B & $\mathrm{C}$ \\
\hline 70 & 7.0 & 7.0 & 0 \\
\hline 100 & 7.1 & 7.0 & 0.3 \\
\hline 150 & 7.1 & 7.1 & 0.7 \\
\hline 200 & 7.2 & 7.1 & 1.1 \\
\hline 250 & 7.3 & 7.1 & 1.6 \\
\hline 300 & 7.4 & 7.2 & 2.0 \\
\hline 350 & 7.5 & 7.2 & 2.4 \\
\hline 400 & 7.6 & 7.3 & 2.9 \\
\hline 450 & 7.7 & 7.3 & 3.4 \\
\hline 500 & 7.8 & 7.4 & 3.8 \\
\hline 550 & 7.9 & 7.4 & 4.3 \\
\hline 600 & 8.0 & 7.5 & 4.8 \\
\hline 650 & 8.2 & 7.5 & 5.3 \\
\hline 700 & 8.3 & 7.6 & 5.8 \\
\hline 750 & 8.4 & 7.6 & 6.3 \\
\hline 800 & 8.6 & 7.7 & 6.8 \\
\hline \multicolumn{4}{|c|}{$\begin{array}{l}\text { GENERAL NOTE: Coefficient A is the instantaneous coefficient of thermal } \\
\text { expansion } \times 10^{-6}\left(\mathrm{in} . / \mathrm{in} . /{ }^{\circ} \mathrm{F}\right) \text {. Coefficient } \mathrm{B} \text { is the mean coefficient of thermal } \\
\text { expansion } \times 10^{-6}\left(\mathrm{in} . / \mathrm{in} . / /^{\circ} \mathrm{F}\right) \text { in going from } 70^{\circ} \mathrm{F} \text { to indicated temperature. Coefficient } \\
\mathrm{C} \text { is the linear thermal expansion (in. } / 100 \mathrm{ft} \text { ) in going from } 70^{\circ} \mathrm{F} \text { to indicated } \\
\text { temperature. }\end{array}$} \\
\hline
\end{tabular}


Table A-7. Thermal expansion for Alloy 617.

\begin{tabular}{|c|c|c|c|}
\hline \multirow{2}{*}{$\begin{array}{c}\text { Temperature, } \\
{ }^{\circ} \mathrm{C}\end{array}$} & \multicolumn{3}{|c|}{ Coefficients for N06617 } \\
\hline & $\mathbf{A}$ & B & $\mathbf{C}$ \\
\hline 20 & 12.6 & 12.6 & 0 \\
\hline 50 & 12.8 & 12.7 & 0.4 \\
\hline 75 & 12.9 & 12.7 & 0.7 \\
\hline 100 & 13.0 & 12.8 & 1.0 \\
\hline 125 & 13.2 & 12.9 & 1.4 \\
\hline 150 & 13.3 & 12.9 & 1.7 \\
\hline 175 & 13.5 & 13.0 & 2.0 \\
\hline 200 & 13.6 & 13.1 & 2.4 \\
\hline 225 & 13.8 & 13.2 & 2.7 \\
\hline 250 & 14.0 & 13.2 & 3.0 \\
\hline 275 & 14.2 & 13.3 & 3.4 \\
\hline 300 & 14.4 & 13.4 & 3.8 \\
\hline 325 & 14.6 & 13.5 & 4.1 \\
\hline 350 & 14.8 & 13.6 & 4.5 \\
\hline 375 & 15.0 & 13.7 & 4.9 \\
\hline 400 & 15.2 & 13.8 & 5.2 \\
\hline 425 & 15.4 & 13.9 & 5.6 \\
\hline \multicolumn{4}{|c|}{$\begin{array}{l}\text { GENERAL NOTE: Coefficient A is the instantaneous coefficient of thermal } \\
\text { expansion } \times 10^{-6}\left(\mathrm{~mm} / \mathrm{mm} /{ }^{\circ} \mathrm{C}\right) \text {. Coefficient } \mathrm{B} \text { is the mean coefficient of thermal } \\
\text { expansion } \times 10^{-6}\left(\mathrm{~mm} / \mathrm{mm} /{ }^{\circ} \mathrm{C}\right) \text { in going from } 20^{\circ} \mathrm{C} \text { to indicated temperature. } \\
\text { Coefficient } \mathrm{C} \text { is the linear thermal expansion }(\mathrm{mm} / \mathrm{m}) \text { in going from } 20^{\circ} \mathrm{C} \text { to } \\
\text { indicated temperature. }\end{array}$} \\
\hline
\end{tabular}


Table A-8. Nominal coefficients of thermal conductivity and thermal diffusivity for Alloy 617.

\begin{tabular}{|c|c|c|}
\hline Temperature $^{\circ} \mathbf{F}$ & $\begin{array}{c}\text { Thermal Conductivity } \\
\text { Btu/hr-ft- }{ }^{\circ} \mathbf{F}\end{array}$ & $\begin{array}{c}\text { Thermal Diffusivity } \\
\mathbf{f t}^{\mathbf{2}} \mathbf{h r}\end{array}$ \\
\hline 70 & 6.0 & 0.112 \\
\hline 100 & 6.2 & 0.114 \\
\hline 150 & 6.6 & 0.118 \\
\hline 200 & 6.9 & 0.122 \\
\hline 250 & 7.2 & 0.125 \\
\hline 300 & 7.5 & 0.129 \\
\hline 350 & 7.8 & 0.132 \\
\hline 400 & 8.1 & 0.136 \\
\hline 450 & 8.4 & 0.139 \\
\hline 500 & 8.7 & 0.142 \\
\hline 550 & 9.0 & 0.145 \\
\hline 600 & 9.3 & 0.149 \\
\hline 650 & 9.5 & 0.152 \\
\hline 700 & 9.8 & 0.155 \\
\hline 750 & 10.0 & 0.158 \\
\hline 800 & 10.3 & 0.161 \\
\hline
\end{tabular}

Table A-9. Nominal coefficients of thermal conductivity and thermal diffusivity for Alloy 617.

\begin{tabular}{|c|c|c|}
\hline Temperature ${ }^{\circ} \mathbf{C}$ & $\begin{array}{c}\text { Thermal Conductivity } \\
\mathbf{W} /\left(\mathbf{m} \cdot{ }^{\circ} \mathbf{C}\right)\end{array}$ & $\begin{array}{c}\text { Thermal Diffusivity } \\
\times \mathbf{1 0 - 6} \mathbf{~ m}^{\mathbf{2}} / \mathbf{s e c}\end{array}$ \\
\hline 20 & 10.3 & 2.88 \\
\hline 50 & 11.0 & 2.99 \\
\hline 75 & 11.6 & 3.08 \\
\hline 100 & 12.1 & 3.17 \\
\hline 125 & 12.6 & 3.25 \\
\hline 150 & 13.1 & 3.33 \\
\hline 175 & 13.6 & 3.41 \\
\hline 200 & 14.0 & 3.49 \\
\hline 225 & 14.5 & 3.57 \\
\hline 250 & 14.9 & 3.64 \\
\hline 275 & 15.3 & 3.71 \\
\hline 300 & 15.8 & 3.79 \\
\hline 325 & 16.2 & 3.86 \\
\hline 350 & 16.6 & 3.93 \\
\hline 375 & 17.0 & 4.01 \\
\hline 400 & 17.4 & 4.08 \\
\hline 425 & 17.8 & 4.15 \\
\hline & & \\
\hline & & \\
\hline
\end{tabular}


Appendix B

\section{Case N-XXX: Use of Alloy 617 (UNS N06617) for Class A Elevated Temperature Service Construction Section III, Division 5}




\section{DRAFT FOR COMMITTEE USE ONLY}

\section{Appendix B}

\section{Case N-XXX: Use of Alloy 617 (UNS N06617) for Class A Elevated Temperature Service Construction Section III, Division 5}

Inquiry: May 52Ni-22Cr-13Co-9Mo, Alloy 617 (UNS N06617) be used at elevated temperatures in the construction of components conforming to the requirements of Section III, Division 5, Subsection HB, Subpart B "Elevated Temperature Service"?

Reply: It is the opinion of the Committee that 52Ni-22Cr-13Co-9Mo, Alloy 617 (UNS N06617) may be used in the construction of components conforming to the requirements of Section III, Division 5, Subsection HB, Subpart B "Elevated Temperature Service" providing the following requirements are met:

(a) The modifications and additions to the rules provided in Subsection HB, Subpart B defined in this Code Case shall be met.

(b) The service temperature shall be limited to $1,750^{\circ} \mathrm{F}\left(950^{\circ} \mathrm{C}\right)$ and below.

(c) Service time shall be limited to 100,000 hours.

(d) All other applicable requirements of Section III, Division 5, Subsection HB, Subpart B shall be met.

(e) This Case number shall be listed on the Data Report Form for the component.

This Code Case was written to be used in conjunction with Section III, Division 5, Subsection HB, Subpart B and all requirements of it shall be met except when these requirements are modified by the corresponding numbered paragraphs of this Code Case or when new requirements are added with new numbered paragraphs of this Code Case. All general notes contained in Section III, Division 5 shall apply to the corresponding figures and tables in this Code Case. References within Section III, Division 5 to figures and tables in Appendix HBB-I-14, design fatigue curves or isochronous stress-strain curves should be extended to include corresponding figures and tables for Alloy 617 within this Code Case.

Thermal expansion, thermal diffusivity, and thermal conductivity are not currently contained in Section II for Alloy 617 (UNS N06617). Values for these properties are shown in Tables TE-4 and TCD of this Code Case. Elastic modulus values for Alloy 617 are currently included in Section II Part D (Table TM-4) for temperatures up to $1,500^{\circ} \mathrm{F}\left(850^{\circ} \mathrm{C}\right)$, but the temperature range must be increased to $1,750^{\circ} \mathrm{F}\left(950^{\circ} \mathrm{C}\right)$. Elastic modulus values are shown in Table TM-4 of this Code Case. 


\section{DRAFT FOR COMMITTEE USE ONLY}

\section{ARTICLE HBB-2000 \\ MATERIAL \\ HBB-2100}

\section{HBB-2160 DETERIORATION OF MATERIAL IN SERVICE}

(d) Long-time, elevated temperature, service may result in the reduction of the subsequent yield and ultimate tensile strengths.

(3) When the yield and ultimate tensile strengths are reduced by the elevated temperature service, it is necessary to appropriately reduce the values of $S_{m t}$ and $S_{m}$. To reflect the effects of long-time elevated temperature service, the $S_{m t}$ values of Tables HBB-I-14.3A through HBB-I-14.3F shall be redefined as the lower of (-a) through $(-g)$ below, and the values of $S_{m}$ shall be defined as the lower of $(-b)$ through $(-g)$ below:

(-g) for Alloy 617, the product of the yield strength at temperature (Table HBB-I-14.5) and the yield strength reduction factor (Table HBB-3225-2).

\section{ARTICLE HBB-3000 DESIGN}

\section{HBB-3200 Design by Analysis}

\section{HBB-3210 Design Criteria}

\section{HBB-3212 Basis for Determining Stress, Strain, and Deformation Quantities}

(d) An additional material of this Subsection, Alloy 617, has several unique characteristics that should be recognized and reflected in multiaxial stress-strain relationships. These include the following:

(1) There is not a clear distinction between time-independent elastic-plastic behavior and time-dependent creep behavior.

(2) Flow stresses are strongly strain-rate sensitive at elevated temperatures.

\section{HBB-3214 Stress Analysis}

\section{HBB-3214.2 Inelastic Analysis}

[Note: Add the following paragraph as a new last paragraph to HBB-3214.2]

For Alloy 617, decoupling of plastic and creep strains in the classical constitutive framework is generally a poor representation of the true material behavior. Unified constitutive equations, which do not distinguish between rate-dependent plasticity and time-dependent creep, represent the rate dependence and softening that occur, particularly at higher temperatures.

\section{HBB-3220 Design Rules and Limits for Load-controlled Stresses in Structures other than Bolts}

\section{HBB-3225 Level D Service Limits}

The following temperature-dependent tensile strength values, $S_{u}$, for Alloy 617 are added in Table HBB-3225-1 of this Code Case.

The following tensile and yield strength reduction factors due to long-time prior elevated temperature service for Alloy 617 are added in Table HBB-3225-2 of this Code Case. 


\section{DRAFT FOR COMMITTEE USE ONLY}

Table HBB-3225-1

Tensile Strength Values, $\boldsymbol{S}_{u}$

\begin{tabular}{cc}
\hline & U.S. Customary Units, ksi \\
& $\begin{array}{c}\text { See Section II, Part D, Subpart 1, Table U } \\
\text { for Values up to 1,000 }{ }^{\circ} \mathbf{F}\end{array}$ \\
\cline { 2 - 2 } $\begin{array}{c}\text { For Metal } \\
\text { Temperature Not } \\
\text { Exceeding, }{ }^{\circ} \mathbf{F}\end{array}$ & UNS N06617 \\
\hline & \\
\hline 1,050 & 85.2 \\
1,100 & 83.4 \\
1,150 & 81.2 \\
1,200 & 78.4 \\
1,250 & 75.2 \\
1,300 & 71.3 \\
1,350 & 66.9 \\
1,400 & 62.0 \\
1,450 & 56.6 \\
1,500 & 50.8 \\
1,550 & 44.7 \\
1,600 & 38.5 \\
1,650 & 32.4 \\
1,700 & 26.4 \\
1,750 & 21.0 \\
\hline & SI Units, MPa \\
\hline
\end{tabular}

Temperature Not

Exceeding, ${ }^{\circ} \mathrm{C}$

UNS N06617

\begin{tabular}{cc} 
Exceeding, & C \\
\hline 550 & 593 \\
575 & 584 \\
600 & 572 \\
625 & 557 \\
650 & 540 \\
675 & 520 \\
700 & 496 \\
725 & 470 \\
750 & 440 \\
775 & 408 \\
800 & 373 \\
825 & 336 \\
850 & 298 \\
875 & 260 \\
900 & 221 \\
925 & 185 \\
950 & 151 \\
\hline
\end{tabular}

GENERAL NOTES:

(a) The tabulated values of tensile strength and yield strength are those which the Committee believes are suitable for use in design calculations required by this Subsection. At temperatures above room temperature, the values of tensile strength tend toward an average or expected value which may be as much as $10 \%$ above the tensile strength trend curve adjusted to the minimum specified room temperature tensile strength. At temperatures above room temperature, the yield strength values correspond to the yield strength trend curve adjusted to the minimum specified room temperature yield strength. Neither the tensile strength nor the yield strength values correspond exactly to either average or minimum as these terms are applied to a statistical treatment of a homogeneous set of data.

(b) Neither the ASME Material Specifications nor the rules of this Subsection required elevated temperature testing for tensile or yield strengths of production material for use in Code components. It is not intended that results of such tests, if performed, be compared with these tabulated tensile and yield strength values for ASME Code acceptance/rejection purposes for materials. If some elevated temperature test results on production material appear lower than the tabulated values by a large amount (more than the typical variability of material and suggesting the possibility of some error), further investigation by retest or other means should be considered. 


\section{DRAFT FOR COMMITTEE USE ONLY}

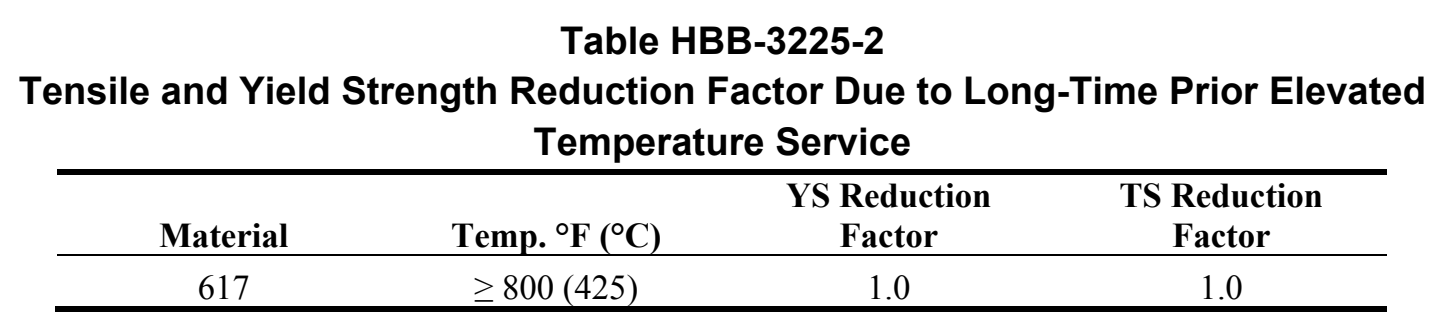

GENERAL NOTE: No reduction factor required for service below the indicated temperature. 


\section{DRAFT FOR COMMITTEE USE ONLY}

\section{ARTICLE HBB-4000 \\ FABRICATION AND INSTALLATION \\ HBB-4200}

\section{HBB-4210}

\section{HBB-4212 Effects of Forming and Bending Processes}

(a) Post fabrication heat treatment [in accordance with (b) below] of materials that have been formed during fabrication, shall be required for fabrication induced strains greater than $5 \%$.

(b) When required, the post fabrication heat treatment shall be in accordance with the following:

(3) For Alloy 617, the post fabrication heat treatment shall consist of the heat treatment specified in the base material specification.

\section{HBB-4800 Relaxation Cracking}

Components that will see service between $932^{\circ} \mathrm{F}\left(500^{\circ} \mathrm{C}\right)$ and $1436^{\circ} \mathrm{F}\left(780^{\circ} \mathrm{C}\right)$ shall be given a heat treatment of three hours at $1796^{\circ} \mathrm{F}\left(980^{\circ} \mathrm{C}\right)$ to eliminate relaxation cracking after post fabrication heat treatment, if needed according to HBB-4212. This heat treatment is required for material in either a welded or solution annealed condition. 


\section{DRAFT FOR COMMITTEE USE ONLY}

\section{MANDATORY APPENDIX HBB-I-14 TABLES AND FIGURES}

The following Tables and Figures have Alloy 617 data added as indicated.

Table HBB-I-14.1(a)

Permissible Base Materials for Structures Other Than Bolting

\begin{tabular}{cccc}
\hline Base Material & Spec. No. & Product Form & Types, Grades or Classes \\
\hline Alloy 617 & SB-166 & Bar, rod & UNS N06617 \\
[Note (7)] & SB-167 & Smls. pipe \& tube & UNS N06617 \\
& SB-168 & Plate, sheet, strip & UNS N06617 \\
& SB-564 & Forgings & UNS N06617 \\
\hline
\end{tabular}

NOTE:

(7) The minimum material thickness shall be 0.125 inches.

Table HBB-I-14.1(b)

Permissible Weld Materials

\begin{tabular}{ccc}
\hline Base Material & $\begin{array}{c}\text { Spec. No. } \\
{[\text { Note (1)] }}\end{array}$ & Class \\
\hline Alloy 617 & SFA-5.14 & ERNiCrCoMo-1 \\
\hline
\end{tabular}

NOTE:

(1) Only Gas Tungsten Arc Welding (GTAW) is permitted. 


\section{DRAFT FOR COMMITTEE USE ONLY}

Table HBB-I-14.2

$S_{o}$ - Maximum Allowable Stress Intensity, ksi (MPa), for Design Condition Calculations

\begin{tabular}{|c|c|c|}
\hline \multicolumn{2}{|c|}{ U.S. Customary Units } & \\
\hline $\begin{array}{c}\text { For Metal Temperature } \\
\text { Not Exceeding, }{ }^{\circ} \text { F }\end{array}$ & N06617 & \\
\hline 700 & - & \\
\hline 750 & - & \\
\hline 800 & 21.5 & \\
\hline 850 & 21.3 & \\
\hline 900 & 21.2 & \\
\hline 950 & 21.0 & \\
\hline 1,000 & 20.9 & \\
\hline 1,050 & 20.9 & \\
\hline 1,100 & 20.8 & \\
\hline 1,150 & 20.7 & \\
\hline 1,200 & 18.1 & \\
\hline 1,250 & 14.5 & \\
\hline 1,300 & 11.2 & \\
\hline 1,350 & 8.7 & \\
\hline 1,400 & 6.6 & \\
\hline 1,450 & 5.1 & \\
\hline 1,500 & 3.9 & \\
\hline 1,550 & 3.0 & \\
\hline 1,600 & 2.3 & \\
\hline 1,650 & 1.8 & \\
\hline 1,700 & 1.4 & \\
\hline 1,750 & 1.1 & \\
\hline \multicolumn{3}{|l|}{ SI Units } \\
\hline $\begin{array}{c}\text { For Metal Temperature } \\
\text { Not Exceeding, }{ }^{\circ} \mathrm{C}\end{array}$ & N06617 & \\
\hline 375 & - & \\
\hline 400 & - & \\
\hline 425 & 148 & \\
\hline 450 & 147 & \\
\hline 475 & 146 & \\
\hline 500 & 145 & \\
\hline 525 & 144 & \\
\hline 550 & 144 & \\
\hline 575 & 144 & \\
\hline 600 & 143 & \\
\hline 625 & 142 & \\
\hline 650 & 124 & \\
\hline 675 & 101 & \\
\hline 700 & 81 & \\
\hline 725 & 64 & \\
\hline 750 & 50 & \\
\hline 775 & 40 & \\
\hline 800 & 31 & \\
\hline 825 & 25 & \\
\hline 850 & 19 & \\
\hline 875 & 15 & \\
\hline 900 & 12 & \\
\hline 925 & 10 & {$[\operatorname{Note}(5)]$} \\
\hline 950 & 7.9 & {$[$ Note $(5)]$} \\
\hline
\end{tabular}

NOTE:

(5) Interpolated from values given in Note G29 of Section II, Part D, Subpart 1, Table 1B. 


\section{DRAFT FOR COMMITTEE USE ONLY}

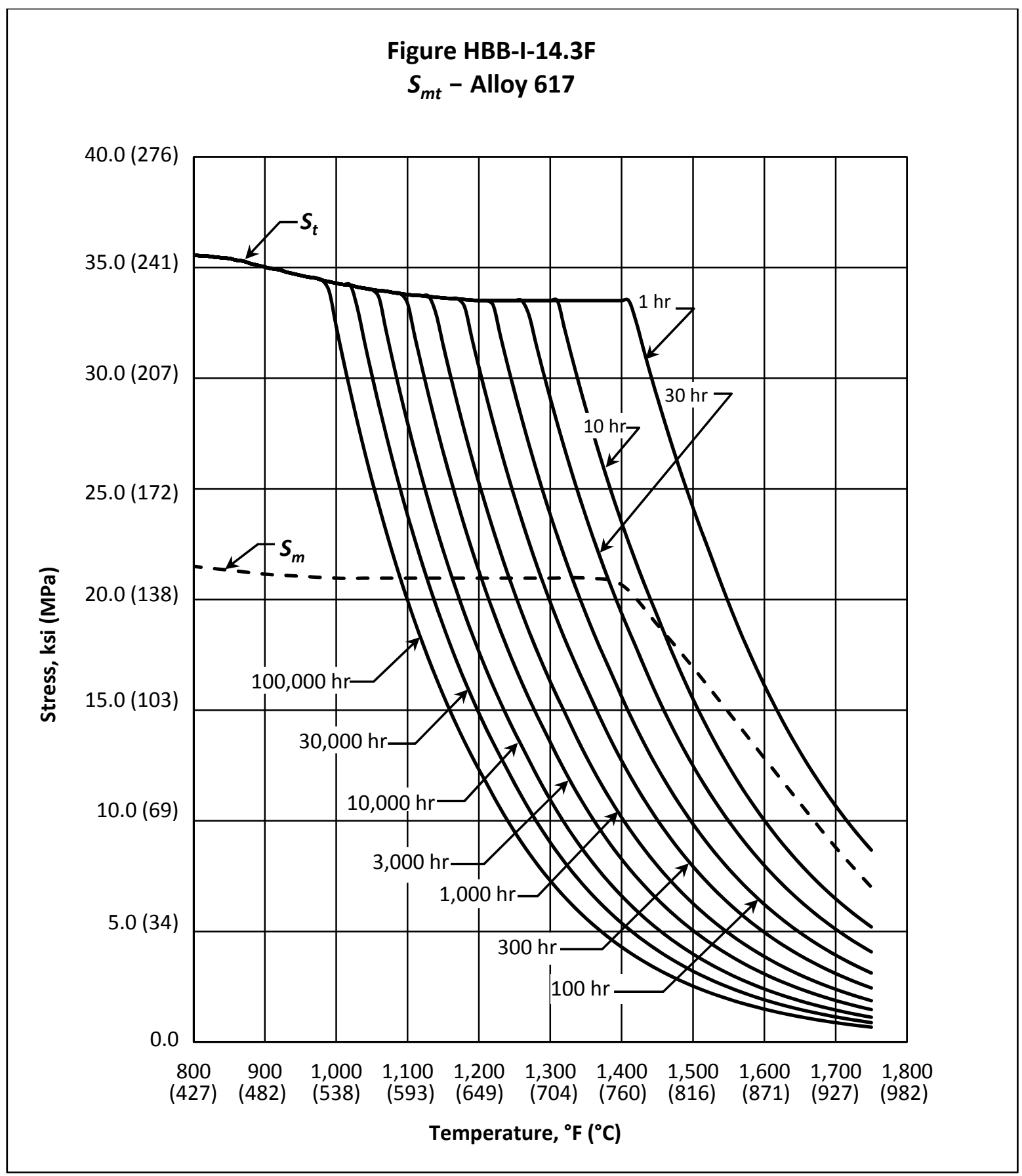




\section{DRAFT FOR COMMITTEE USE ONLY}

Table HBB-I-14.3F

$S_{m t}-$ Allowable Stress Intensity Values, ksi (MPa), Alloy 617

\begin{tabular}{|c|c|c|c|c|c|c|c|c|c|c|}
\hline \multicolumn{11}{|c|}{ U.S. Customary Units } \\
\hline Temp., ${ }^{\circ} \mathbf{F}$ & $1 \mathrm{hr}$ & $10 \mathrm{hr}$ & $30 \mathrm{hr}$ & $100 \mathrm{hr}$ & $300 \mathrm{hr}$ & $1,000 \mathrm{hr}$ & $3,000 \mathrm{hr}$ & $10,000 \mathrm{hr}$ & $30,000 \mathrm{hr}$ & $100,000 \mathrm{hr}$ \\
\hline 800 & 21.5 & 21.5 & 21.5 & 21.5 & 21.5 & 21.5 & 21.5 & 21.5 & 21.5 & 21.5 \\
\hline 850 & 21.3 & 21.3 & 21.3 & 21.3 & 21.3 & 21.3 & 21.3 & 21.3 & 21.3 & 21.3 \\
\hline 900 & 21.2 & 21.2 & 21.2 & 21.2 & 21.2 & 21.2 & 21.2 & 21.2 & 21.2 & 21.2 \\
\hline 950 & 21.1 & 21.1 & 21.1 & 21.1 & 21.1 & 21.1 & 21.1 & 21.1 & 21.1 & 21.1 \\
\hline 1,000 & 21.0 & 21.0 & 21.0 & 21.0 & 21.0 & 21.0 & 21.0 & 21.0 & 21.0 & 21.0 \\
\hline 1,050 & 21.0 & 21.0 & 21.0 & 21.0 & 21.0 & 21.0 & 21.0 & 21.0 & 21.0 & 21.0 \\
\hline 1,100 & 21.0 & 21.0 & 21.0 & 21.0 & 21.0 & 21.0 & 21.0 & 21.0 & 21.0 & 20.0 \\
\hline 1,150 & 21.0 & 21.0 & 21.0 & 21.0 & 21.0 & 21.0 & 21.0 & 21.0 & 18.8 & 15.7 \\
\hline 1,200 & 21.0 & 21.0 & 21.0 & 21.0 & 21.0 & 21.0 & 21.0 & 17.6 & 14.9 & 12.3 \\
\hline 1,250 & 21.0 & 21.0 & 21.0 & 21.0 & 21.0 & 20.3 & 17.0 & 14.0 & 11.7 & 9.5 \\
\hline 1,300 & 21.0 & 21.0 & 21.0 & 21.0 & 19.9 & 16.3 & 13.6 & 11.0 & 9.0 & 7.3 \\
\hline 1,350 & 21.0 & 21.0 & 21.0 & 19.3 & 16.0 & 12.9 & 10.6 & 8.5 & 7.0 & 5.6 \\
\hline 1,400 & 21.0 & 20.7 & 19.4 & 15.6 & 12.7 & 10.2 & 8.3 & 6.6 & 5.4 & 4.3 \\
\hline 1,450 & 19.3 & 18.9 & 15.6 & 12.4 & 10.0 & 8.0 & 6.5 & 5.1 & 4.2 & 3.3 \\
\hline 1,500 & 16.9 & 15.5 & 12.5 & 9.9 & 7.9 & 6.3 & 5.0 & 4.0 & 3.2 & 2.5 \\
\hline 1,550 & 14.9 & 12.5 & 10.0 & 7.8 & 6.3 & 4.9 & 3.9 & 3.1 & 2.5 & 1.9 \\
\hline 1,600 & 12.8 & 10.0 & 8.0 & 6.2 & 5.0 & 3.9 & 3.1 & 2.4 & 1.9 & 1.5 \\
\hline 1,650 & 10.8 & 8.1 & 6.4 & 4.9 & 3.9 & 3.0 & 2.4 & 1.9 & 1.5 & 1.1 \\
\hline 1,700 & 8.8 & 6.5 & 5.1 & 3.9 & 3.1 & 2.4 & 1.9 & 1.4 & 1.1 & 0.9 \\
\hline 1,750 & 7.0 & 5.2 & 4.1 & 3.1 & 2.4 & 1.9 & 1.5 & 1.1 & 0.9 & 0.7 \\
\hline \multicolumn{11}{|c|}{ SI Units } \\
\hline Temp., ${ }^{\circ} \mathrm{C}$ & $1 \mathrm{~h}$ & $10 \mathrm{~h}$ & $30 \mathrm{~h}$ & $100 \mathrm{~h}$ & $300 \mathrm{~h}$ & $1,000 \mathrm{~h}$ & 3,000 h & $10,000 \mathrm{~h}$ & 30,000 h & $100,000 \mathrm{~h}$ \\
\hline 425 & 148 & 148 & 148 & 148 & 148 & 148 & 148 & 148 & 148 & 148 \\
\hline 450 & 148 & 148 & 148 & 148 & 148 & 148 & 148 & 148 & 148 & 148 \\
\hline 475 & 146 & 146 & 146 & 146 & 146 & 146 & 146 & 146 & 146 & 146 \\
\hline 500 & 146 & 146 & 146 & 146 & 146 & 146 & 146 & 146 & 146 & 146 \\
\hline 525 & 145 & 145 & 145 & 145 & 145 & 145 & 145 & 145 & 145 & 145 \\
\hline 550 & 145 & 145 & 145 & 145 & 145 & 145 & 145 & 145 & 145 & 145 \\
\hline 575 & 145 & 145 & 145 & 145 & 145 & 145 & 145 & 145 & 145 & 145 \\
\hline 600 & 145 & 145 & 145 & 145 & 145 & 145 & 145 & 145 & 145 & 130 \\
\hline 625 & 145 & 145 & 145 & 145 & 145 & 145 & 145 & 145 & 125 & 105 \\
\hline 650 & 145 & 145 & 145 & 145 & 145 & 145 & 145 & 121 & 102 & 84 \\
\hline 675 & 145 & 145 & 145 & 145 & 145 & 142 & 119 & 98 & 82 & 67 \\
\hline 700 & 145 & 145 & 145 & 145 & 142 & 116 & 97 & 79 & 65 & 52 \\
\hline 725 & 145 & 145 & 145 & 141 & 117 & 95 & 78 & 63 & 51 & 41 \\
\hline 750 & 145 & 145 & 144 & 117 & 95 & 76 & 62 & 50 & 41 & 33 \\
\hline 775 & 145 & 136 & 119 & 95 & 77 & 61 & 50 & 40 & 32 & 26 \\
\hline 800 & 124 & 121 & 98 & 77 & 62 & 49 & 40 & 32 & 26 & 20 \\
\hline 825 & 112 & 99 & 80 & 63 & 51 & 40 & 32 & 25 & 20 & 16 \\
\hline 850 & 99 & 82 & 65 & 51 & 41 & 32 & 26 & 20 & 16 & 13 \\
\hline 875 & 87 & 67 & 53 & 42 & 33 & 26 & 21 & 16 & 13 & 10 \\
\hline 900 & 74 & 55 & 44 & 34 & 27 & 21 & 16 & 13 & 10 & 8 \\
\hline 925 & 62 & 45 & 36 & 27 & 22 & 17 & 13 & 10 & 8 & 6 \\
\hline 950 & 50 & 37 & 29 & 22 & 18 & 13 & 11 & 8 & 6 & 5 \\
\hline
\end{tabular}

GENERAL NOTE: As described in HBB-2160(d), it may be necessary to adjust the values of $S_{m t}$ to account for the effects of longtime service at elevated temperature. 


\section{DRAFT FOR COMMITTEE USE ONLY}

Figure HBB-I-14.4F

$S_{t}-$ Alloy 617

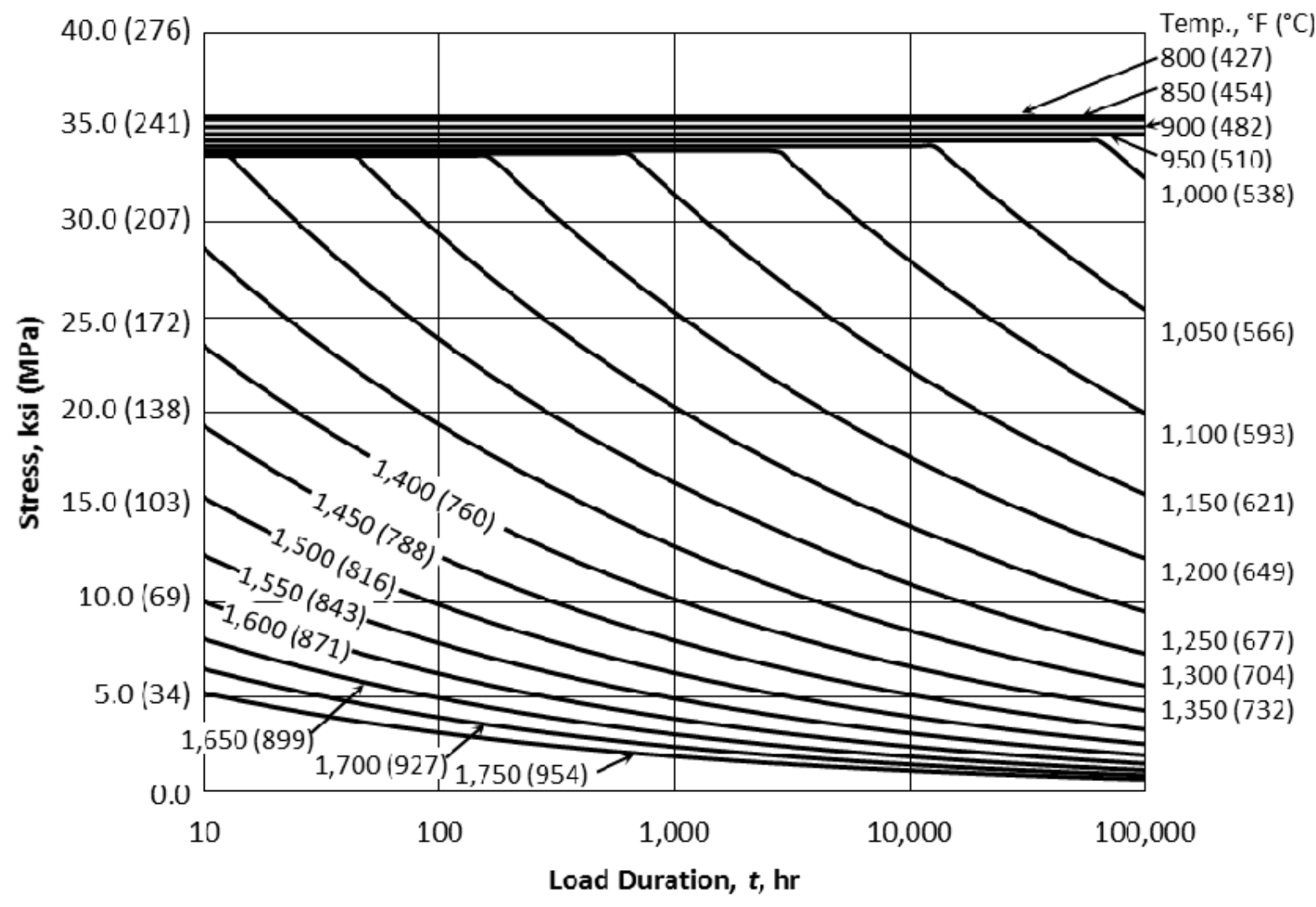




\section{DRAFT FOR COMMITTEE USE ONLY}

Table HBB-I-14.4F

$S_{t}-$ Allowable Stress Intensity Values, ksi (MPa), Alloy 617

\begin{tabular}{|c|c|c|c|c|c|c|c|c|c|c|}
\hline \multicolumn{11}{|c|}{ U.S. Customary Units } \\
\hline Temp., ${ }^{\circ} \mathbf{F}$ & $1 \mathrm{hr}$ & $10 \mathrm{hr}$ & $30 \mathrm{hr}$ & $100 \mathrm{hr}$ & $300 \mathrm{hr}$ & $1,000 \mathrm{hr}$ & $3,000 \mathrm{hr}$ & $10,000 \mathrm{hr}$ & $30,000 \mathrm{hr}$ & $100,000 \mathrm{hr}$ \\
\hline 800 & 35.6 & 35.6 & 35.6 & 35.6 & 35.6 & 35.6 & 35.6 & 35.6 & 35.6 & 35.6 \\
\hline 850 & 35.4 & 35.4 & 35.4 & 35.4 & 35.4 & 35.4 & 35.4 & 35.4 & 35.4 & 35.4 \\
\hline 900 & 35.0 & 35.0 & 35.0 & 35.0 & 35.0 & 35.0 & 35.0 & 35.0 & 35.0 & 35.0 \\
\hline 950 & 34.6 & 34.6 & 34.6 & 34.6 & 34.6 & 34.6 & 34.6 & 34.6 & 34.6 & 34.6 \\
\hline 1,000 & 34.3 & 34.3 & 34.3 & 34.3 & 34.3 & 34.3 & 34.3 & 34.3 & 34.3 & 32.3 \\
\hline 1,050 & 34.0 & 34.0 & 34.0 & 34.0 & 34.0 & 34.0 & 34.0 & 34.0 & 30.1 & 25.4 \\
\hline 1,100 & 33.8 & 33.8 & 33.8 & 33.8 & 33.8 & 33.8 & 33.4 & 28.0 & 23.8 & 20.0 \\
\hline 1,150 & 33.6 & 33.6 & 33.6 & 33.6 & 33.6 & 31.5 & 26.7 & 22.2 & 18.8 & 15.7 \\
\hline 1,200 & 33.5 & 33.5 & 33.5 & 33.5 & 30.5 & 25.3 & 21.3 & 17.6 & 14.9 & 12.3 \\
\hline 1,250 & 33.5 & 33.5 & 33.5 & 29.4 & 24.6 & 20.3 & 17.0 & 14.0 & 11.7 & 9.5 \\
\hline 1,300 & 33.5 & 33.5 & 29.1 & 23.8 & 19.9 & 16.3 & 13.6 & 11.0 & 9.0 & 7.3 \\
\hline 1,350 & 33.5 & 28.6 & 23.7 & 19.3 & 16.0 & 12.9 & 10.6 & 8.5 & 7.0 & 5.6 \\
\hline 1,400 & 33.5 & 23.5 & 19.4 & 15.6 & 12.7 & 10.2 & 8.3 & 6.6 & 5.4 & 4.3 \\
\hline 1,450 & 29.1 & 19.3 & 15.6 & 12.4 & 10.0 & 8.0 & 6.5 & 5.1 & 4.2 & 3.3 \\
\hline 1,500 & 24.2 & 15.5 & 12.5 & 9.9 & 7.9 & 6.3 & 5.0 & 4.0 & 3.2 & 2.5 \\
\hline 1,550 & 19.8 & 12.5 & 10.0 & 7.8 & 6.3 & 4.9 & 3.9 & 3.1 & 2.5 & 1.9 \\
\hline 1,600 & 16.1 & 10.0 & 8.0 & 6.2 & 5.0 & 3.9 & 3.1 & 2.4 & 1.9 & 1.5 \\
\hline 1,650 & 13.1 & 8.1 & 6.4 & 4.9 & 3.9 & 3.0 & 2.4 & 1.9 & 1.5 & 1.1 \\
\hline 1,700 & 10.7 & 6.5 & 5.1 & 3.9 & 3.1 & 2.4 & 1.9 & 1.4 & 1.1 & 0.9 \\
\hline 1,750 & 8.7 & 5.2 & 4.1 & 3.1 & 2.4 & 1.9 & 1.5 & 1.1 & 0.9 & 0.7 \\
\hline \multicolumn{11}{|c|}{ SI Units } \\
\hline Temp., ${ }^{\circ} \mathrm{C}$ & $1 \mathrm{~h}$ & $10 \mathrm{~h}$ & $30 \mathrm{~h}$ & $100 \mathrm{~h}$ & $300 \mathrm{~h}$ & $\mathbf{1 , 0 0 0 ~ h}$ & $\mathbf{3 , 0 0 0 ~ h}$ & $10,000 \mathrm{~h}$ & $\mathbf{3 0 , 0 0 0 ~ h}$ & $\mathbf{1 0 0 , 0 0 0 ~ h}$ \\
\hline 425 & 245 & 245 & 245 & 245 & 245 & 245 & 245 & 245 & 245 & 245 \\
\hline 450 & 245 & 245 & 245 & 245 & 245 & 245 & 245 & 245 & 245 & 245 \\
\hline 475 & 242 & 242 & 242 & 242 & 242 & 242 & 242 & 242 & 242 & 242 \\
\hline 500 & 240 & 240 & 240 & 240 & 240 & 240 & 240 & 240 & 240 & 240 \\
\hline 525 & 238 & 238 & 238 & 238 & 238 & 238 & 238 & 238 & 238 & 238 \\
\hline 550 & 235 & 235 & 235 & 235 & 235 & 235 & 235 & 235 & 235 & 200 \\
\hline 575 & 234 & 234 & 234 & 234 & 234 & 234 & 234 & 225 & 192 & 161 \\
\hline 600 & 233 & 233 & 233 & 233 & 233 & 233 & 218 & 182 & 155 & 130 \\
\hline 625 & 232 & 232 & 232 & 232 & 232 & 210 & 178 & 148 & 125 & 105 \\
\hline 650 & 231 & 231 & 231 & 231 & 208 & 173 & 145 & 121 & 102 & 84 \\
\hline 675 & 231 & 231 & 231 & 205 & 172 & 142 & 119 & 98 & 82 & 67 \\
\hline 700 & 231 & 231 & 207 & 170 & 142 & 116 & 97 & 79 & 65 & 52 \\
\hline 725 & 231 & 208 & 173 & 141 & 117 & 95 & 78 & 63 & 51 & 41 \\
\hline 750 & 231 & 174 & 144 & 117 & 95 & 76 & 62 & 50 & 41 & 33 \\
\hline 775 & 219 & 146 & 119 & 95 & 77 & 61 & 50 & 40 & 32 & 26 \\
\hline 800 & 185 & 121 & 98 & 77 & 62 & 49 & 40 & 32 & 26 & 20 \\
\hline 825 & 156 & 99 & 80 & 63 & 51 & 40 & 32 & 25 & 20 & 16 \\
\hline 850 & 130 & 82 & 65 & 51 & 41 & 32 & 26 & 20 & 16 & 13 \\
\hline 875 & 108 & 67 & 53 & 42 & 33 & 26 & 21 & 16 & 13 & 10 \\
\hline 900 & 90 & 55 & 44 & 34 & 27 & 21 & 16 & 13 & 10 & 8 \\
\hline 925 & 75 & 45 & 36 & 27 & 22 & 17 & 13 & 10 & 8 & 6 \\
\hline 950 & 62 & 37 & 29 & 22 & 18 & 13 & 11 & 8 & 6 & 5 \\
\hline
\end{tabular}


Table HBB-I-14.5

Yield Strength Values, $\boldsymbol{S}_{\boldsymbol{y}}$, Versus Temperature

\begin{tabular}{cc}
\hline & U.S. Customary Units \\
\cline { 2 - 2 } Temp., ${ }^{\circ} \mathbf{F}$ & Stresses, ksi \\
\hline RT & UNS N06617 \\
$:$ & See Section II, Part D, \\
1,000 & Subpart 1, Table Y-1 for \\
1,050 & Values up to $1,000^{\circ} \mathrm{F}$ \\
\cline { 2 - 2 } 1,100 & 23.3 \\
1,150 & 23.3 \\
1,200 & 23.3 \\
1,250 & 23.3 \\
1,300 & 23.3 \\
1,350 & 23.3 \\
1,400 & 23.3 \\
1,450 & 23.3 \\
1,500 & 23.3 \\
1,550 & 22.6 \\
1,600 & 21.6 \\
1,650 & 20.4 \\
1,700 & 19.0 \\
1,750 & 17.4 \\
\hline \multicolumn{2}{c}{} \\
\hline
\end{tabular}

\begin{tabular}{cc} 
& SI Units \\
\hline & Stresses, MPa \\
\cline { 2 - 2 } Temp., ${ }^{\circ}$ C & UNS N06617 \\
\hline RT & See Section II, Part D, \\
$:$ & Subpart 1, Table Y-1 for \\
525 & Values up to 538 ${ }^{\circ} \mathrm{C}$ \\
550 & 161 \\
575 & 161 \\
600 & 161 \\
625 & 161 \\
650 & 161 \\
675 & 161 \\
700 & 161 \\
725 & 161 \\
750 & 161 \\
775 & 161 \\
800 & 159 \\
825 & 153 \\
850 & 147 \\
875 & 139 \\
900 & 131 \\
925 & 121 \\
950 & 110 \\
\hline
\end{tabular}




\section{DRAFT FOR COMMITTEE USE ONLY}

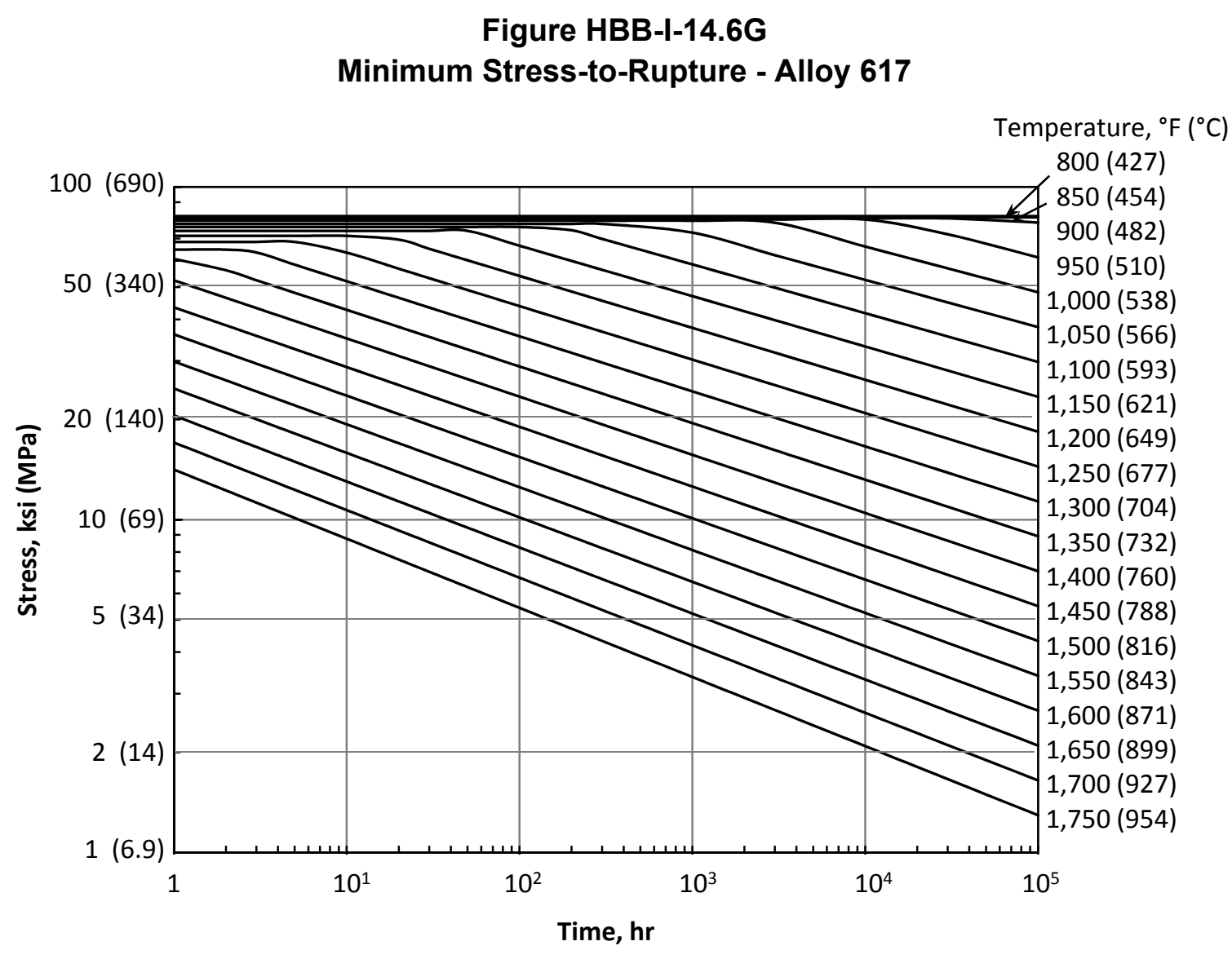


Table HBB-I-14.6G

Expected Minimum Stress-to-Rupture Values, ksi (MPa), Alloy 617

\begin{tabular}{|c|c|c|c|c|c|c|c|c|c|c|c|}
\hline \multirow[b]{2}{*}{ Temp., ${ }^{\circ} \mathbf{F}$} & \multicolumn{11}{|c|}{ U.S. Customary Units } \\
\hline & $1 \mathrm{hr}$ & $3 \mathrm{hr}$ & $10 \mathrm{hr}$ & $30 \mathrm{hr}$ & $100 \mathrm{hr}$ & $300 \mathrm{hr}$ & $1,000 \mathrm{hr}$ & $3,000 \mathrm{hr}$ & $10,000 \mathrm{hr}$ & $30,000 \mathrm{hr}$ & $100,000 \mathrm{hr}$ \\
\hline 800 & 81.7 & 81.7 & 81.7 & 81.7 & 81.7 & 81.7 & 81.7 & 81.7 & 81.7 & 81.7 & 81.7 \\
\hline 850 & 81.1 & 81.1 & 81.1 & 81.1 & 81.1 & 81.1 & 81.1 & 81.1 & 81.1 & 81.1 & 81.1 \\
\hline 900 & 80.5 & 80.5 & 80.5 & 80.5 & 80.5 & 80.5 & 80.5 & 80.5 & 80.5 & 80.5 & 78.2 \\
\hline 950 & 79.8 & 79.8 & 79.8 & 79.8 & 79.8 & 79.8 & 79.8 & 79.8 & 79.8 & 72.1 & 61.4 \\
\hline 1,000 & 79.2 & 79.2 & 79.2 & 79.2 & 79.2 & 79.2 & 79.2 & 78.1 & 66.2 & 56.9 & 48.3 \\
\hline 1,050 & 77.5 & 77.5 & 77.5 & 77.5 & 77.5 & 77.5 & 72.9 & 62.4 & 52.6 & 45.0 & 37.9 \\
\hline 1,100 & 75.8 & 75.8 & 75.8 & 75.8 & 75.8 & 69.8 & 58.5 & 49.8 & 41.8 & 35.5 & 29.8 \\
\hline 1,150 & 73.8 & 73.8 & 73.8 & 73.8 & 66.6 & 56.4 & 47.0 & 39.8 & 33.2 & 28.1 & 23.4 \\
\hline 1,200 & 71.3 & 71.3 & 71.3 & 65.2 & 54.0 & 45.5 & 37.7 & 31.8 & 26.3 & 22.2 & 18.4 \\
\hline 1,250 & 68.4 & 68.4 & 63.5 & 53.2 & 43.8 & 36.7 & 30.3 & 25.4 & 20.9 & 17.5 & 14.4 \\
\hline 1,300 & 64.8 & 63.6 & 52.1 & 43.4 & 35.6 & 29.7 & 24.3 & 20.3 & 16.6 & 13.8 & 11.3 \\
\hline 1,350 & 60.8 & 52.4 & 42.7 & 35.4 & 28.9 & 24.0 & 19.5 & 16.2 & 13.2 & 10.9 & 8.9 \\
\hline 1,400 & 52.4 & 43.3 & 35.1 & 28.9 & 23.4 & 19.3 & 15.7 & 12.9 & 10.5 & 8.6 & 7.0 \\
\hline 1,450 & 43.5 & 35.7 & 28.8 & 23.6 & 19.0 & 15.6 & 12.6 & 10.3 & 8.3 & 6.8 & 5.5 \\
\hline 1,500 & 36.1 & 29.4 & 23.6 & 19.3 & 15.4 & 12.6 & 10.1 & 8.2 & 6.6 & 5.4 & 4.3 \\
\hline 1,550 & 29.9 & 24.3 & 19.4 & 15.7 & 12.5 & 10.2 & 8.1 & 6.6 & 5.2 & 4.3 & 3.4 \\
\hline 1,600 & 24.8 & 20.0 & 15.9 & 12.8 & 10.2 & 8.2 & 6.5 & 5.3 & 4.2 & 3.4 & 2.7 \\
\hline 1,650 & 20.6 & 16.5 & 13.0 & 10.5 & 8.2 & 6.6 & 5.2 & 4.2 & 3.3 & 2.7 & 2.1 \\
\hline 1,700 & 17.1 & 13.6 & 10.7 & 8.5 & 6.7 & 5.4 & 4.2 & 3.4 & 2.6 & 2.1 & 1.6 \\
\hline \multirow[t]{2}{*}{1,750} & 14.1 & 11.3 & 8.8 & 7.0 & 5.4 & 4.3 & 3.4 & 2.7 & 2.1 & 1.7 & 1.3 \\
\hline & \multicolumn{11}{|c|}{ SI Units } \\
\hline Temp., ${ }^{\circ} \mathrm{C}$ & $1 \mathrm{~h}$ & $3 \mathbf{~ h}$ & $10 \mathrm{~h}$ & $30 \mathrm{~h}$ & $100 \mathrm{~h}$ & $300 \mathrm{~h}$ & $\mathbf{1 , 0 0 0 ~ h}$ & $\mathbf{3 , 0 0 0 ~ h}$ & $\mathbf{1 0 , 0 0 0 ~ h}$ & $\mathbf{3 0 , 0 0 0 ~ h}$ & $100,000 \mathrm{~h}$ \\
\hline 425 & 564 & 564 & 564 & 564 & 564 & 564 & 564 & 564 & 564 & 564 & 564 \\
\hline 450 & 560 & 560 & 560 & 560 & 560 & 560 & 560 & 560 & 560 & 560 & 560 \\
\hline 475 & 555 & 555 & 555 & 555 & 555 & 555 & 555 & 555 & 555 & 555 & 555 \\
\hline 500 & 552 & 552 & 552 & 552 & 552 & 552 & 552 & 552 & 552 & 541 & 462 \\
\hline 525 & 548 & 548 & 548 & 548 & 548 & 548 & 548 & 548 & 508 & 438 & 372 \\
\hline $\mathbf{5 5 0}$ & 539 & 539 & 539 & 539 & 539 & 539 & 539 & 488 & 412 & 354 & 299 \\
\hline 575 & 531 & 531 & 531 & 531 & 531 & 531 & 466 & 398 & 335 & 286 & 241 \\
\hline 600 & 520 & 520 & 520 & 520 & 520 & 457 & 383 & 325 & 272 & 232 & 194 \\
\hline 625 & 506 & 506 & 506 & 506 & 446 & 377 & 314 & 266 & 221 & 187 & 156 \\
\hline 650 & 491 & 491 & 491 & 446 & 369 & 311 & 258 & 217 & 180 & 152 & 126 \\
\hline 675 & 473 & 473 & 443 & 371 & 306 & 257 & 212 & 177 & 146 & 123 & 101 \\
\hline 700 & 451 & 451 & 371 & 309 & 254 & 212 & 174 & 145 & 119 & 99 & 81 \\
\hline 725 & 427 & 380 & 310 & 258 & 210 & 175 & 142 & 118 & 97 & 80 & 65 \\
\hline 750 & 387 & 320 & 260 & 215 & 174 & 144 & 117 & 97 & 78 & 65 & 53 \\
\hline 775 & 327 & 269 & 217 & 179 & 144 & 119 & 96 & 79 & 64 & 52 & 42 \\
\hline 800 & 276 & 226 & 182 & 149 & 120 & 98 & 79 & 64 & 52 & 42 & 34 \\
\hline 825 & 233 & 190 & 152 & 124 & 99 & 81 & 65 & 53 & 42 & 34 & 27 \\
\hline 850 & 197 & 160 & 127 & 103 & 82 & 67 & 53 & 43 & 34 & 28 & 22 \\
\hline 875 & 167 & 135 & 106 & 86 & 68 & 55 & 44 & 35 & 28 & 22 & 18 \\
\hline 900 & 141 & 113 & 89 & 72 & 56 & 45 & 36 & 29 & 23 & 18 & 14 \\
\hline 925 & 119 & 95 & 75 & 60 & 47 & 37 & 29 & 23 & 18 & 15 & 12 \\
\hline 950 & 100 & 80 & 62 & 50 & 39 & 31 & 24 & 19 & 15 & 12 & 9 \\
\hline
\end{tabular}




\section{DRAFT FOR COMMITTEE USE ONLY}

Table HBB-I-14.10F-1

Stress Rupture Factors for Alloy 617 Welded with ERNiCrCoMo-1

\begin{tabular}{cc|cc}
\hline \multicolumn{2}{c|}{ U.S. Customary Units } & \multicolumn{2}{c}{ SI Units } \\
\hline Temp., ${ }^{\circ} \mathrm{F}$ & Ratio & Temp., ${ }^{\circ} \mathrm{C}$ & Ratio \\
\hline 800 & 1.0 & 425 & 1.0 \\
850 & 1.0 & 450 & 1.0 \\
900 & 1.0 & 475 & 1.0 \\
950 & 1.0 & 500 & 1.0 \\
1,000 & 1.0 & 525 & 1.0 \\
1,050 & 1.0 & 550 & 1.0 \\
1,100 & 1.0 & 575 & 1.0 \\
1,150 & 1.0 & 600 & 1.0 \\
1,200 & 1.0 & 625 & 1.0 \\
1,250 & 1.0 & 650 & 1.0 \\
1,300 & 1.0 & 675 & 1.0 \\
1,350 & 1.0 & 700 & 1.0 \\
1,400 & 1.0 & 725 & 1.0 \\
1,450 & 1.0 & 750 & 1.0 \\
1,500 & 1.0 & 775 & 1.0 \\
1,550 & 1.0 & 800 & 1.0 \\
1,600 & 0.85 & 825 & 1.0 \\
1,650 & 0.85 & 850 & 0.85 \\
1,700 & 0.85 & 875 & 0.85 \\
1,750 & 0.85 & 900 & 0.85 \\
& & 925 & 0.85 \\
& & 950 & 0.85 \\
\hline
\end{tabular}

Table HBB-I-14.11

Permissible Materials for Bolting

Not applicable for Alloy 617. 


\section{DRAFT FOR COMMITTEE USE ONLY}

\section{NONMANDATORY APPENDIX HBB-T \\ RULES FOR STRAIN, DEFORMATION, AND FATIGUE LIMITS AT ELEVATED TEMPERATURES}

\section{HBB-T-1300 Deformation and Strain Limits for Structural Integrity HBB-T-1320 Satisfaction of Strain Limits Using Elastic Analysis}

HBB-T-1321 General Requirements

(e) Paragraph HBB-T-1321, HBB-T-1322 and HBB-T-1323 are not applicable to Alloy 617 above $1200^{\circ} \mathrm{F}\left(650^{\circ} \mathrm{C}\right)$.

HBB-T-1323 Test No. A-2 below.

The following data are added for Alloy 617 in Table HBB-T-1323 of this Code Case as indicated

Table HBB-T-1323

\begin{tabular}{cc} 
Temperatures at Which $\mathbf{S}_{\mathbf{m}}=\mathbf{S}_{\mathbf{t}}$ at $\mathbf{1 0}^{\mathbf{5}} \mathbf{~ h r}$ \\
\hline Material & Temp. $^{\circ} \mathbf{F}\left({ }^{\circ} \mathbf{C}\right)$ \\
\hline Alloy 617 & $1090(588)$ \\
\hline
\end{tabular}

HBB-T-1324 Test No. A-3 below.

The following data are added for Alloy 617 in Table HBB-T-1324 of this Code Case as indicated

Table HBB-T-1324

Values of the $r$ and $s$ Parameters

\begin{tabular}{ccc}
\hline Material & $\boldsymbol{r}$ & $\boldsymbol{s}$ \\
\hline Alloy 617 & 1.0 & 1.5 \\
\hline
\end{tabular}

The reference for determination of maximum allowable time, $t_{i d}$, shall be revised to Figure HBB-I-14.6G of this Code Case for expected minimum stress-to-rupture.

\section{HBB-T-1330 Satisfaction of Strain Limits Using Simplified Inelastic Analysis} HBB-T-1331 General Requirements

(i) Paragraph HBB-T-1331 is not applicable to Alloy 617 above $1200^{\circ} \mathrm{F}\left(650^{\circ} \mathrm{C}\right)$.

HBB-T-1332 Tests No. B-1 and B-2

(e) Paragraph HBB-T-1332 is not applicable to Alloy 617 above $1200^{\circ} \mathrm{F}\left(650^{\circ} \mathrm{C}\right)$.

HBB-T-1333 Test No. B-3

(d) Paragraph HBB-T-1333 is not applicable to Alloy 617 above $1200^{\circ} \mathrm{F}\left(650^{\circ} \mathrm{C}\right)$.

HBB-T-1340 Satisfaction of Strain Limits Using Elastic-Perfectly Plastic Analysis HBB-T-1341 General Requirements

As an alternative to HBB-T-1320 and HBB-T-1330, the strain limits of HBB-T-1310 and HBB-T-1713 are considered satisfied if the requirements of this Subsubarticle are satisfied. 


\section{DRAFT FOR COMMITTEE USE ONLY}

The design methodology employed for evaluation of strain limits is based on ratcheting analyses using a small strain theory elastic-perfectly plastic material model where the yield stress is adjusted based on a pseudo-yield stress selected to bound accumulated inelastic strain. Guidance on ratcheting analysis is provided in HBB-T-1346. The term "pseudo-yield stress" refers to a temperature-dependent isochronous stress based on the total time duration of elevated temperature service and a target inelastic strain, not to exceed the yield strength of the material at temperature and is explicitly defined in HBB-T-1344.2.

(a) This design methodology is not applicable to skeletal structures, e.g., a constant diameter bar with uniform axial load throughout, nor to structures where geometrical nonlinearities exist, e.g., canopy or omega seals.

\section{HBB-T-1342 Load Definition}

Define all applicable loads and load cases per Section III, Division 5, HBB-3113.2, Service Loadings.

HBB-T-1342.1 Composite Cycle Definition. For the purpose of performing an elastic-perfectly plastic ratcheting analysis, an overall cycle must be defined that includes all relevant features from the individual Level A, B and C Service Loadings identified in the Design Specification. Relevant features include, as a minimum, the time-dependent sequence of thermal, mechanical and pressure loading, including starting and ending conditions. Such an overall cycle is defined herein as a composite cycle subject to the following requirements.

(a) An individual cycle, as defined in the Design Specification, cannot be further subdivided into individual cycles to satisfy these requirements.

(b) Except as described in paragraph (c) below, a single cycle from each Level A, B and C Service Loading cycle type shall be included in the composite cycle for evaluation of strain limits.

(c) Level C Service Loadings may be combined with the applicable Level A and B Service Loadings to define an additional composite cycle(s) to be evaluated separately from the composite cycle defined in paragraph HBB-T-1342.1. Multiple composite cycles that include Level C Service Loadings may be defined for separate evaluation. The total number of Level C Service Loading cycles shall not exceed 25 .

\section{HBB-T-1343 Numerical Model}

Develop a numerical model of the component, including all relevant geometry characteristics. The model used for the analysis shall be selected to accurately represent the component geometry, boundary conditions, and applied loads. The model must also be accurate for small details, such as small holes, fillets, corner radii, and other stress risers. The local temperature history shall be determined from a thermal transient analysis based on the thermal boundary conditions determined from the loading conditions defined in HBB-T-1342.

\section{HBB-T-1344 Requirements for Satisfaction of Strain Limits}

Perform a ratcheting analysis for each of the composite cyclic histories defined in HBB-T-1342.1. Each of these cyclic histories must be shown to be free from ratcheting based on the pseudo-yield stress, $S_{x T}$, as defined in HBB-T-1344.2. In the following steps, inelastic strain for a particular stress, time and temperature is obtained by subtracting the elastic strain from the total strain as given by the isochronous stress-strain curve at the same stress, time and temperature. Additional requirements for weldments are shown in HBB-T-1345.

HBB-T-1344.1 Step 1. Define $t_{\text {design }}$ as the total time duration of elevated temperature service for all Level A, B, and C Service Loadings when the temperature is above $800^{\circ} \mathrm{F}\left(425^{\circ} \mathrm{C}\right)$. 


\section{DRAFT FOR COMMITTEE USE ONLY}

HBB-T-1344.2 Step 2. Select a target inelastic strain, $\mathrm{x}$, where $0<\mathrm{x}<\varepsilon_{\text {avg }}$ and $\varepsilon_{\text {avg }}$ is equal to 0.01 for base metal or 0.005 for weldments. Define a pseudo-yield stress, $\mathrm{S}_{\mathrm{xT}}$, at each location, ${ }^{\mathrm{a}}$ using the temperature determined from the transient thermal analysis. This pseudo-yield stress is equal to the lesser of the quantities defined below in (a) and (b).

(a) The yield strength, $\mathrm{S}_{\mathrm{y}}$, given in Table HBB-I-14.5 of this Code Case;

(b) The stress to cause $\mathrm{x}$ inelastic strain in time $t_{\text {design }}$, as determined from the isochronous stress-strain curves in HBB-T-1800 of this Code Case.

HBB-T-1344.3 Step 3. Perform a cyclic elastic-perfectly plastic analysis for each composite cycle defined in HBB-T-1342.1 above with temperature-dependent pseudo-yield stress, $\mathrm{S}_{\mathrm{xT}}$. If ratcheting does not occur, obtain the plastic strain distribution throughout the component. The plastic strain, $\varepsilon_{\mathrm{p}}$, is evaluated according to

$\varepsilon_{p}=\sqrt{\frac{2}{3}\left[\left(\varepsilon_{x}^{p}\right)^{2}+\left(\varepsilon_{y}^{p}\right)^{2}+\left(\varepsilon_{z}^{p}\right)^{2}+2\left(\varepsilon_{x y}^{p}\right)^{2}+2\left(\varepsilon_{y z}^{p}\right)^{2}+2\left(\varepsilon_{z x}^{p}\right)^{2}\right]}$

where the plastic strain components, $\varepsilon_{x}^{p}, \varepsilon_{y}^{p}, \varepsilon_{z}^{p}, \varepsilon_{x y}^{p}, \varepsilon_{y z}^{p}$ and $\varepsilon_{z x}^{p}$, are those strains accumulated at the end of the composite cycle.

HBB-T-1344.4 Step 4. Assess acceptability in accordance with (a) and (b) below by using the plastic strains, $\varepsilon_{\mathrm{p}}$, from Step 3. If the requirements of both (a) and (b) are satisfied, then the strain limits of HBB-T-1310 for base metal and HBB-T-1713 for weldments are also considered satisfied. This condition is illustrated in Figure HBB-T-1344, sketch (a).

(a) The requirement $x+\varepsilon_{p} \leq \varepsilon_{a v g}$ must be satisfied at least at one point for all through-thickness locations. As defined in Step 2, $\varepsilon_{\text {avg }}$ is equal to 0.01 for base metal or 0.005 for weldments. Failure of this requirement is illustrated in Figure HBB-T-1344, sketch (b).

(b) The requirement $x+\varepsilon_{p} \leq \varepsilon_{\text {local }}$ must be satisfied at all points. The local strain limit, $\varepsilon_{\text {local }}$, is equal to 0.05 for base metal and 0.025 for weldments. Failure of this requirement is illustrated in Figure HBB-T-1344, sketch (c).

(c) In order to proceed if either of the requirements of (a) or (b) above are not satisfied, return to Step 2 and select a smaller value of the target inelastic strain, $x$. If it is not possible to find a value of $x$ that does not ratchet and also satisfies the requirements of Step 4, then the loading conditions of HBB-T-1342 applied to the component configuration defined in HBB-T-1343 do not meet the requirements of HBB-T-1340.

a. "Each location" refers to nodal points or integration points in the finite element mesh where the calculations are performed. 


\section{DRAFT FOR COMMITTEE USE ONLY}

\section{Figure HBB-T-1344 Strain Limits Pass/Fail Criteria Illustrated}
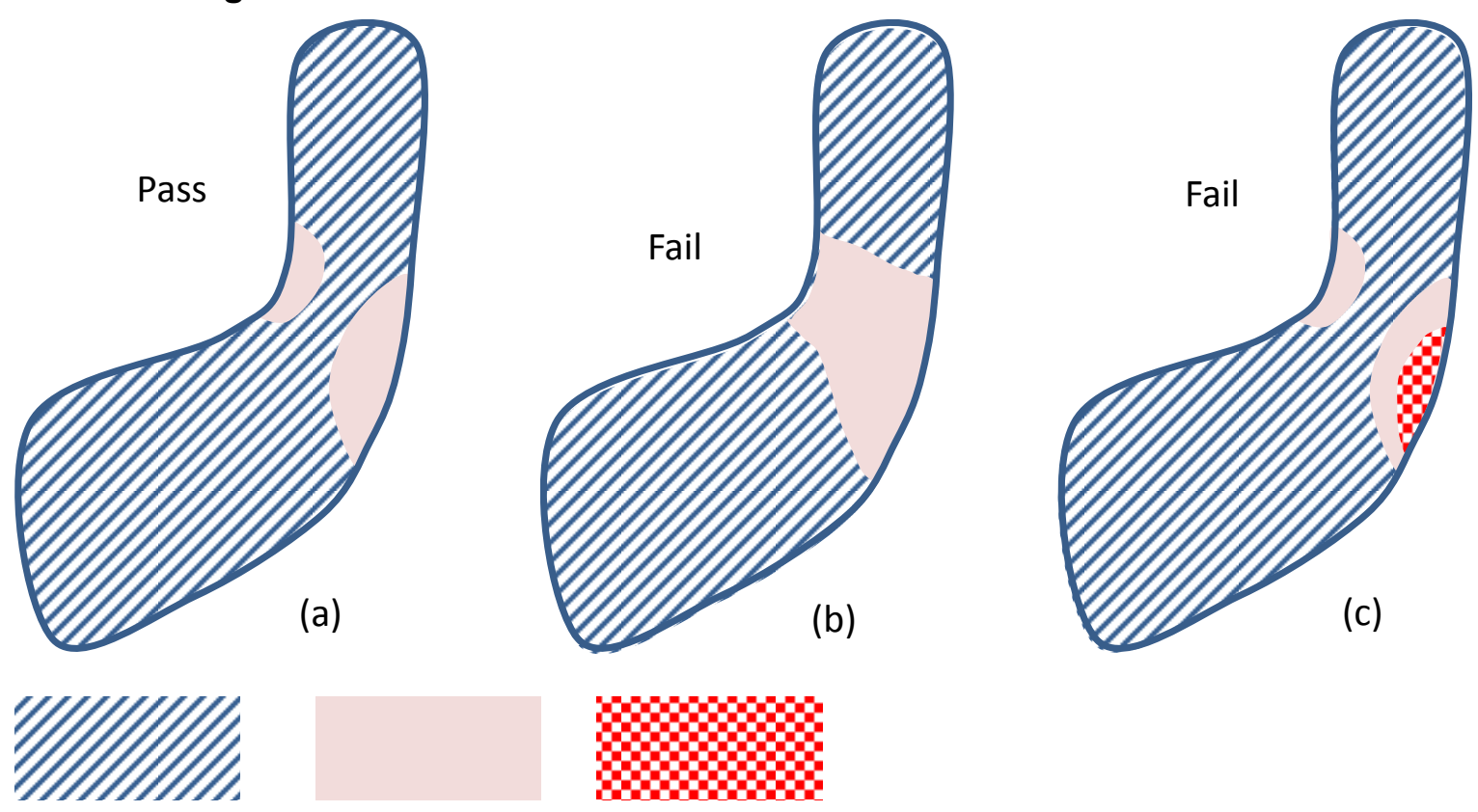

$x+\varepsilon_{p} \leq \varepsilon_{a v g}$

$\varepsilon_{a v g}<x+\varepsilon_{p} \leq \varepsilon_{\text {local }}$

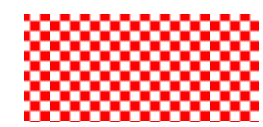

$x+\varepsilon_{p} \geq \varepsilon_{\text {local }}$

\section{HBB-T-1345 Weldments}

Implementation of the strain limits for weldments defined above in HBB-T-1344 requires additional consideration.

HBB-T-1345.1 Weld Region Model Boundaries. Figure HBB-T-1345 shows a full-penetration butt weld as an example of the definition of a weld region. As shown, $w_{1}$ and $w_{2}$ are needed to define the weld region for use in this Code Case and are approximations consistent with the specified weld configuration and parameters. The specified weld region must include applicable stress concentrations in accordance with the requirements for analysis of geometry, HBB-T-1714, unless ground flush.

The weld shown in Figure HBB-T-1345 represents a full-penetration butt weld in a shell. Other weld configurations may be needed for construction of an elevated temperature service component in accordance with Section III, Division 5, Subsection HB, Subpart B. Section III, Division 5, HBB-4200 refers to various Section III, Division 1, Article NB-4000 paragraphs for weld configurations and requirements. These NB-4000 weld configurations are represented by the shaded region.

\section{Figure HBB-T-1345 Weld Region Model Boundaries}

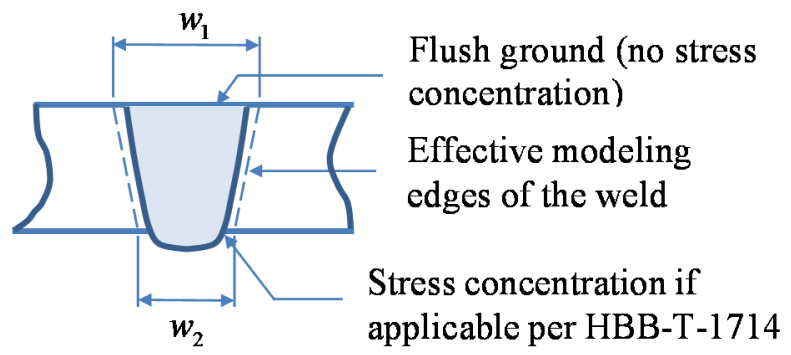




\section{DRAFT FOR COMMITTEE USE ONLY}

HBB-T-1345.2 Geometry. The requirements for analysis of geometry of Section III, Division 5, HBB-T-1714 are applicable for satisfaction of the requirements of this Code Case.

HBB-T-1345.3 Physical Properties. The thermal/physical properties of weldments shall be assumed to be the same as the corresponding base metal for the base metal-weld combinations listed in Table HBB-I-14.10F-1.

HBB-T-1345.4 Dissimilar Metal Welds. Requirements for dissimilar metal welds are in the course of preparation.

\section{HBB-T-1346 Ratcheting Analysis}

The steps to perform a ratcheting analysis to demonstrate compliance with strain limits are as follows:

(a) Define Composite Cycle Load Time-Histories and Analysis Step(s).

(1) It may consist of histories of mechanical loads, pressure loads, displacements, temperatures and thermal boundary conditions.

(2) Time-independent parts of the cycle may be truncated because the elastic-perfectly plastic analysis is not time-dependent.

(3) The cycle should not have discontinuities. Discontinuities arising from the selection of the specified cycles to form a composite cycle should be eliminated by a simple and reasonable transition from one operating state to the next.

(4) Subject to the requirements in (b) below, the composite cycle time does not affect the result of the ratcheting analysis.

(5) Temperatures, thermal boundary conditions, boundary displacements and mechanical loads over a cycle should be cyclic; that is, begin and end at the same value.

(6) A single analysis step may represent one cycle. Dividing a single cycle into more than one step to facilitate definition of the load cycle, and to ensure that maximum loads are analyzed, is often helpful.

(b) Define Analysis Types.

(1) A sequentially coupled thermal-mechanical analysis of the composite cycle may be performed. First, a thermal analysis is performed to generate temperature histories. Next, the mechanical analyses are performed using these temperature histories as inputs. Care must be taken that times in the mechanical analysis step and in the previous thermal analysis are the same or do not conflict, depending on the requirements of the analysis software.

(2) Alternatively, a coupled thermal-mechanical analysis may be performed. The composite temperature history to be used in the mechanical analysis should be cyclic; that is, the beginning and end temperature distributions should be the same.

(c) Define Material Properties.

(1) For the thermal analyses, density and temperature-dependent specific heat and conductivity will generally be required.

(2) For the mechanical analyses, the temperature-dependent properties required are elastic modulus, Poisson's ratio, and the mean expansion coefficient. Density may also be required.

(3) In addition, the mechanical analyses temperature-dependent yield stress will need to be adjusted based on the selected pseudo-yield stress, $S_{x T}$, defined in HBB-T-1344.2. 


\section{DRAFT FOR COMMITTEE USE ONLY}

(d) Perform Analyses.

(1) Perform an elastic-perfectly plastic cyclic mechanical and thermal stress analysis using the temperature-dependent pseudo-yield stress defined above. Enough cycles are required to demonstrate ratcheting or the absence of ratcheting.

(2) Care must be taken to ensure that the analysis deals with all the changes within a cycle. Elastic-plastic analysis routines increase increment size where possible, and may miss a detail in the loading. A conservative limit to maximum increment size can address this problem, as can division of the cycle into more than one step, as discussed in (a)(6) above.

(e) Detect Ratcheting.

(1) Ratcheting is defined as repeated non-cyclic deflections; that is, between the beginning and end of a cycle, a repeated finite displacement change occurs somewhere in the structure.

(2) Detecting ratcheting is most easily done by plotting nodal deflections over time. Cyclic (repeated) behavior indicates non-ratcheting. History plots of equivalent plastic strains will also identify ratcheting.

\section{HBB-T-1400 Creep - Fatigue Evaluation}

\section{HBB-T-1410 General Requirements}

\section{HBB-T-1411 Damage Equation}

(d) The constant $C$ for Alloy 617 that is used in determining the equivalent stress is under development. The following Alloy 617 data are added in Table HBB-T-1411-1 of this Code Case.

Table HBB-T-1411-1

\begin{tabular}{ccc}
\hline & \multicolumn{2}{c}{$K^{\prime}$} \\
\cline { 2 - 3 } Material & Elastic Analysis & Inelastic Analysis \\
\hline Alloy 617 & 0.9 & 0.67 \\
\hline
\end{tabular}

\section{HBB-T-1420 Limits Using Inelastic Analysis}

(b) The fatigue damage term of Equation HBB-T-1411(10) is evaluated by entering a design fatigue curve at the strain range $\epsilon_{t}$. The strain range $\epsilon_{t}$ is defined as $\epsilon_{t}=\Delta \epsilon_{\max }$; where $\Delta \epsilon_{\max }$ is the value calculated in either HBB-T-1413 or HBB-T-1414. The appropriate design fatigue curve for Alloy 617 is Figure HBB-T-1420-1F and corresponds to the maximum metal temperature experienced during the cycle.

(c) The total damage, $D$, shall not exceed the creep-fatigue damage envelope in Figure HBB-T-1420-2 of this Code Case. 


\section{DRAFT FOR COMMITTEE USE ONLY}

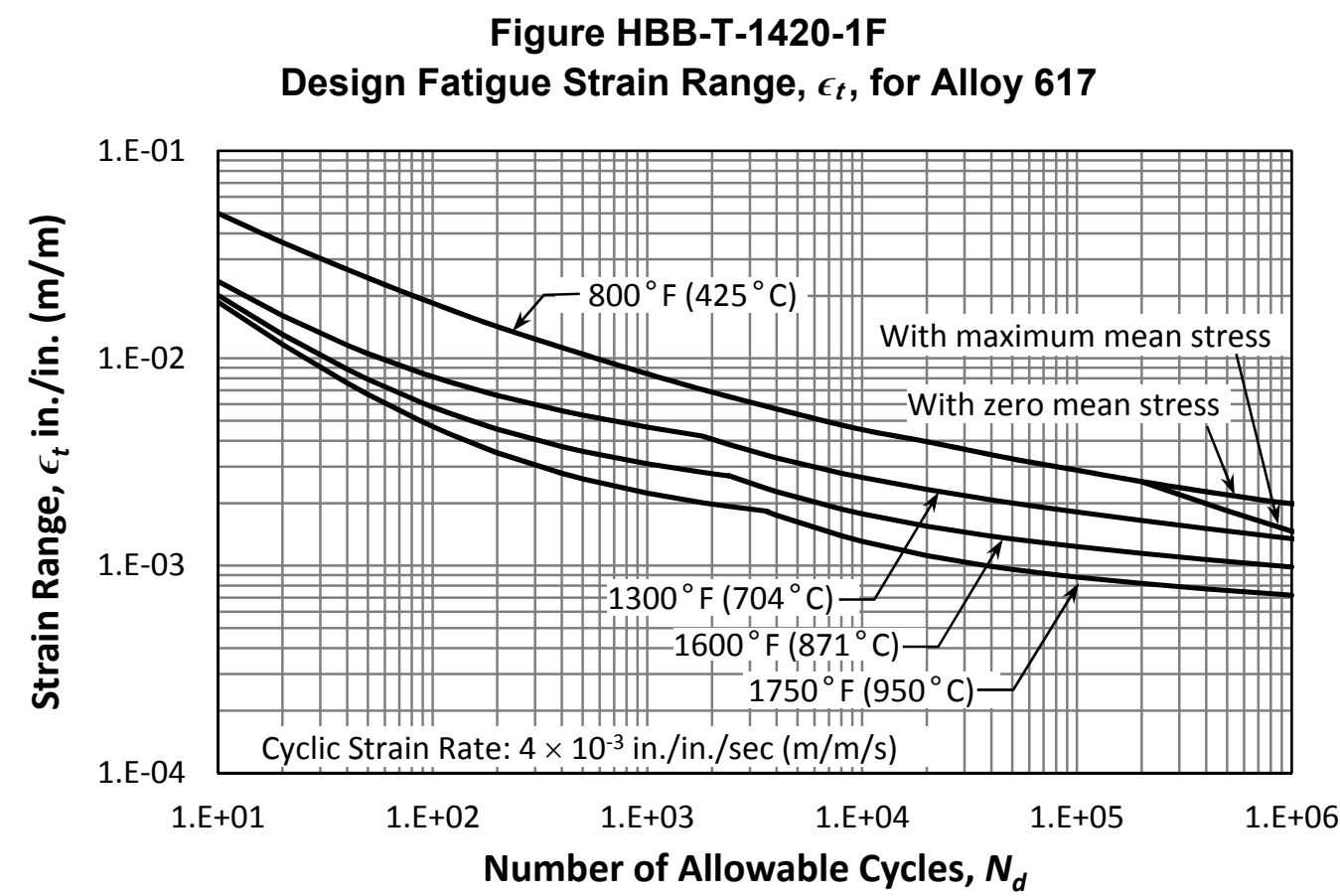

\begin{tabular}{|c|c|c|c|c|c|}
\hline \multirow{4}{*}{$\begin{array}{c}\text { Number of Cycles, } \\
N_{d} \\
\text { [Note (1)] }\end{array}$} & \multicolumn{5}{|c|}{ U.S. Customary Units } \\
\hline & \multicolumn{5}{|c|}{ Strain Range, $\varepsilon$, in./in. at Temperature } \\
\hline & $800^{\circ} \mathrm{F}$ & $800^{\circ} \mathrm{F}$ & $1,300^{\circ} \mathrm{F}$ & $1,600^{\circ} \mathrm{F}$ & $1,750^{\circ} \mathrm{F}$ \\
\hline & Zero Mean Stress & \multicolumn{4}{|l|}{ Maximum Mean Stress } \\
\hline $1 . \mathrm{E}+01$ & 0.05007 & 0.05007 & 0.02354 & 0.02015 & 0.01868 \\
\hline 2.E+01 & 0.03621 & 0.03621 & 0.01606 & 0.01303 & 0.01166 \\
\hline 4. $\mathrm{E}+01$ & 0.02681 & 0.02681 & 0.01156 & 0.00885 & 0.00760 \\
\hline 1.E+02 & 0.01846 & 0.01846 & 0.00815 & 0.00582 & 0.00469 \\
\hline 2.E+02 & 0.01421 & 0.01421 & 0.00661 & 0.00455 & 0.00350 \\
\hline 4.E+02 & 0.01123 & 0.01123 & 0.00558 & 0.00375 & 0.00279 \\
\hline 1.E +03 & 0.00842 & 0.00842 & 0.00466 & 0.00310 & 0.00223 \\
\hline $2 . E+03$ & 0.00686 & 0.00686 & 0.00407 & 0.00278 & 0.00198 \\
\hline 4. $\mathrm{E}+03$ & 0.00570 & 0.00570 & 0.00331 & 0.00227 & 0.00175 \\
\hline 1. $E+04$ & 0.00453 & 0.00453 & 0.00266 & 0.00178 & 0.00131 \\
\hline 2.E +04 & 0.00396 & 0.00396 & 0.00233 & 0.00155 & 0.00112 \\
\hline 4. $E+04$ & 0.00340 & 0.00340 & 0.00207 & 0.00139 & 0.00099 \\
\hline $1 . \mathrm{E}+05$ & 0.00289 & 0.00289 & 0.00181 & 0.00124 & 0.00088 \\
\hline 2.E+05 & 0.00254 & 0.00254 & 0.00165 & 0.00115 & 0.00082 \\
\hline 4. $E+05$ & 0.00227 & 0.00199 & 0.00151 & 0.00107 & 0.00077 \\
\hline \multirow[t]{2}{*}{ 1.E+06 } & 0.00199 & 0.00146 & 0.00135 & 0.00098 & 0.00072 \\
\hline & \multicolumn{5}{|c|}{ SI Units } \\
\hline \multirow{2}{*}{$\begin{array}{c}\text { Number of Cycles, } \\
N_{d} \\
{[\text { Note (1)] }}\end{array}$} & \multicolumn{5}{|c|}{ Strain Range, $\varepsilon, \mathbf{m} / \mathbf{m}$ at Temperature } \\
\hline & $\begin{array}{c}425^{\circ} \mathrm{C} \\
\text { Zero Mean Stress }\end{array}$ & $\begin{array}{c}425^{\circ} \mathrm{C} \\
\text { Maximum Mean Stress }\end{array}$ & $704^{\circ} \mathrm{C}$ & $871^{\circ} \mathrm{C}$ & $950^{\circ} \mathrm{C}$ \\
\hline $1 . \mathrm{E}+01$ & 0.05007 & 0.05007 & 0.02354 & 0.02015 & 0.01868 \\
\hline 2.E+01 & 0.03621 & 0.03621 & 0.01606 & 0.01303 & 0.01166 \\
\hline 4.E+01 & 0.02681 & 0.02681 & 0.01156 & 0.00885 & 0.00760 \\
\hline $1 . \mathrm{E}+02$ & 0.01846 & 0.01846 & 0.00815 & 0.00582 & 0.00469 \\
\hline 2.E+02 & 0.01421 & 0.01421 & 0.00661 & 0.00455 & 0.00350 \\
\hline 4.E+02 & 0.01123 & 0.01123 & 0.00558 & 0.00375 & 0.00279 \\
\hline 1.E+03 & 0.00842 & 0.00842 & 0.00466 & 0.00310 & 0.00223 \\
\hline 2. $\mathrm{E}+03$ & 0.00686 & 0.00686 & 0.00407 & 0.00278 & 0.00198 \\
\hline 4. $E+03$ & 0.00570 & 0.00570 & 0.00331 & 0.00227 & 0.00175 \\
\hline
\end{tabular}




\section{DRAFT FOR COMMITTEE USE ONLY}

\begin{tabular}{|c|c|c|c|c|c|}
\hline \multirow{4}{*}{$\begin{array}{c}\text { Number of Cycles, } \\
N_{d} \\
\text { [Note (1)] } \\
\end{array}$} & \multicolumn{4}{|c|}{$\begin{array}{c}\text { Figure HBB-T-1420-1F } \\
\text { Strain Ranae }{ }^{2} \text { for Allov } 617\end{array}$} & \\
\hline & \multicolumn{5}{|c|}{ SI Units } \\
\hline & \multicolumn{5}{|c|}{ Strain Range, $\varepsilon, \mathrm{m} / \mathrm{m}$ at Temperature } \\
\hline & $\begin{array}{c}425^{\circ} \mathrm{C} \\
\text { Zero Mean Stress }\end{array}$ & $\begin{array}{c}425^{\circ} \mathrm{C} \\
\text { Maximum Mean Stress }\end{array}$ & $7^{204^{\circ}} \mathrm{C}$ & $871^{\circ} \mathrm{C}$ & $950^{\circ} \mathrm{C}$ \\
\hline $1 . \mathrm{E}+04$ & 0.00453 & 0.00453 & 0.00266 & 0.00178 & 0.00131 \\
\hline 2.E+04 & 0.00396 & 0.00396 & 0.00233 & 0.00155 & 0.00112 \\
\hline 4.E+04 & 0.00340 & 0.00340 & 0.00207 & 0.00139 & 0.00099 \\
\hline 1.E+05 & 0.00289 & 0.00289 & 0.00181 & 0.00124 & 0.00088 \\
\hline 2.E+05 & 0.00254 & 0.00254 & 0.00165 & 0.00115 & 0.00082 \\
\hline 4.E +05 & 0.00227 & 0.00199 & 0.00151 & 0.00107 & 0.00077 \\
\hline 1.E+06 & 0.00199 & 0.00146 & 0.00135 & 0.00098 & 0.00072 \\
\hline
\end{tabular}

NOTE:

(1) Cyclic strain rate: $1 \times 10^{-3}$ and $4 \times 10^{-3} \mathrm{in} . / \mathrm{in} . / \mathrm{sec}(\mathrm{m} / \mathrm{m} / \mathrm{s})$

Figure HBB-T-1420-2

Creep-Fatigue Damage Envelope for Alloy 617

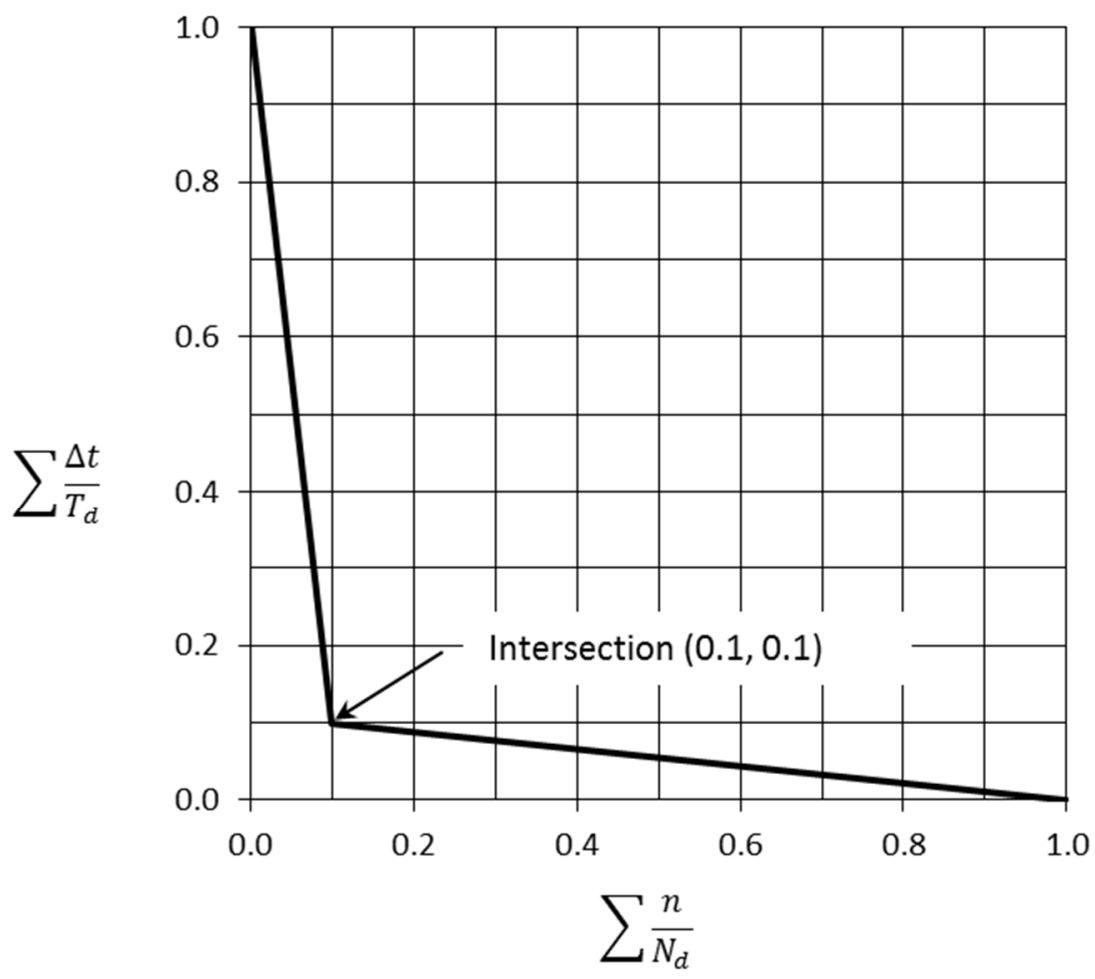




\section{DRAFT FOR COMMITTEE USE ONLY}

\section{HBB-T-1430 Limits Using Elastic Analysis}

\section{HBB-T-1431 General Requirements}

(b) Revise the reference to the appropriate design fatigue curve to HBB-T-1420-1F of this Code Case.

(d) The total damage, D, shall not exceed the creep- fatigue damage envelope of Figure HBB-T-1420-2 of this Code Case.

(e) Paragraph HBB-T-1431 is not applicable to Alloy 617 above $1200^{\circ} \mathrm{F}\left(650^{\circ} \mathrm{C}\right)$.

\section{HBB-T-1432 Strain Range Determination}

(c) Revise the references to the appropriate time -independent isochronous stress-strain curves to be Figures HBB-T-1800-F-1 through HBB-T-1800-F-20 of this Code Case.

(g) Revise the reference to the isochronous stress-strain curve to Figures HBB-T-1800-F-1 through HBB-T-1800-F-20 of this Code Case.

(h) Revise the reference to the design fatigue curves to HBB-T-1420-1F of this Code Case.

\section{HBB-T-1433 Creep Damage Evaluation}

(a) In Step 4, revise the references to the time-independent isochronous stress-strain curves to be Figures HBB-T-1800-F-1 through HBB-T-1800-F-20 of this Code Case. In Step 5(b), revise the references to the appropriate time-independent isochronous stress-strain curves to be Figures HBB-T-1800-F-1 through HBB-T-1800-F-20 of this Code Case. In Step 10, revise the reference to the expected minimum stress-to-rupture curve to Figure HBB-I-14.6G of this Code Case and $\mathrm{K}$ ' is from Table HBB-T-1411-1 of this Code Case.

(b) Revise the reference to the expected minimum stress-to-rupture curve to Figure HBB-I-14.6G of this Code Case and $\mathrm{K}^{\prime}$ is from Table HBB-T-1411-1 of this Code Case.

\section{HBB-T-1435 Alternate Creep-Fatigue Evaluation}

(a) The reference to Section III Appendices, Mandatory Appendix I is replaced by Figure HBB-T-1420-1F, where Sa is one-half the product of $\epsilon$ and Young's Modulus, E, is at the metal temperature of the cycle for the point under consideration.

\section{HBB-T-1440 Limits Using Elastic-Perfectly Plastic Analysis}

\section{HBB-T-1441 General Requirements}

Fatigue and cyclic creep damage may be evaluated using elastic-perfectly plastic material models instead of the procedures of HBB-T-1420, HBB-T-1430 and HBB-T-1715, when performed in accordance with the requirements of this Subsubarticle.

The design methodology employed for evaluation of creep damage is based on elastic shakedown analyses using an elastic-perfectly plastic material model, small strain theory, and a pseudo-yield stress selected to bound creep damage. In this Subsubarticle, "shakedown" refers to the achievement of cyclic elastic behavior throughout the part, based on real or pseudo-yield stress. In this Code Case, the term "pseudo-yield stress" refers to a temperature-dependent minimum stress-to-rupture value based on a selected trial time duration, not to exceed the yield strength of the material at temperature and is explicitly defined in HBB-T-1444.2. Guidance on shakedown analysis is provided in HBB-T-1447.

HBB-T-1441.1 Allowable Damage Accumulation. The combination of Levels A, B, and C Service Loadings shall be evaluated for accumulated creep and fatigue damage, including hold time and strain rate effects. For a design to be acceptable, the creep and fatigue damage at each point in the component shall satisfy the following relation: 


\section{DRAFT FOR COMMITTEE USE ONLY}

$D_{c}+D_{f} \leq D$

where

$D=$ total creep-fatigue damage, as limited by Figure HBB-T-1420-2 of this Code Case

$D_{c}=$ creep damage, as determined in paragraph HBB-T-1444, below

$D_{f}=$ fatigue damage, as determined in paragraph HBB-T-1445, below

This design methodology is not applicable to structures where geometrical nonlinearities exist, e.g., canopy and omega seals.

\section{HBB-T-1442 Load Definition}

Define all applicable loads and load cases per Section III, Division 5, HBB-3113.2, Service Loadings.

HBB-T-1442.1 Composite Cycle Definition. For the purpose of performing an elastic-perfectly plastic shakedown analysis, an overall cycle must be defined that includes all relevant features from the individual Level A, B and C Service Loadings identified in the Design Specification. Relevant features include, as a minimum, the time-dependent sequence of thermal, mechanical and pressure loading, including starting and ending conditions. Such an overall cycle is defined herein as a composite cycle subject to the following requirements:

(a) An individual cycle as defined in the Design Specification cannot be further subdivided into individual cycles to satisfy these requirements.

(b) Except as described in (c) below, a single cycle from each Level A, B and C Service Loading cycle type shall be included in the composite cycle for evaluation of creep-fatigue.

(c) Level C Service Loadings may be combined with the applicable Level A and B Service Loadings to define a composite cycle(s) to be evaluated separately from the composite cycle defined in (b) above. Multiple composite cycles that include Level C Service Loadings may be defined for separate evaluation. The total number of Level C Service Loading cycles shall not exceed 25.

\section{HBB-T-1443 Numerical Model}

Develop a numerical model of the component, including all relevant geometry characteristics. The model used for the analysis shall be selected to accurately represent the component geometry, boundary conditions, and applied loads. The model must also be accurate for small details, such as small holes, fillets, corner radii, and other stress risers. The local temperature history shall be determined from a thermal transient analysis based on the thermal boundary conditions determined from the loading conditions defined in paragraph HBB-T-1442.

\section{HBB-T-1444 Calculation of Creep Damage}

Perform a shakedown analysis for each of the composite cyclic histories defined in HBB-T-1442.1. Each of these cyclic histories must be shown to shakedown based on the pseudo-yield stress, $S_{T d}$, as defined in HBB-T-1444.2. Additional requirements for welds are found in HBB-T-1446.

HBB-T-1444.1 Step 1. Define $t_{\text {design }}$ as the total time duration of elevated temperature service for all Level A, B, and C Service Loadings when the temperature is above $800^{\circ} \mathrm{F}\left(425^{\circ} \mathrm{C}\right)$.

HBB-T-1444.2 Step 2. Select a trial time duration, $\boldsymbol{T}_{\boldsymbol{d}}{ }^{\prime}$, in order to define a pseudo-yield stress, $\boldsymbol{S}_{T d^{\prime}}$, at each location, using the temperature determined from the transient thermal analysis. This pseudo-yield stress is equal to the lesser of the quantities defined in (a) and (b) below.

(a) The yield strength, $S_{y}$, given in Table HBB-I-14.5 of this Code Case; 


\section{DRAFT FOR COMMITTEE USE ONLY}

(b) $S_{r}$, where $S_{r}$ is the minimum stress to rupture in time, $T_{d}{ }^{\prime}$, from Figure HBB-I-14.6G multiplied by the factor, $K^{\prime}$, from Table HBB-T-1411-1 of this Code Case, using the tabulated values for elastic analysis.

HBB-T-1444.3 Step 3. Perform a cyclic elastic-perfectly plastic analysis for each composite cycle defined in HBB-T-1442 above with temperature-dependent pseudo-yield stress, $\boldsymbol{S}_{\boldsymbol{T} \boldsymbol{d}^{\prime}}$. The assessment temperature shall be taken as the local instantaneous temperature at every location in the numerical model of the component. If shakedown occurs, that is, cycles with eventual elastic behavior everywhere, proceed to HBB-T-1444.4.

HBB-T-1444.4 Step 4. The maximum creep damage over the structure for the composite cycle under consideration is:

$$
D_{c}=\frac{t_{d e s i g n}}{T_{d}{ }^{\prime}}
$$

The above value of $D_{c}$ is used to evaluate total damage in Equation (2). If the pseudo-yield stress in HBB-T-1444.2 Step 2 is governed by the yield strength as defined in HBB-T-1444.2(a), then the trial time duration for use in Equation (2) is given by the time at which the minimum stress to rupture is equal to the yield strength; $S_{r}=S_{y}$. Linear extrapolation of $S_{r}$ values corresponding to the two longest tabulated times can be used to obtained the trial time duration, when necessary.

(a) Steps 2, 3 and 4 may be repeated to revise the value of $D_{c}$ by selecting alternative values of the trial time duration, $T_{d}{ }^{\prime}$. Longer values of $T_{d}{ }^{\prime}$ will reduce the calculated creep damage. However, these longer values will lead to lower values of the pseudo-yield stress, $S_{T d^{\prime}}$, which will make shakedown more difficult to achieve. If it is not possible to achieve shakedown, then the loading conditions of HBB-T-1442 applied to the component configuration defined in HBB-T-1443 do not meet the requirements of HBB-T-1440.

\section{HBB-T-1445 Calculation of Fatigue Damage}

The fatigue damage summation, $D_{f}$, in Equation (2) is determined in accordance with Steps 1 through 3 below. Additional requirements for welds are found in HBB-T-1446.

HBB-T-1445.1 Step 1. Determine all of the total (elastic plus plastic) strain components for the composite cycle at each point of interest from the shakedown analysis performed in Step 3 of HBB-T-1444.3 above.

HBB-T-1445.2 Step 2. Calculate the equivalent strain range in accordance with HBB-T-1413, or HBB-T-1414 when applicable, with Poisson's ratio $v^{*}=0.3$.

HBB-T-1445.3 Step 3. Determine the fatigue damage for each composite cycle from the expression:

$$
D_{f}=\sum_{j} \frac{n_{j}}{\left(N_{d}\right)_{j}}
$$

where

$$
\begin{aligned}
n_{j}= & \text { number of applied repetitions of cycle type, } j \\
\left(N_{d}\right)_{j}= & \text { number of design allowable cycles for cycle type, } j, \text { determined from Figure } \\
& \begin{array}{l}
\text { HBB-T-1420-1F, corresponding to the maximum metal temperature occurring during the } \\
\text { cycle. }
\end{array}
\end{aligned}
$$

The value of $D_{f}$ used to evaluate total damage in Equation (2) is the maximum value at any location in the numerical model. 


\section{DRAFT FOR COMMITTEE USE ONLY}

\section{HBB-T-1446 Weldments}

Implementation of the evaluation of creep-fatigue damage in HBB-T-1444 and HBB-T-1445 above for weldments requires additional consideration.

HBB-T-1446.1 Pseudo-Yield Stress. In the weld region, the pseudo-yield stress value, $\boldsymbol{S}_{T d}$, defined by $\boldsymbol{T}_{\boldsymbol{d}}{ }^{\prime}$ in HBB-1444.2 is reduced further by multiplying the value of $S_{r}$ for the base metal by the applicable weld strength reduction factor from Table HBB-I-14.10F-1.

HBB-T-1446.2 Allowable Cycles. The number of allowable cycles, $\left(N_{d}\right)_{j}$, in the weld region is one-half the number of allowable cycles from Figure HBB-T-1420-1F for base metal.

HBB-T-1446.3 Geometry. The requirements for analysis of geometry of HBB-T-1714 are applicable for satisfaction of the requirements of this Code Case.

HBB-T-1446.4 Physical Properties. The thermal/physical properties of weldments shall be assumed to be the same as the corresponding base metal for the base metal-weld combinations listed in Table HBB-I-14.10F-1.

HBB-T-1446.5 Weld Region Model Boundaries. Figure HBB-T-1345 shows a full-penetration butt weld as an example of the definition of a weld region. As shown, $w_{1}$ and $w_{2}$ are needed to define the weld region for use in this Code Case and are approximations consistent with the specified weld configuration and parameters. The specified weld region must include applicable stress concentrations in accordance with the requirements for analysis of geometry, HBB-T-1714, unless ground flush.

The weld shown in Figure HBB-T-1345 represents a full-penetration butt weld in a shell. Other weld configurations may be needed for construction of an elevated temperature service component in accordance with Section III, Division 5, Subsection HB, Subpart B. Section III, Division 5, HBB-4200 refers to various Section III, Division 1, Article NB-4000 paragraphs for weld configurations and requirements. These NB-4000 weld configurations are represented by the shaded region.

\section{Figure HBB-T-1446 Weld Region Model Boundaries}

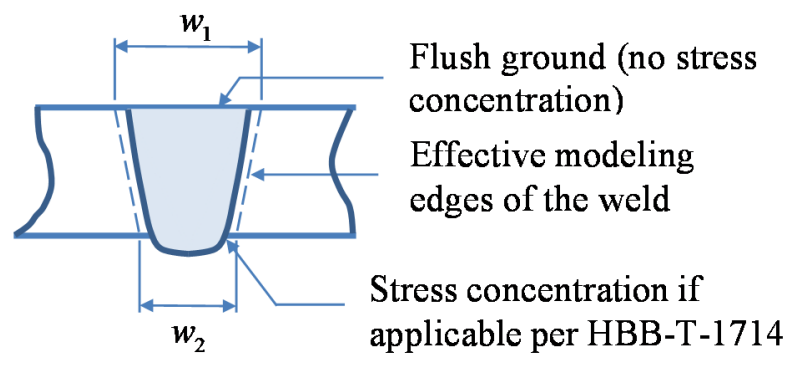

HBB-T-1446.6 Dissimilar metal welds. The requirements for dissimilar metal welds are in the course of preparation.

\section{HBB-T-1447 Shakedown Analysis}

The steps to perform a shakedown analysis to calculate bounding cyclic creep damage are as follows:

(a) Define Composite Cycle Load Time-Histories and Analysis Step(s).

(1) It may consist of histories of mechanical loads, pressure loads, displacements, temperatures and thermal boundary conditions.

(2) Time-independent parts of the cycle may be truncated because the elastic-perfectly plastic analysis is not time-dependent. 


\section{DRAFT FOR COMMITTEE USE ONLY}

(3) The cycle should not have discontinuities. Discontinuities arising from the selection of the specified cycles to form a composite cycle should be eliminated by a simple and reasonable transition from one operating state to the next.

(4) Subject to the requirements in (b) below, the composite cycle time does not affect the result of the shakedown analysis.

(5) Temperatures, thermal boundary conditions, boundary displacements and mechanical loads over a cycle should be cyclic; that is, begin and end at the same value.

(6) A single analysis step may represent one cycle. Dividing a single cycle into more than one step to facilitate definition of the load cycle, and to ensure that maximum loads are analyzed, is often helpful.

(b) Define Analysis Types.

(1) A sequentially coupled thermal-mechanical analysis of the composite cycle may be performed. First, a thermal analysis is performed to generate temperature histories. Next, the mechanical analyses are performed using these temperature histories as inputs. Care must be taken that times in the mechanical analysis step and in the previous thermal analysis are the same or do not conflict, depending on the requirements of the analysis software.

(2) Alternatively, a coupled thermal-mechanical analysis may be performed. The composite temperature history to be used in the mechanical analysis should be cyclic; that is, the beginning and end temperature distributions should be the same.

(c) Define Material Properties.

(1) For thermal analyses, density, temperature-dependent specific heat and conductivity will generally be required.

(2) For the mechanical analyses, the temperature-dependent properties required are elastic modulus, Poisson's ratio, and mean expansion coefficient. Density may also be required.

(d) Perform Analyses.

(1) Perform an elastic-perfectly plastic cyclic mechanical and thermal stress analysis using the temperature-dependent pseudo-yield stress defined above. Enough cycles are required to demonstrate shakedown or otherwise.

(2) Care must be taken to ensure that the analysis deals with all the changes within a cycle. Elastic-plastic analysis routines increase increment size where possible, and may miss a detail in the loading. A conservative limit to maximum increment size can address this problem, as can division of the cycle into more than one step, as discussed in (a)(6) above.

(e) Shakedown.

(1) Shakedown is defined in this Code Case as eventual elastic behavior everywhere in the model. Failure to achieve shakedown may be identified by plotting history plots of equivalent plastic strain.

\section{HBB-T-1500 BUCKLING AND INSTABILITY}

\section{HBB-T-1520 Buckling Limits}

\section{HBB-T-1522 Time-Dependent Buckling}

The following curves for Alloy 617 are added to Figures HBB-T-1522-1, HBB-T-1522-2, and HBBT-1522-3. 


\section{DRAFT FOR COMMITTEE USE ONLY}

Figure HBB-T-1522-1 Buckling Chart for Cylinder Under Axial Load

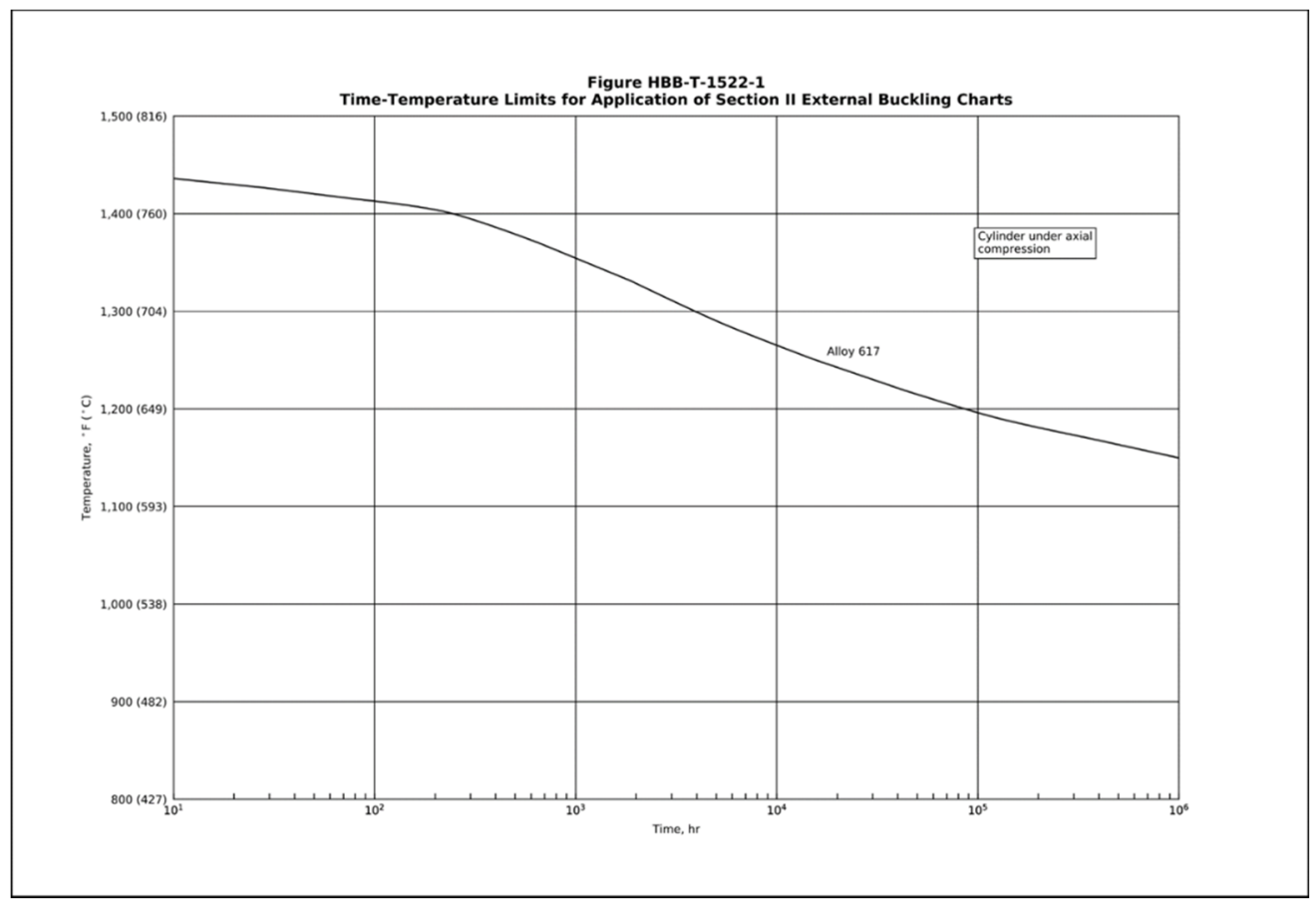

Figure HBB-1522-2 Buckling Chart for Sphere Under External Pressure

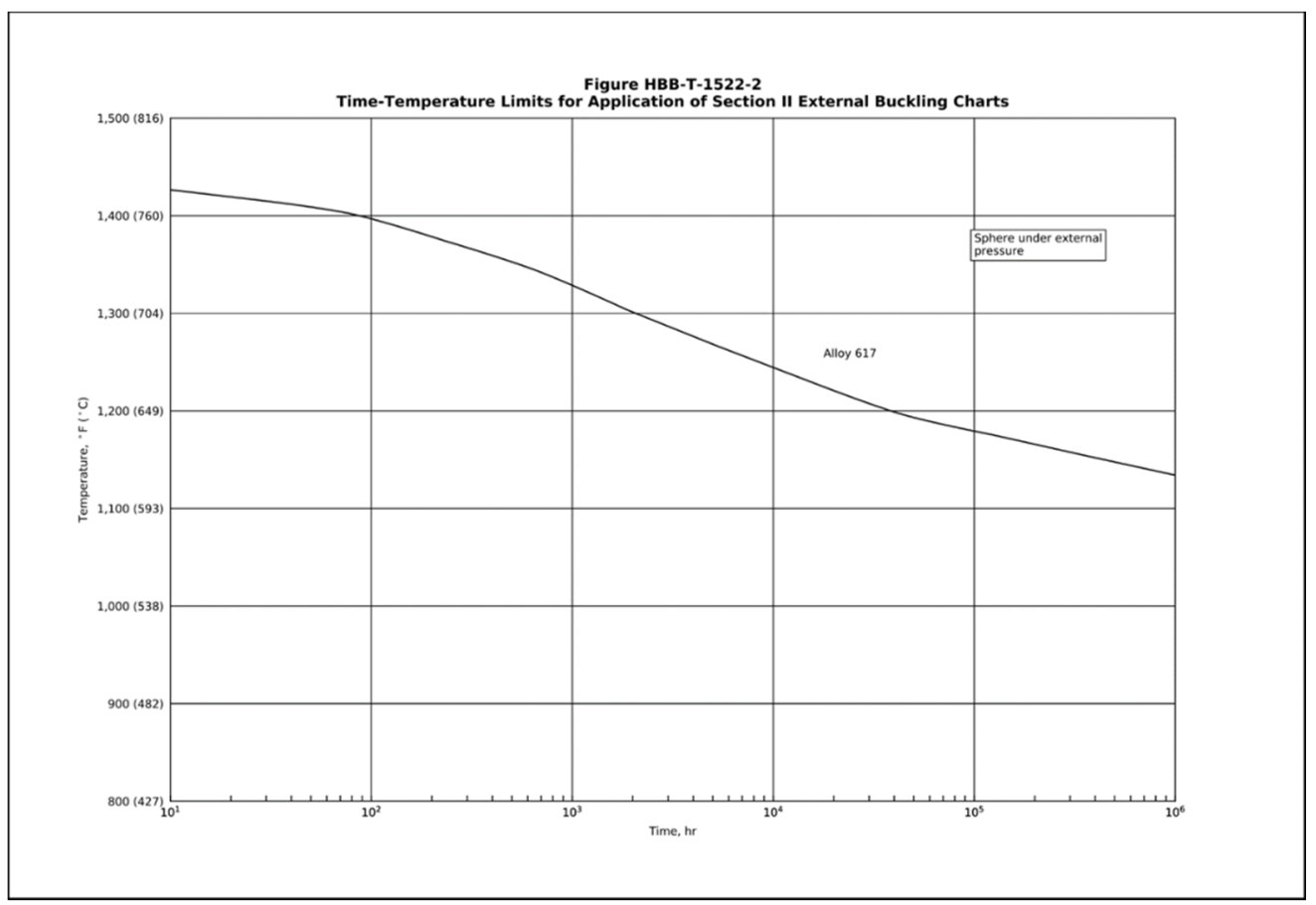




\section{DRAFT FOR COMMITTEE USE ONLY}

Figure HBB-T-1522-3 Buckling Chart for Cylinder Under External Pressure

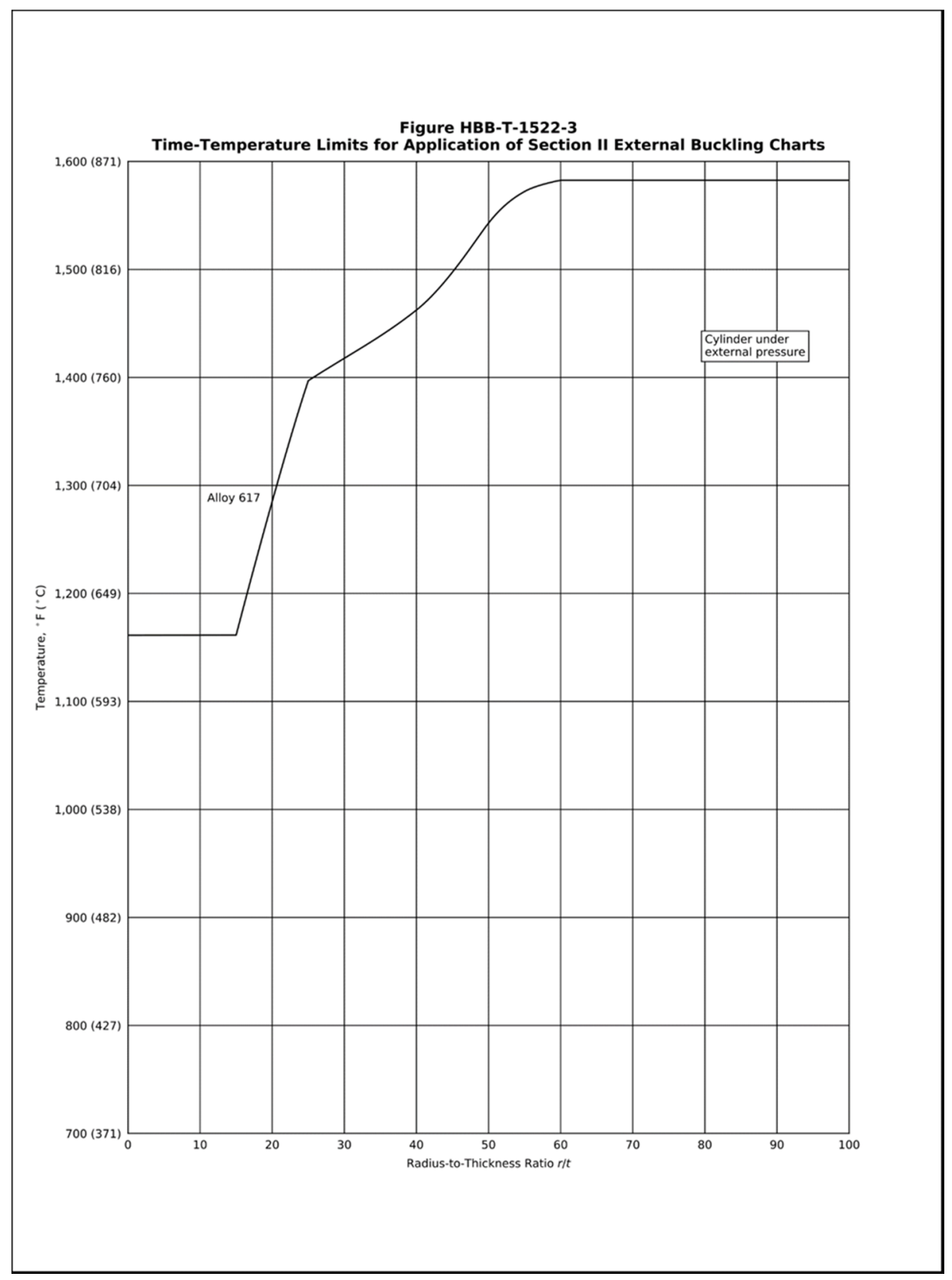




\section{DRAFT FOR COMMITTEE USE ONLY}

\section{ARTICLE HBB-T-1800 ISOCHRONOUS STRESS-STRAIN RELATIONS HBB-T-1820 MATERIALS AND TEMPERATURE LIMITS}

\begin{tabular}{|ccc|}
\hline \multicolumn{3}{|c|}{ Table HBB-T-1820-1 } \\
\hline Material & $\begin{array}{c}\text { Maximum } \\
\text { Temp., }{ }^{\circ} \mathbf{F}\left({ }^{\circ} \mathrm{C}\right)\end{array}$ & $\begin{array}{c}\text { Temperature } \\
\text { Increment, }{ }^{\circ} \mathbf{F}\left({ }^{\circ} \mathbf{C}\right)\end{array}$ \\
\hline Alloy 617 & $1750(950)$ & $50(28)$ \\
\hline & & \\
\hline
\end{tabular}

The following figures are appended to the isochronous stress-strain curves listed in HBB-T1800 .

Figure HBB-T-1800-F-1 Isochronous Stress Strain Curve for $800^{\circ} \mathrm{F}$

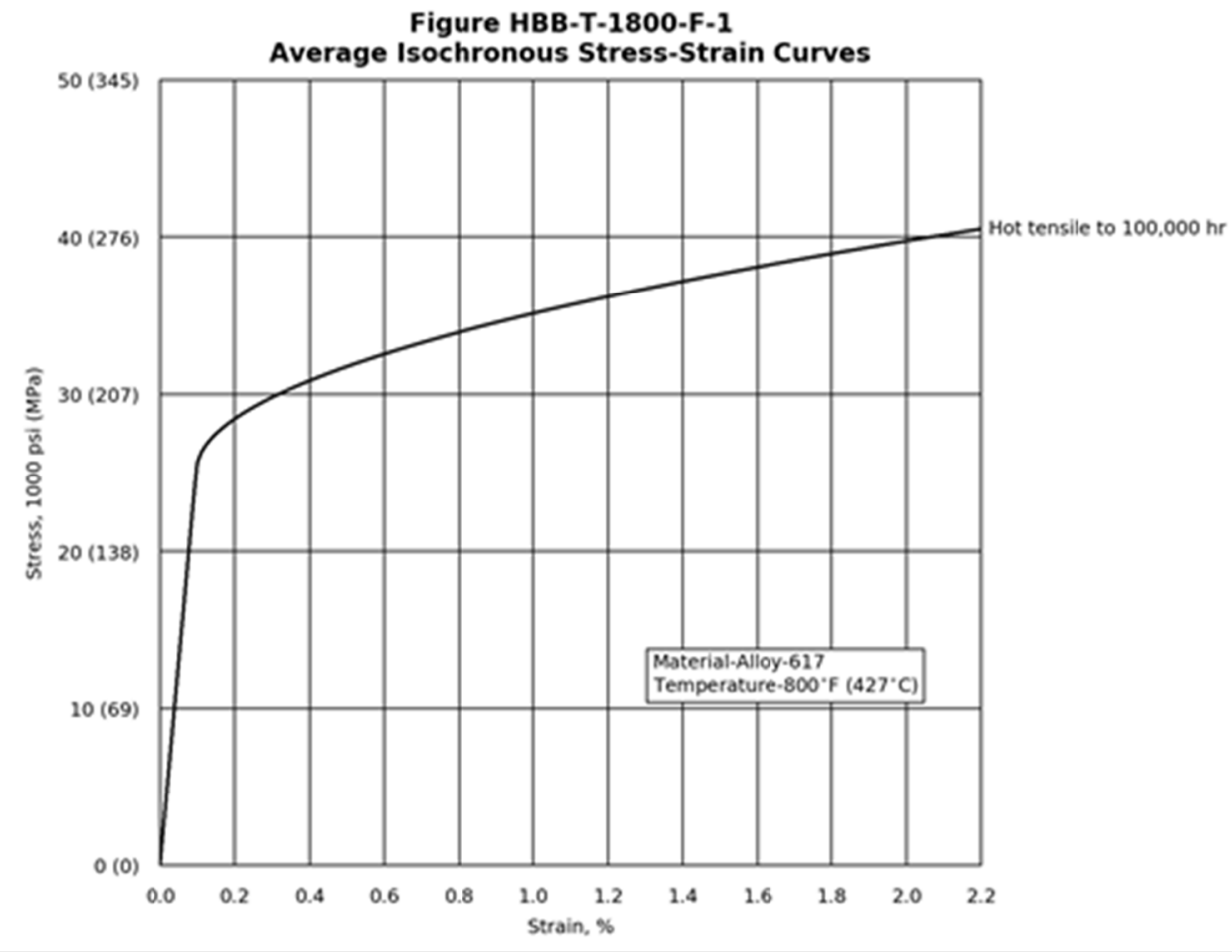




\section{DRAFT FOR COMMITTEE USE ONLY}

Figure HBB-T-1800-F-2 Isochronous Stress Strain Curve for $850^{\circ} \mathrm{F}$

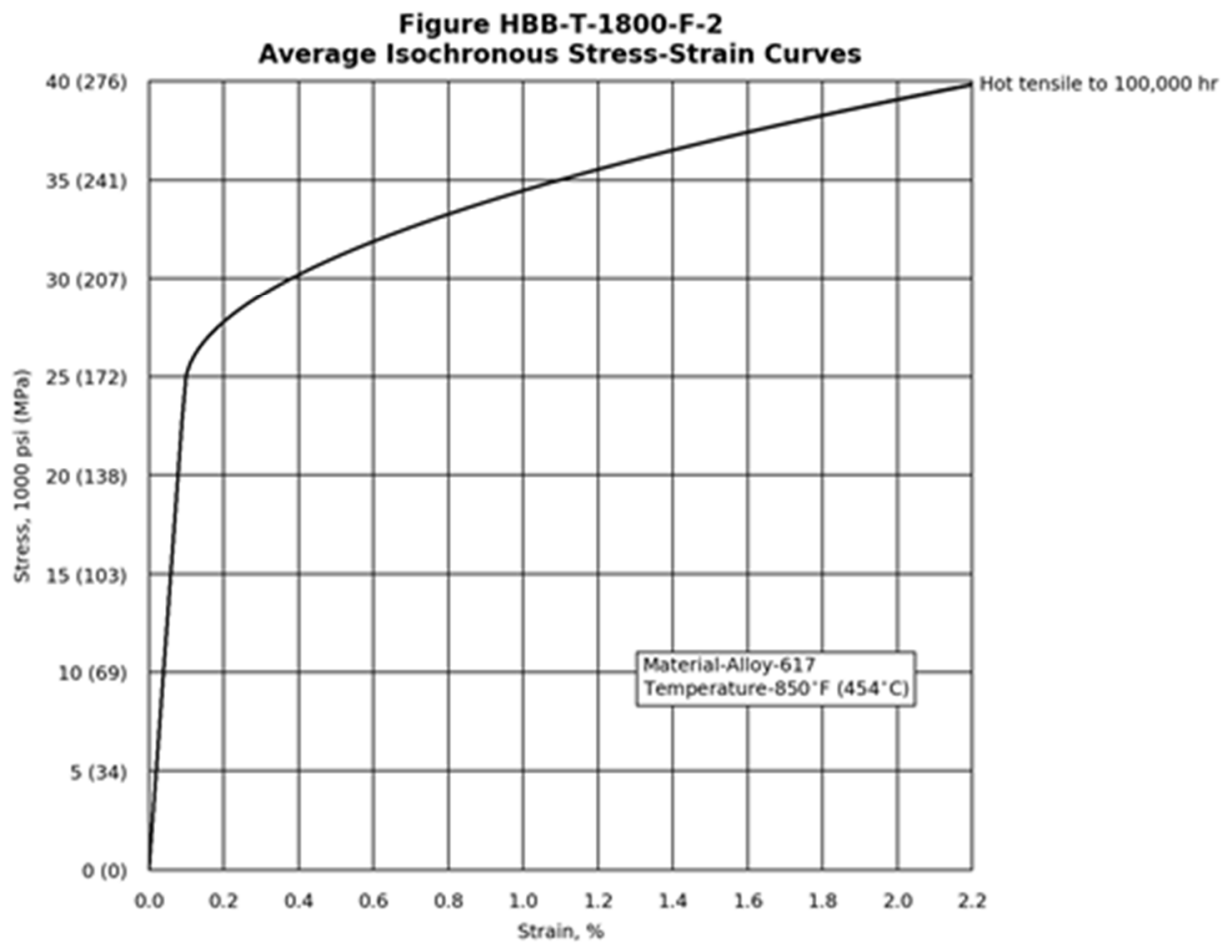

Figure HBB-T-1800-F-3 Isochronous Stress Strain Curve for $900^{\circ} \mathrm{F}$

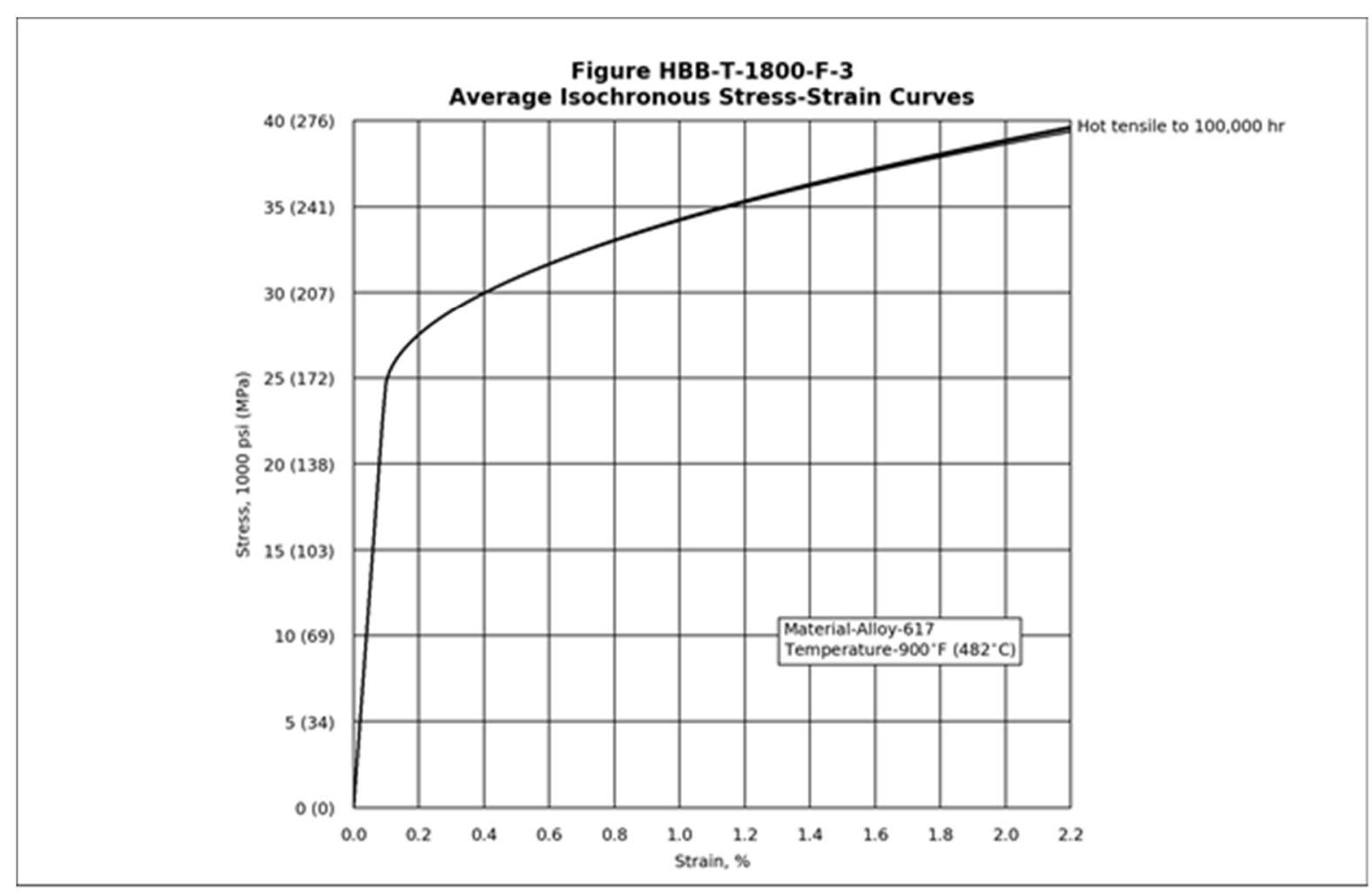




\section{DRAFT FOR COMMITTEE USE ONLY}

Figure HBB-T-1800-F-4 Isochronous Stress Strain Curve for $950^{\circ} \mathrm{F}$

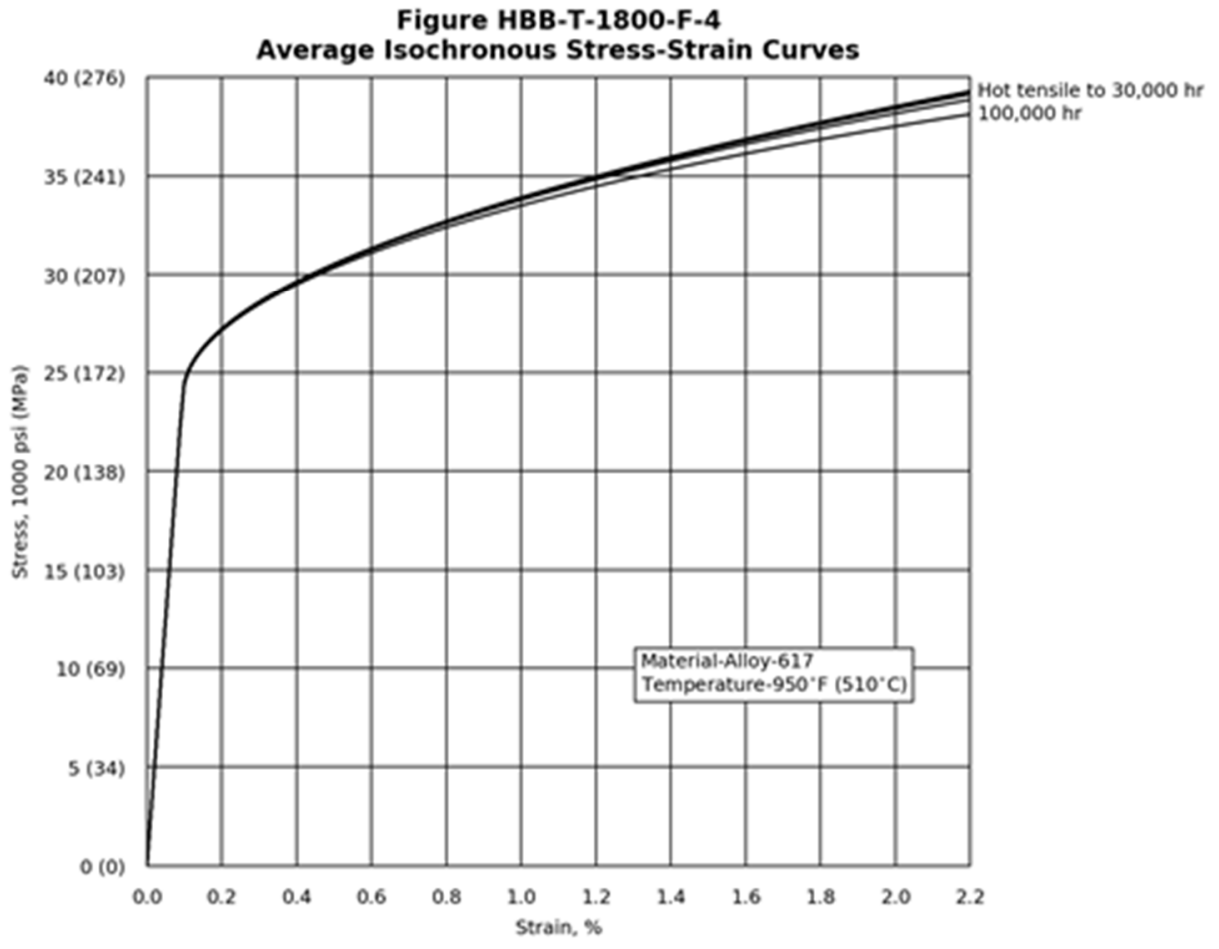

Figure HBB-T-1800-F-5 Isochronous Stress Strain Curve for $1000^{\circ} \mathrm{F}$

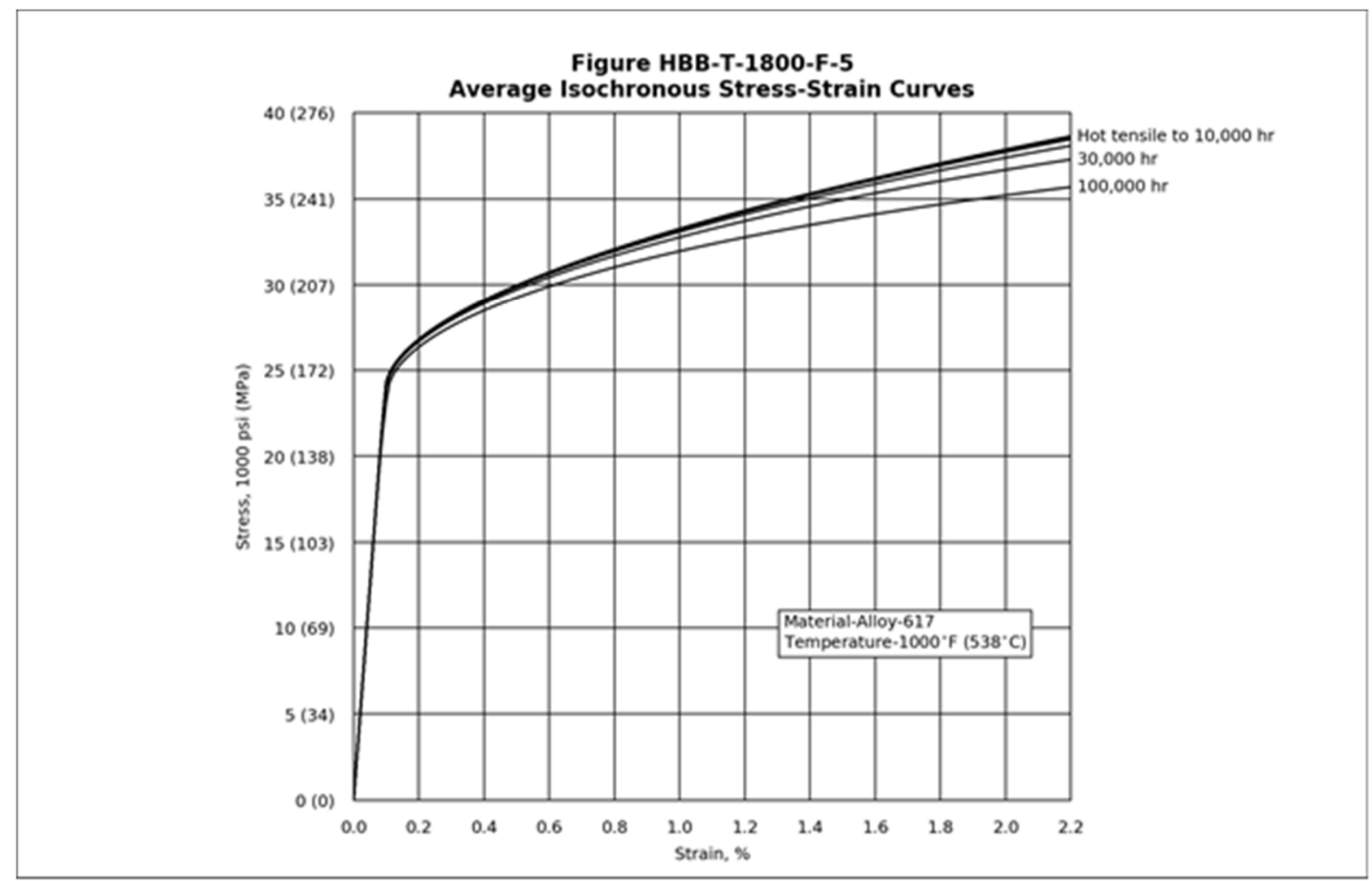




\section{DRAFT FOR COMMITTEE USE ONLY}

Figure HBB-T-1800-F-6 Isochronous Stress Strain Curve for $1050^{\circ} \mathrm{F}$

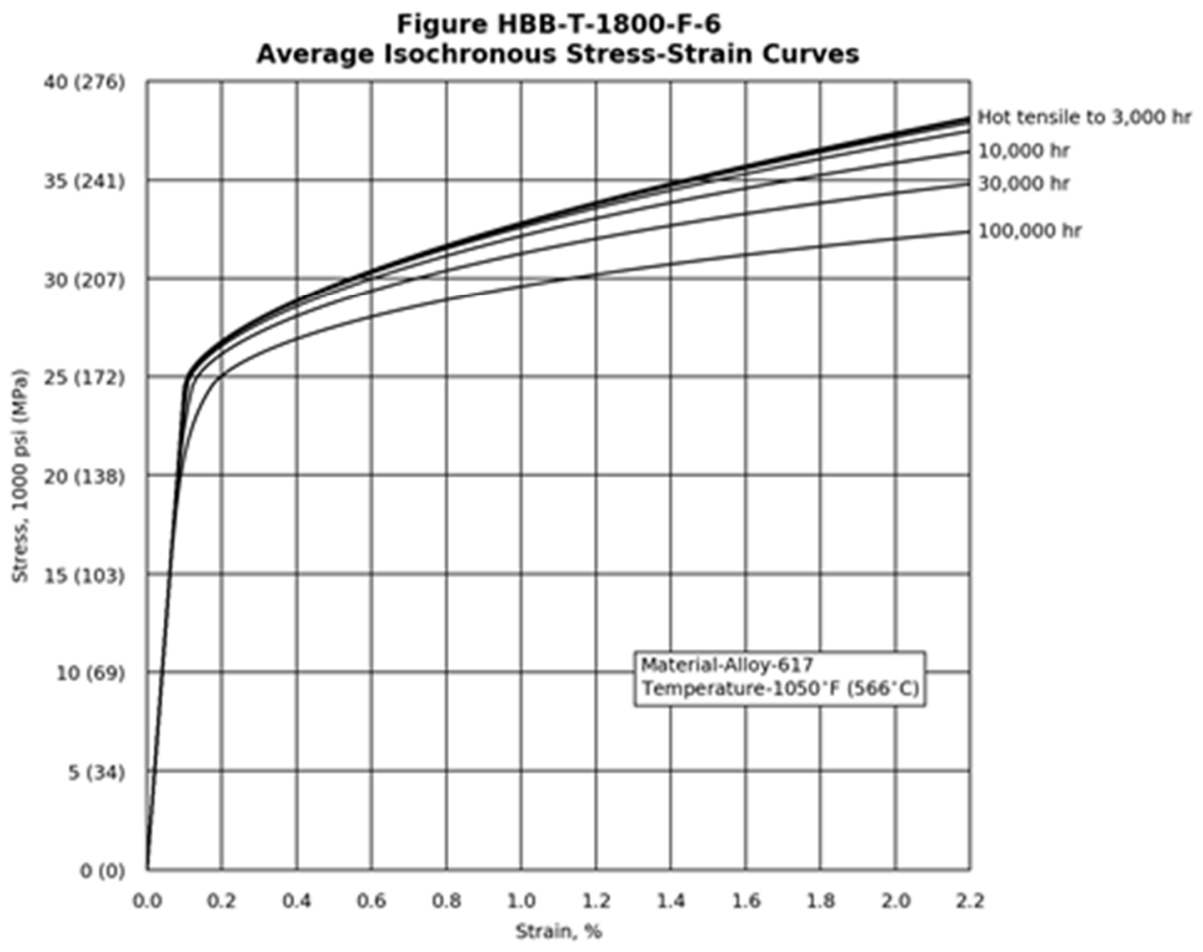

Figure HBB-T-1800-F-7 Isochronous Stress Strain Curve for $1100^{\circ} \mathrm{F}$

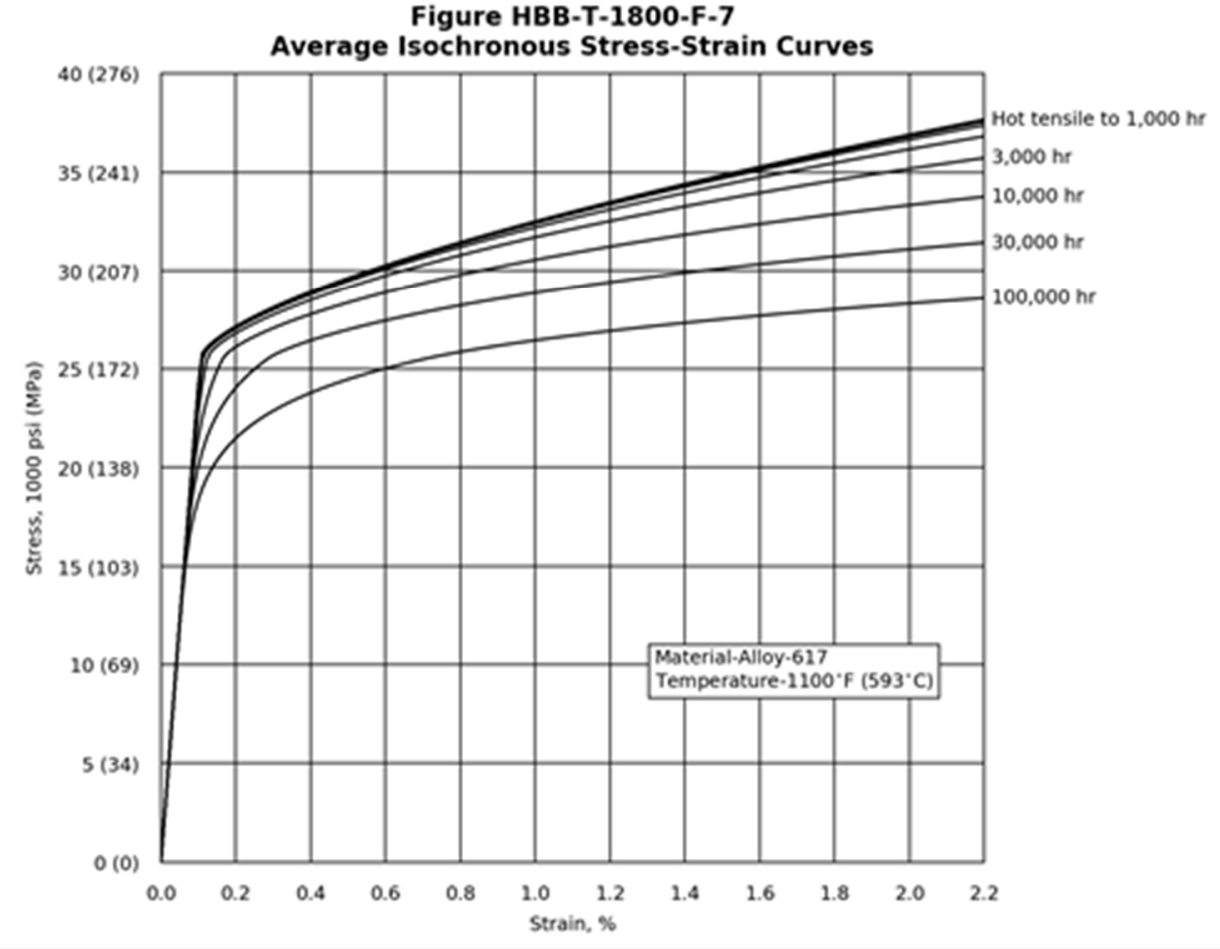




\section{DRAFT FOR COMMITTEE USE ONLY}

Figure HBB-T-1800-F-8 Isochronous Stress Strain Curve for $1150^{\circ} \mathrm{F}$

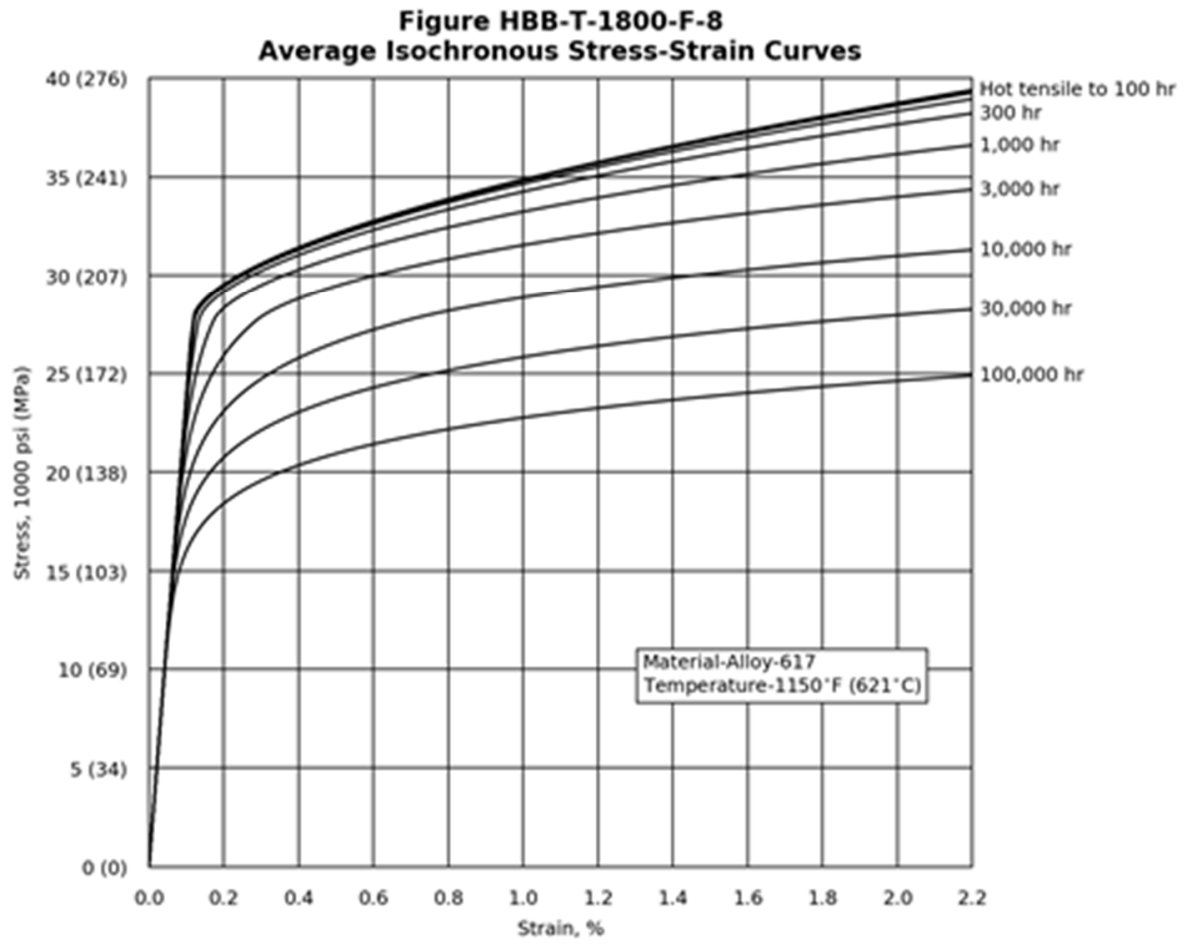

Figure HBB-T-1800-F-9 Isochronous Stress Strain Curve for $1200^{\circ} \mathrm{F}$

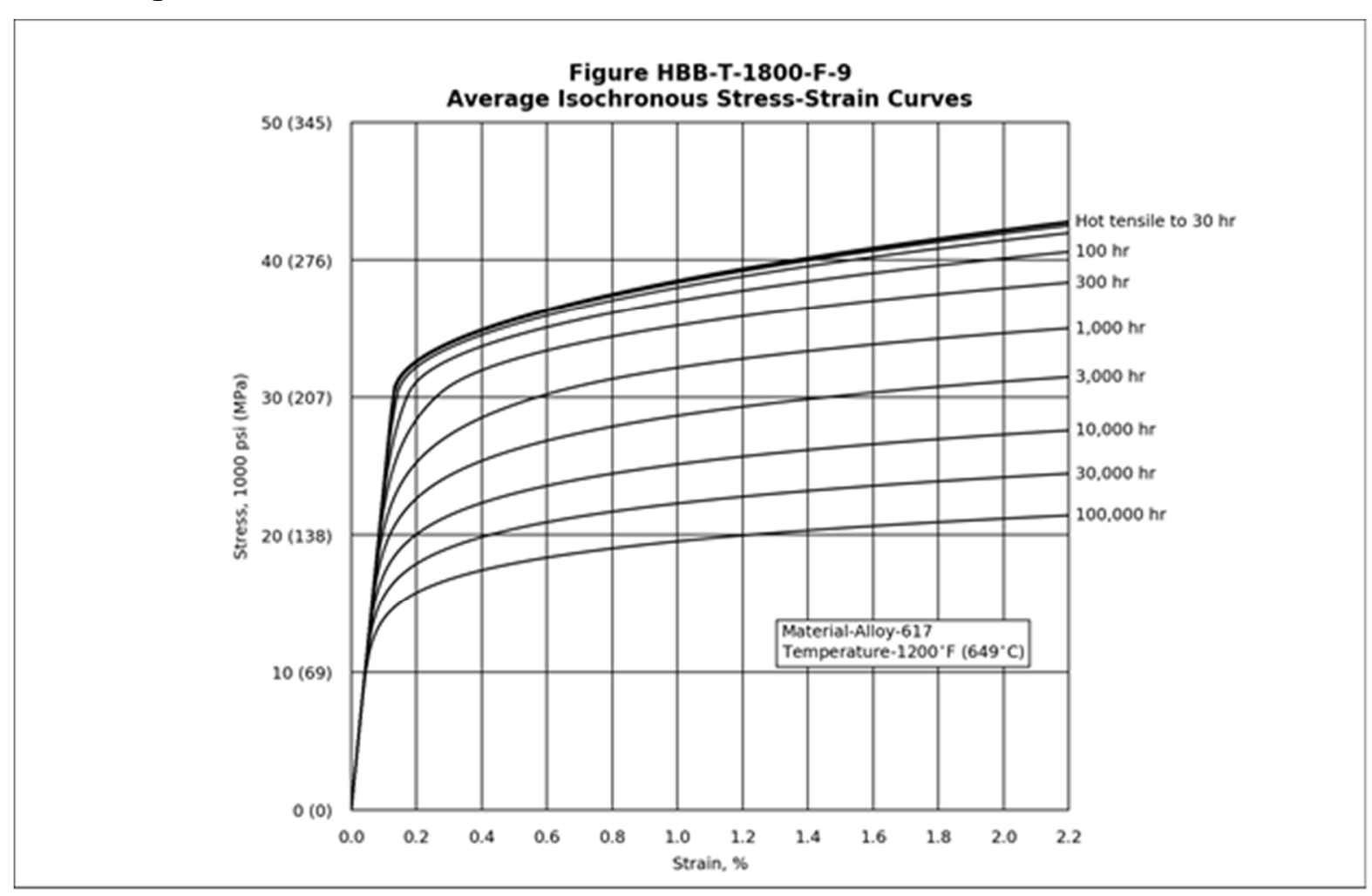




\section{DRAFT FOR COMMITTEE USE ONLY}

Figure HBB-T-1800-F-10 Isochronous Stress Strain Curve for $1250^{\circ} \mathrm{F}$

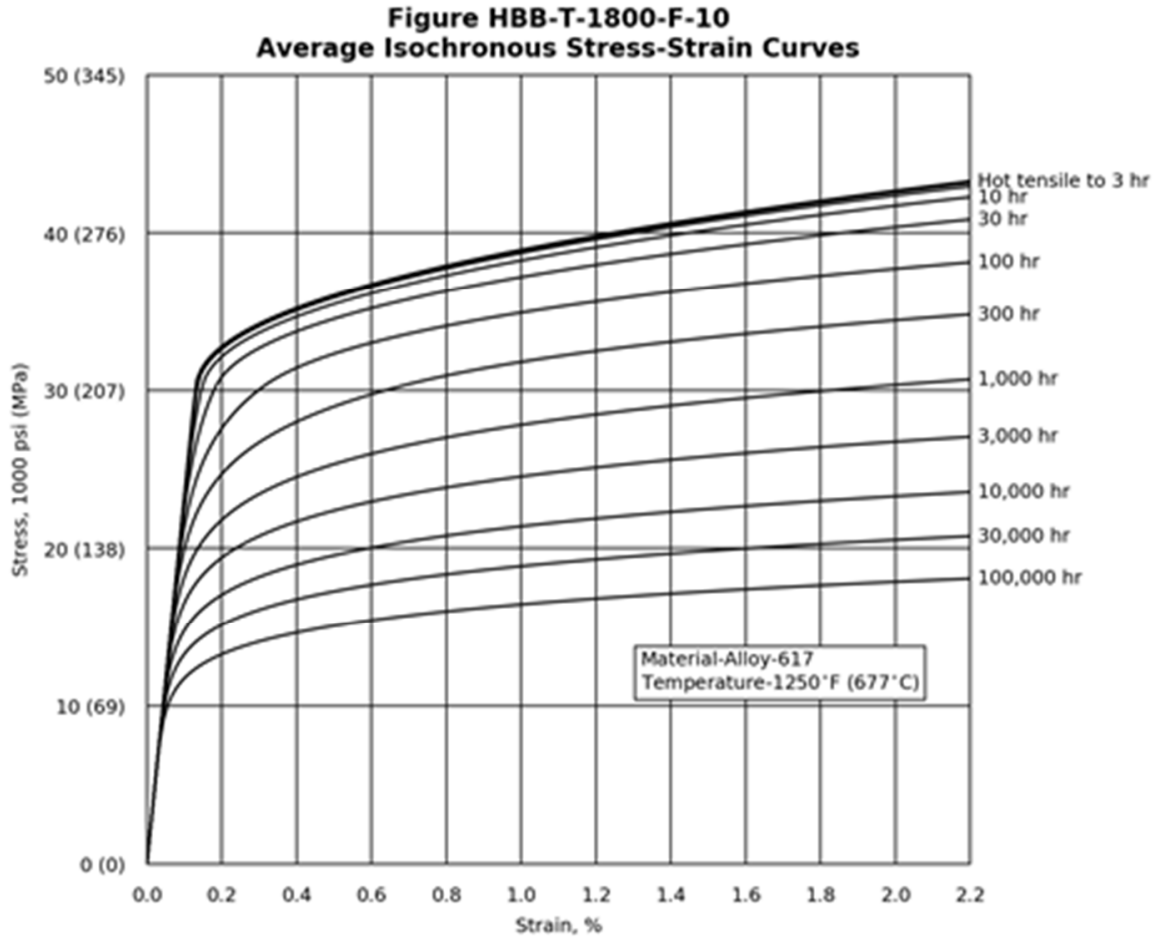

Figure HBB-T-1800-F-11 Isochronous Stress Strain Curve for $1300^{\circ} \mathrm{F}$

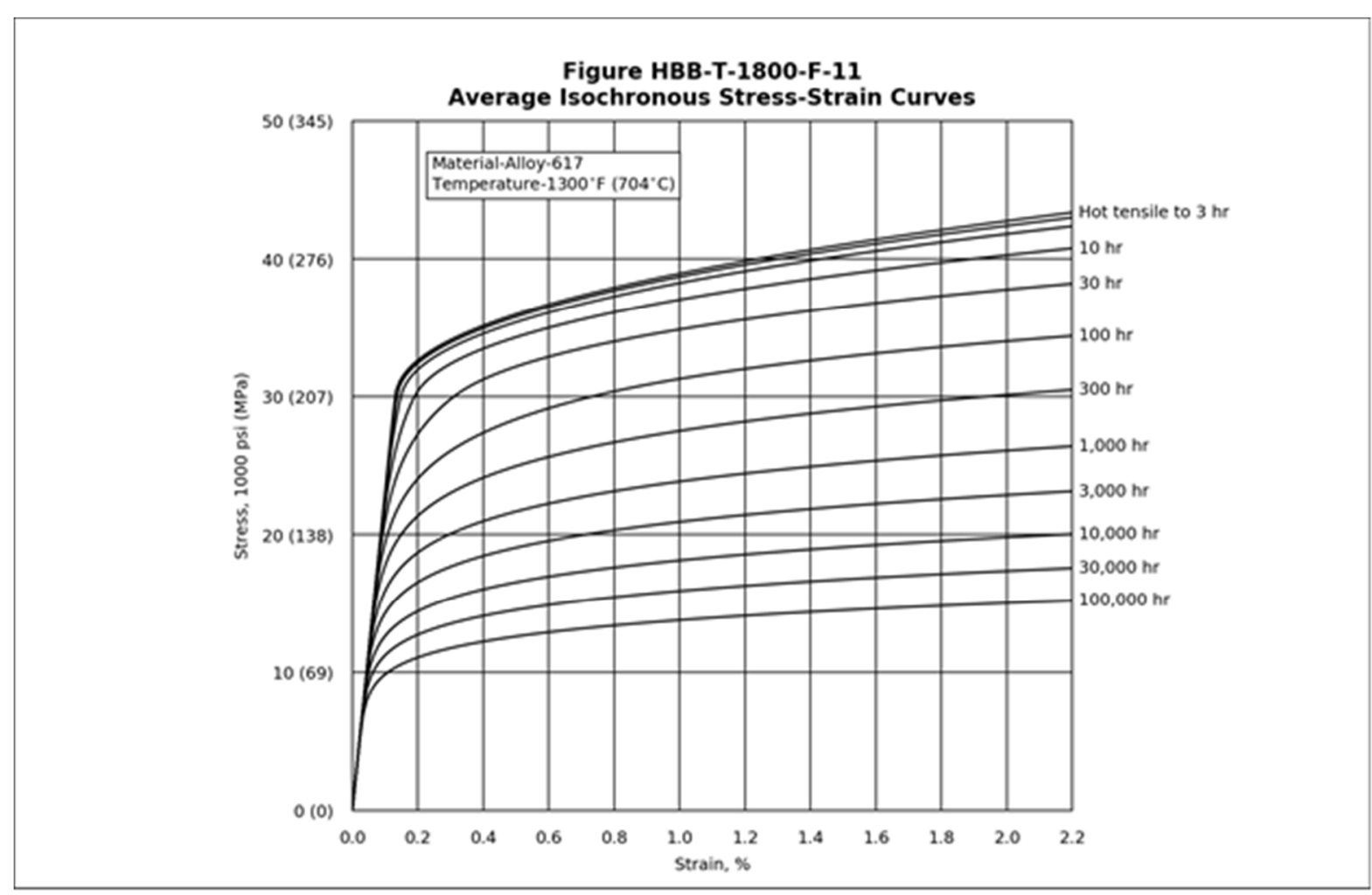




\section{DRAFT FOR COMMITTEE USE ONLY}

Figure HBB-T-1800-F-12 Isochronous Stress Strain Curve for $1350^{\circ} \mathrm{F}$

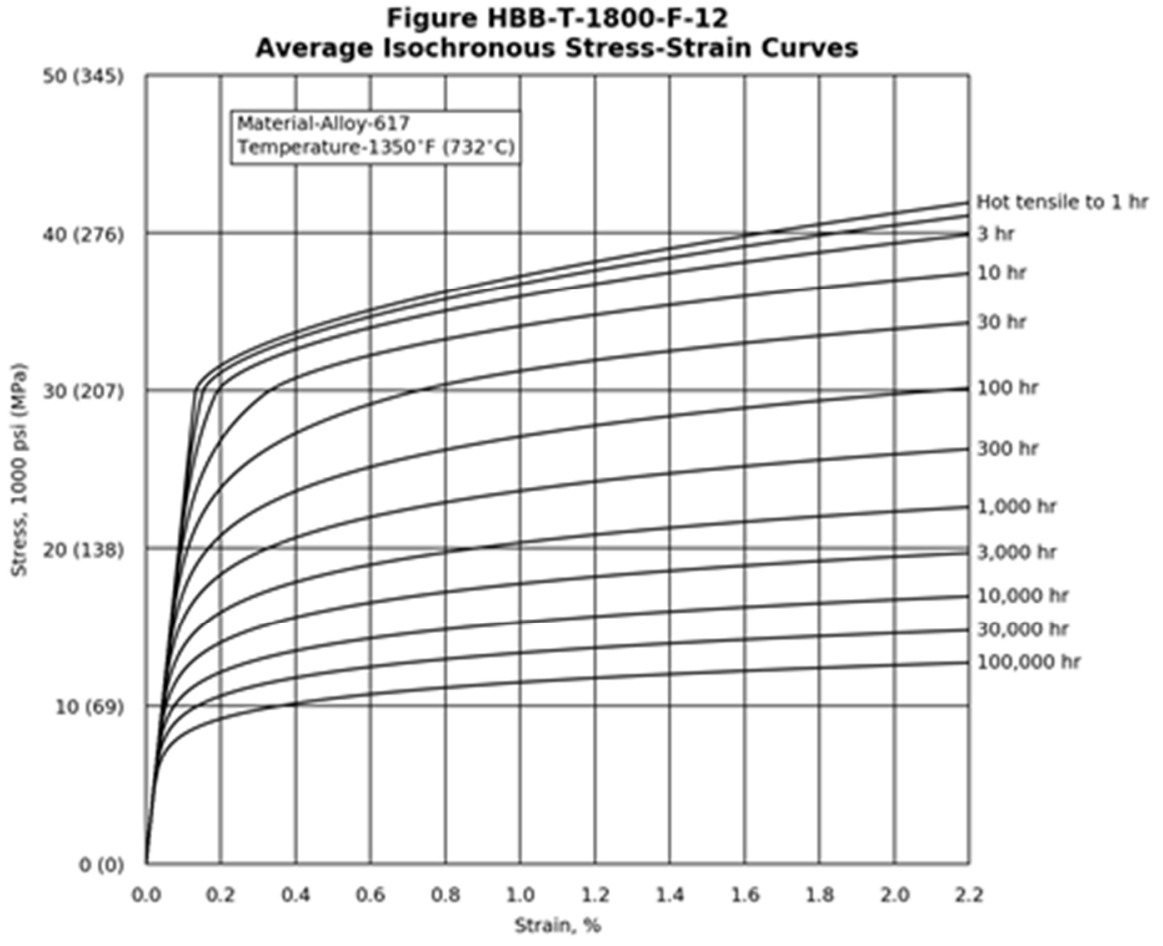

Figure HBB-T-1800-F-13 Isochronous Stress Strain Curve for $1400^{\circ} \mathrm{F}$

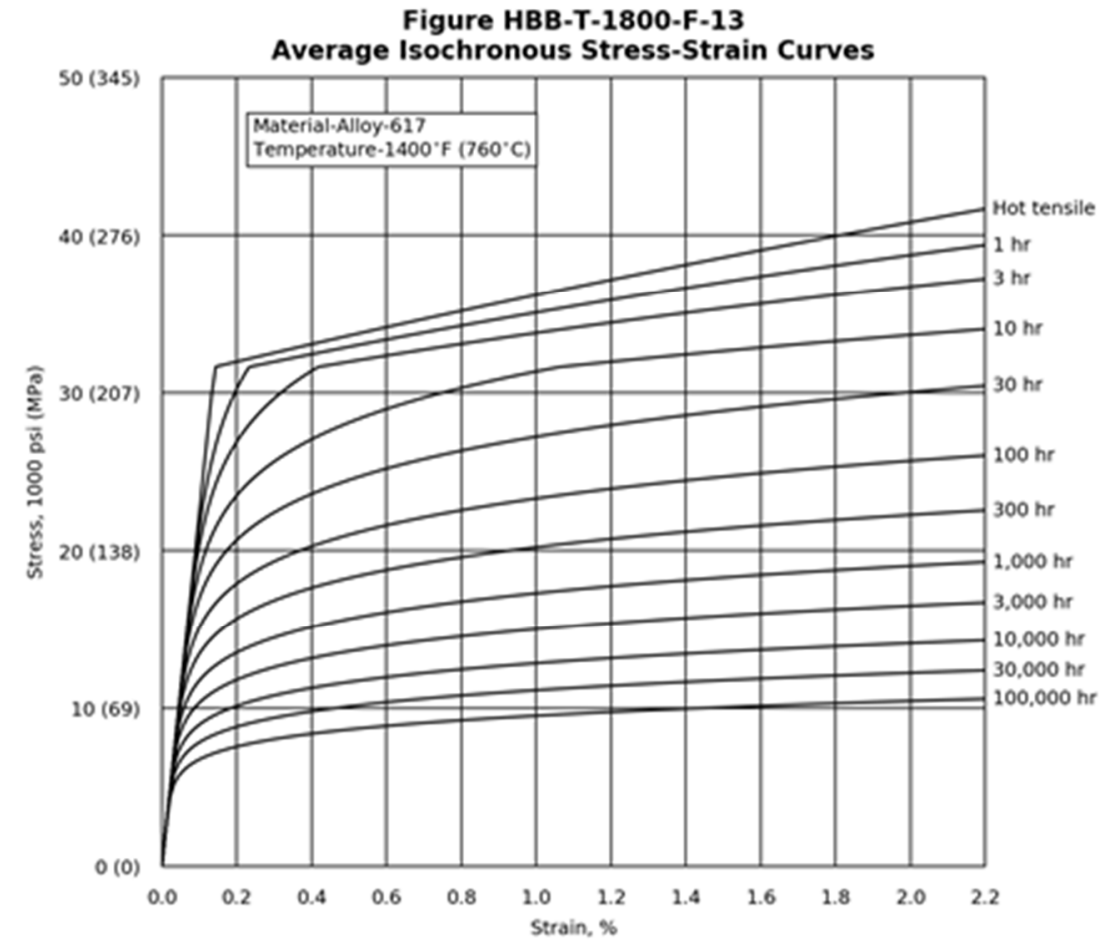




\section{DRAFT FOR COMMITTEE USE ONLY}

Figure HBB-T-1800-F-14 Isochronous Stress Strain Curve for $1450^{\circ} \mathrm{F}$

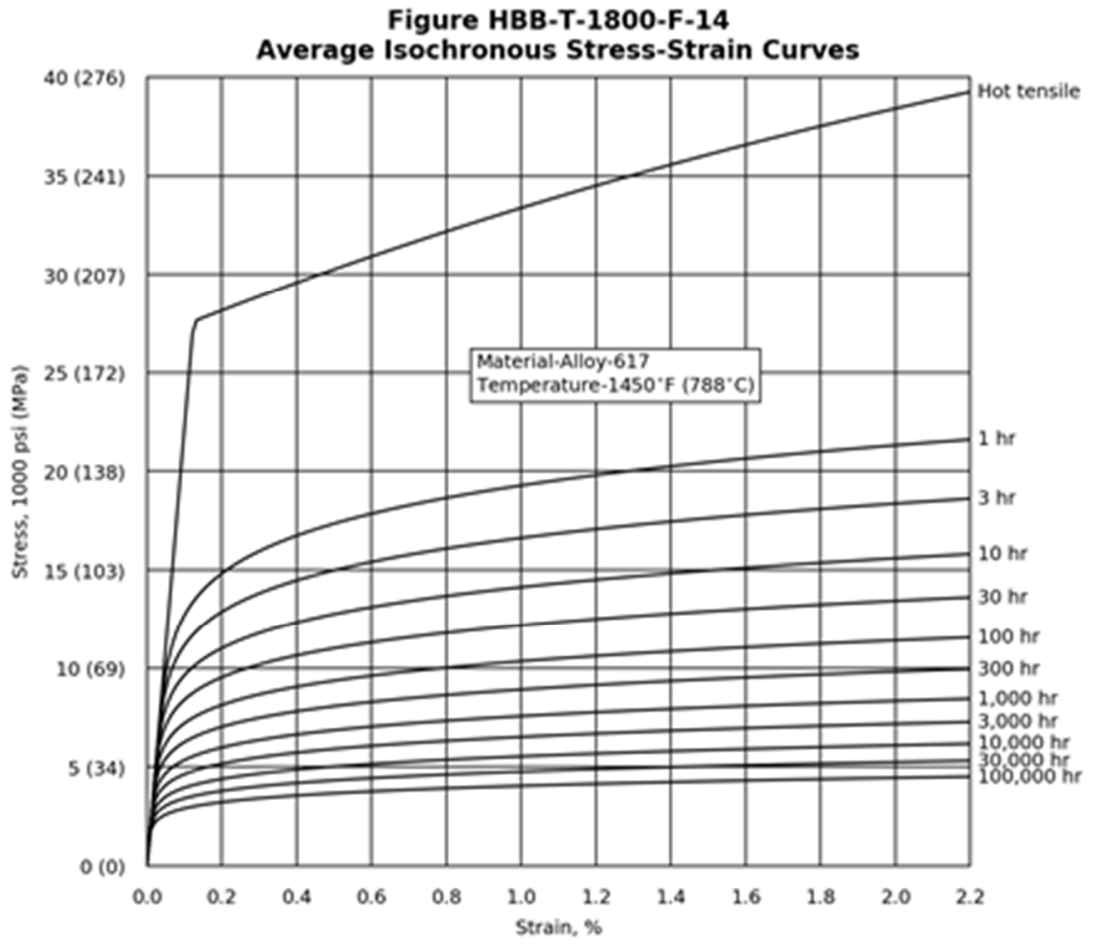

Figure HBB-T-1800-F-15 Isochronous Stress Strain Curve for $1500^{\circ} \mathrm{F}$

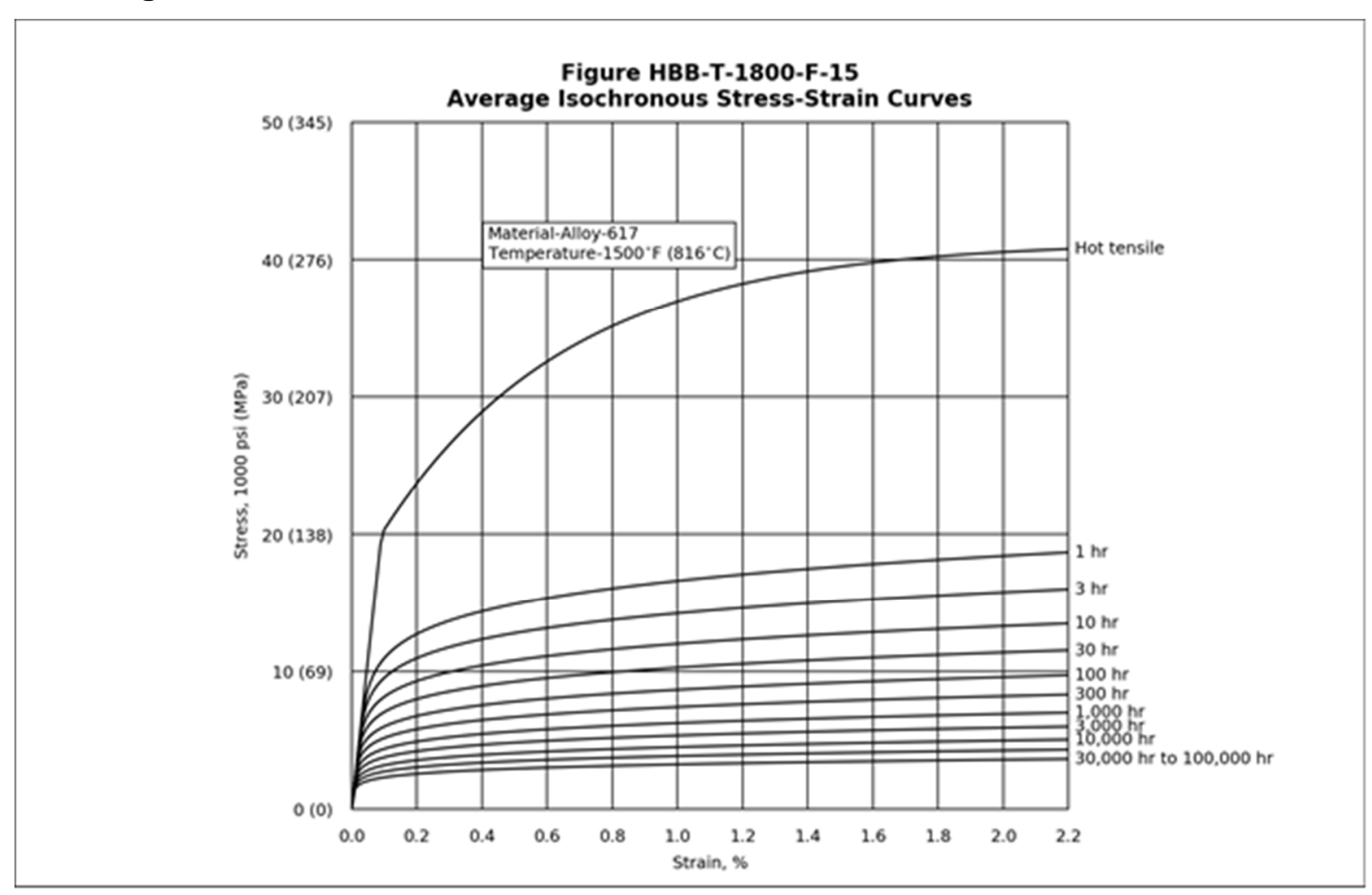




\section{DRAFT FOR COMMITTEE USE ONLY}

Figure HBB-T-1800-F-16 Isochronous Stress Strain Curve for $1550^{\circ} \mathrm{F}$

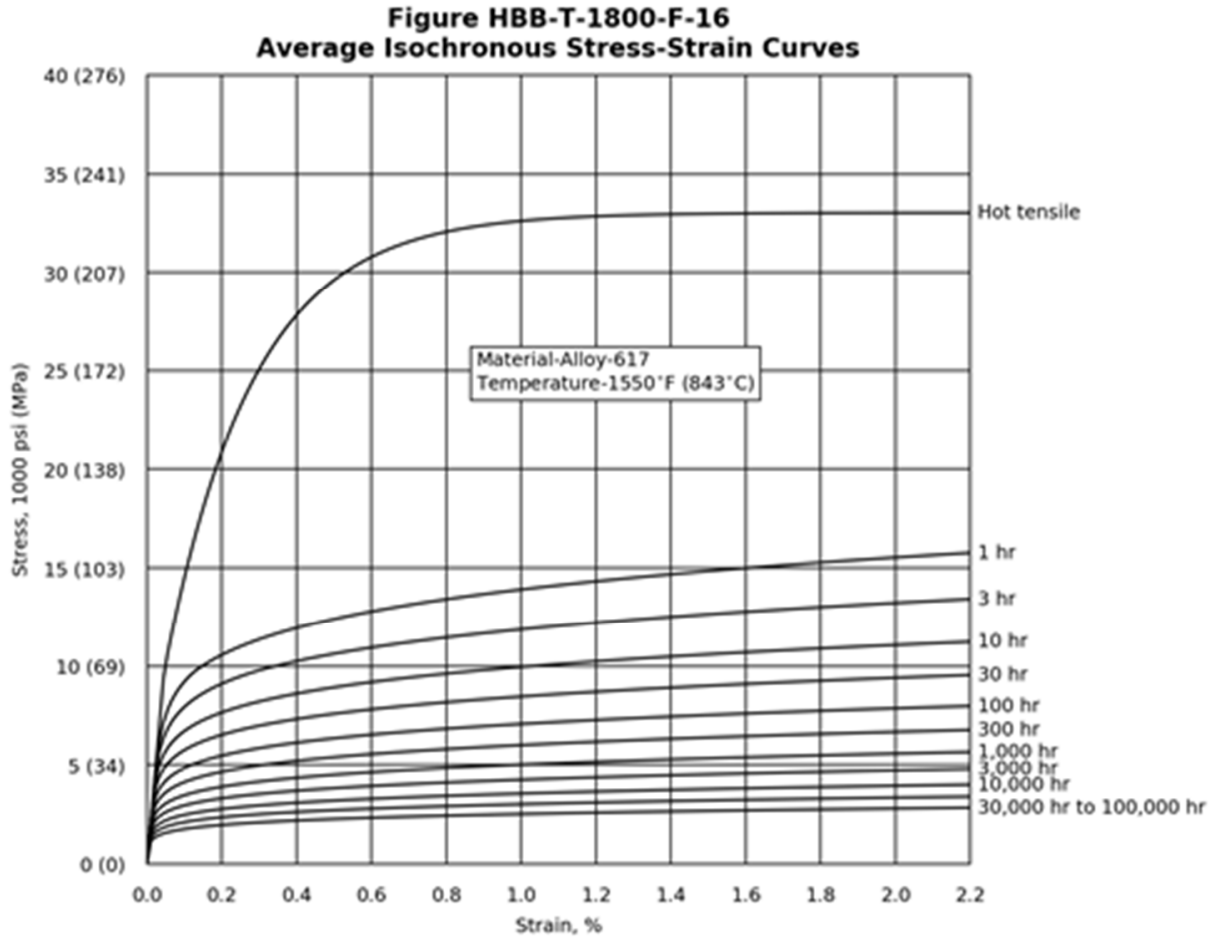

Figure HBB-T-1800-F-17 Isochronous Stress Strain Curve for $1600^{\circ} \mathrm{F}$

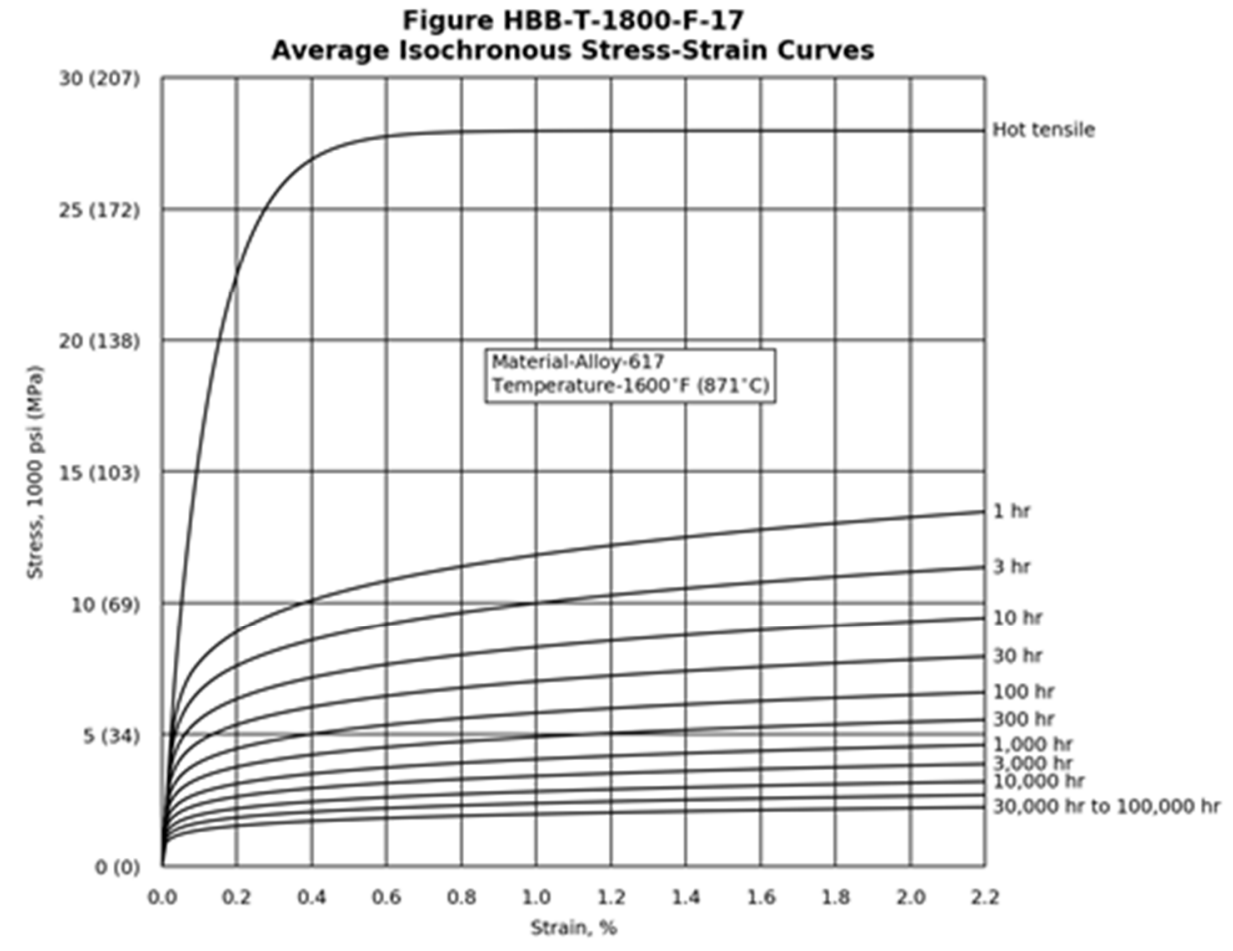




\section{DRAFT FOR COMMITTEE USE ONLY}

Figure HBB-T-1800-F-18 Isochronous Stress Strain Curve for $1650^{\circ} \mathrm{F}$

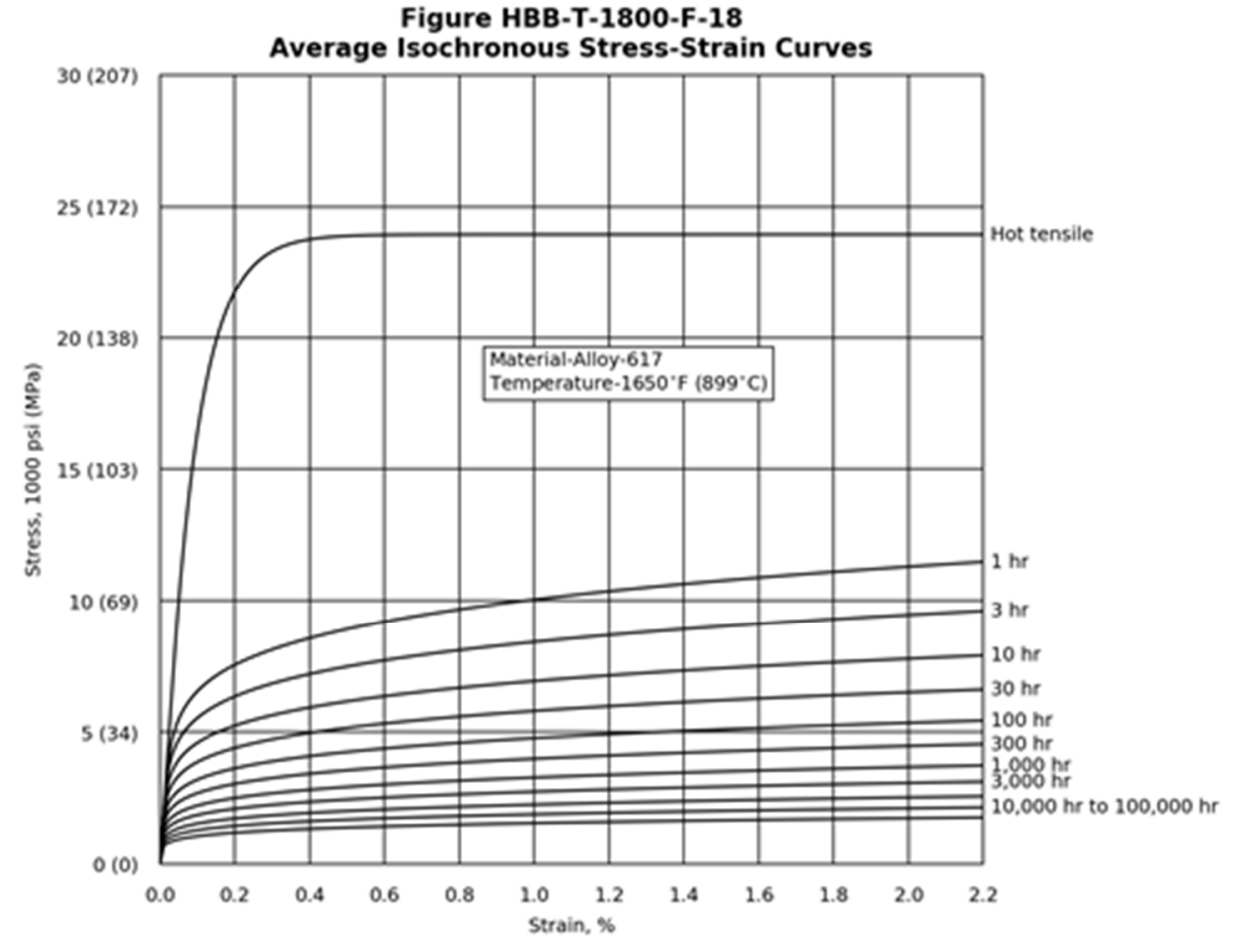

Figure HBB-T-1800-F-19 Isochronous Stress Strain Curve for $1700^{\circ} \mathrm{F}$

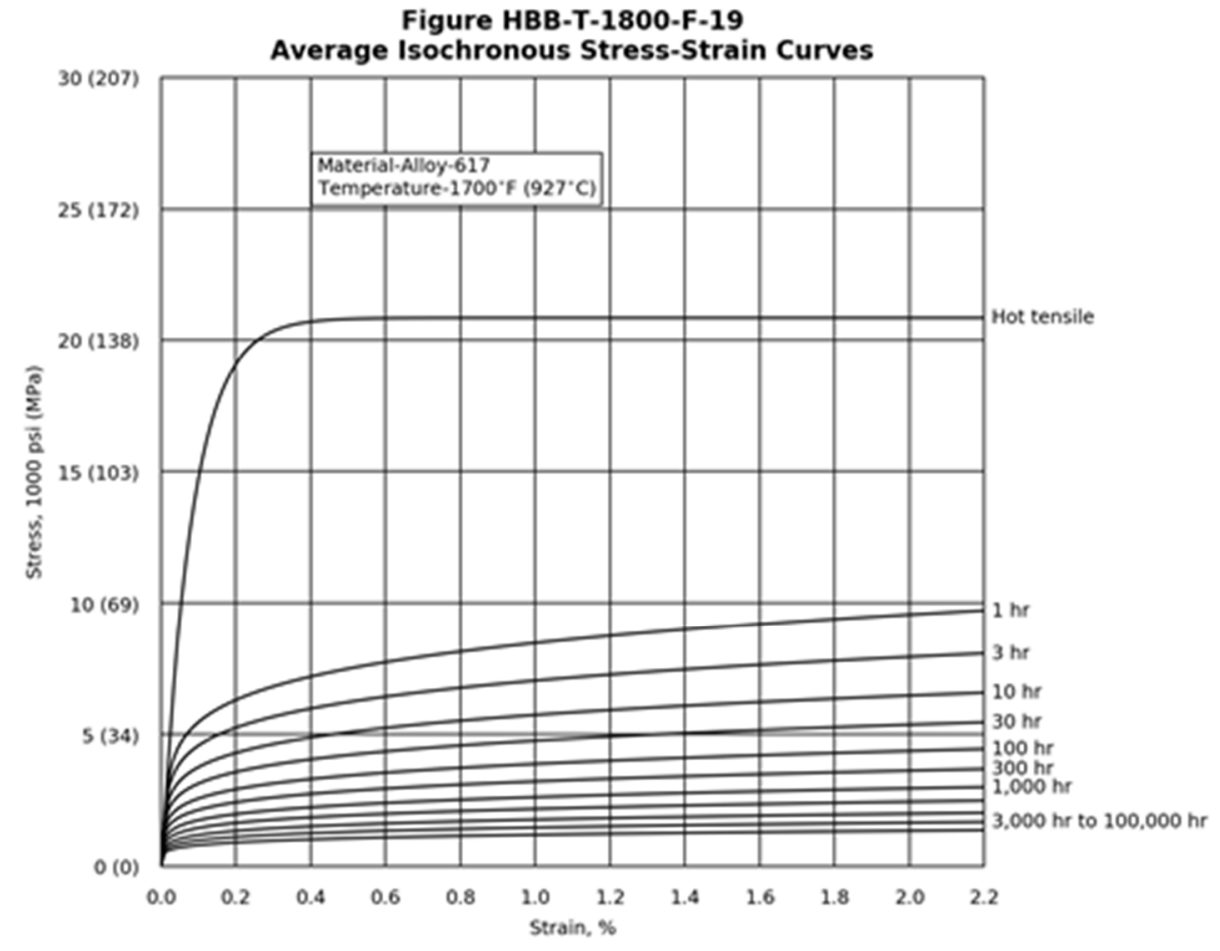




\section{DRAFT FOR COMMITTEE USE ONLY}

Figure HBB-T-1800-F-20 Isochronous Stress Strain Curve for $1750^{\circ} \mathrm{F}$

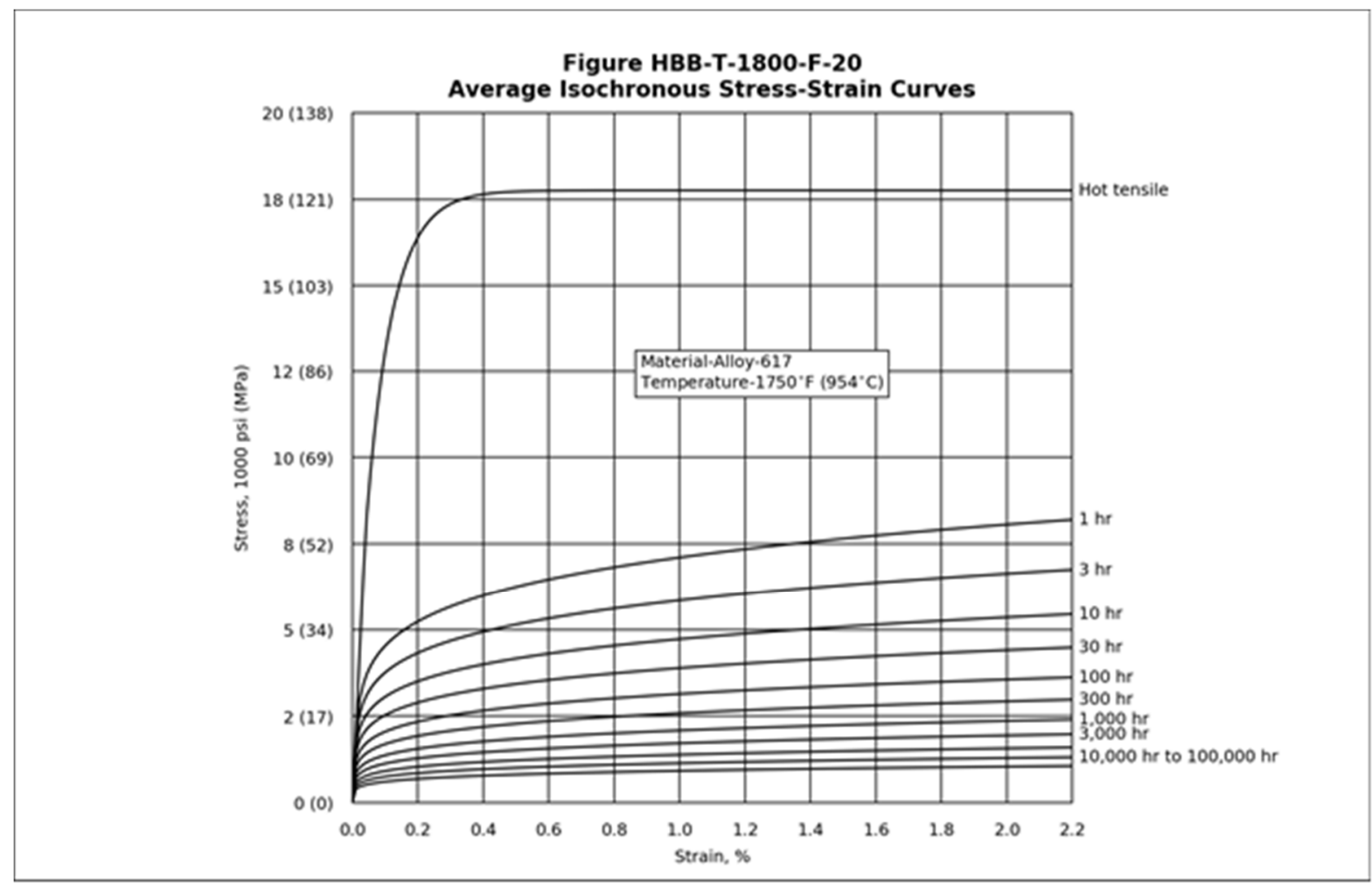

\section{HBB-T-1700 Special Requirements}

\section{HBB-T-1710 Special Strain Requirements at Welds}

\section{HBB-T-1715 Creep-Fatigue Reduction Factors}

Revise the reference for allowable number of design cycles, $N_{d}$, for parent material to Figure HBB-T-1420-1F of this Code Case. Revise the reference for the allowable time duration, $T_{d}$, based on parent material stress-to-rupture to HBB-I-14.6G of this Code Case and the reference for weld strength reduction factor to Table HBB-I-14.10F-1 of this Code Case. The factor $K^{\prime}$ is from Table HBB-T-1411-1 of this Code Case.

\section{HBB-T-1800 Isochronous Stress - Strain Relations HBB-T-1810 Objective}

Figures HBB-T-1800-F-1 through HBB-T-1800-F-20 of this Code Case provide graphs giving isochronous stress-strain curves, each graph being for Alloy 617 at a specific temperature. These graphs are currently under preparation.

\section{HBB-T-1820 Materials and Temperature Limits}

Data for Alloy 617 is added in Table HBB-T-1820-1 of this Code Case as indicated below.

Table HBB-T-1820-1

\begin{tabular}{cccc}
\hline Material & $\begin{array}{c}\text { Maximum } \\
\text { Temp. }^{\circ} \mathbf{F}\left({ }^{\circ} \mathbf{C}\right)\end{array}$ & $\begin{array}{c}\text { Temperature } \\
\text { Increment, }{ }^{\circ} \mathbf{F}\left({ }^{\circ} \mathbf{C}\right)\end{array}$ \\
\hline F & Alloy 617 & $1,750(950)$ & $50(28)$ \\
\hline
\end{tabular}




\section{DRAFT FOR COMMITTEE USE ONLY}

Appendix B 


\section{PHYSICAL PROPERTIES TABLES \\ THERMAL EXPANSION}

Table TE-4

Thermal Expansion for Alloy 617

\begin{tabular}{|c|c|c|c|}
\hline \multirow[b]{2}{*}{ Temperature, ${ }^{\circ} \mathbf{F}$} & \multicolumn{3}{|c|}{ Coefficients for N06617 } \\
\hline & $\mathbf{A}$ & $\mathbf{B}$ & $\mathbf{C}$ \\
\hline 70 & 7.0 & 7.0 & 0.0 \\
\hline 100 & 7.1 & 7.0 & 0.3 \\
\hline 150 & 7.1 & 7.1 & 0.7 \\
\hline 200 & 7.2 & 7.1 & 1.1 \\
\hline 250 & 7.3 & 7.1 & 1.6 \\
\hline 300 & 7.4 & 7.2 & 2.0 \\
\hline 350 & 7.5 & 7.2 & 2.4 \\
\hline 400 & 7.6 & 7.3 & 2.9 \\
\hline 450 & 7.7 & 7.3 & 3.4 \\
\hline 500 & 7.8 & 7.4 & 3.8 \\
\hline 550 & 7.9 & 7.4 & 4.3 \\
\hline 600 & 8.0 & 7.5 & 4.8 \\
\hline 650 & 8.2 & 7.5 & 5.3 \\
\hline 700 & 8.3 & 7.6 & 5.8 \\
\hline 750 & 8.4 & 7.6 & 6.3 \\
\hline 800 & 8.6 & 7.7 & 6.8 \\
\hline 850 & 8.7 & 7.8 & 7.3 \\
\hline 900 & 8.9 & 7.8 & 7.8 \\
\hline 950 & 9.0 & 7.9 & 8.4 \\
\hline 1,000 & 9.2 & 8.0 & 8.9 \\
\hline 1,050 & 9.4 & 8.0 & 9.5 \\
\hline 1,100 & 9.5 & 8.1 & 10.0 \\
\hline 1,150 & 9.7 & 8.2 & 10.6 \\
\hline 1,200 & 9.9 & 8.2 & 11.2 \\
\hline 1,250 & 10.1 & 8.3 & 11.8 \\
\hline 1,300 & 10.3 & 8.4 & 12.4 \\
\hline 1,350 & 10.5 & 8.5 & 13.0 \\
\hline 1,400 & 10.7 & 8.5 & 13.7 \\
\hline 1,450 & 10.9 & 8.6 & 14.3 \\
\hline 1,500 & 11.1 & 8.7 & 15.0 \\
\hline 1,550 & 11.3 & 8.8 & 15.6 \\
\hline 1,600 & 11.5 & 8.9 & 16.3 \\
\hline 1,650 & 11.8 & 9.0 & 17.0 \\
\hline 1,700 & 12.0 & 9.1 & 17.7 \\
\hline 1,750 & 12.2 & 9.1 & 18.5 \\
\hline $\begin{array}{l}\text { GENERAL NOTE: } \mathrm{C} \\
\text { thermal expansion } \mathrm{x} \\
\text { coefficient of thermal } \\
\text { to indicated temperatu } \\
\text { (in. } / 100 \mathrm{ft} \text { ) in going fro }\end{array}$ & $\begin{array}{l}\text { ent A } \\
\text { in./in.// } \\
\text { ion } \times 1 \\
\text { fficient } \\
\text { F t }\end{array}$ & $\begin{array}{l}\text { tantan } \\
\text { fficie } \\
\left.. /{ }^{\circ} \mathrm{F}\right) \\
\text { linea } \\
\text { mner }\end{array}$ & $\begin{array}{l}\text { efficie } \\
\text { the } \\
\text { from } \\
\text { expa }\end{array}$ \\
\hline
\end{tabular}


Table TE-4 (M)

Thermal Expansion for Alloy 617

\begin{tabular}{|c|c|c|c|}
\hline \multirow[b]{2}{*}{ Temperature, ${ }^{\circ} \mathrm{C}$} & \multicolumn{3}{|c|}{ Coefficients for N06617 } \\
\hline & $\mathbf{A}$ & B & $\mathbf{C}$ \\
\hline 20 & 12.6 & 12.6 & 0.0 \\
\hline 50 & 12.8 & 12.7 & 0.4 \\
\hline 75 & 12.9 & 12.7 & 0.7 \\
\hline 100 & 13.0 & 12.8 & 1.0 \\
\hline 125 & 13.2 & 12.9 & 1.4 \\
\hline 150 & 13.3 & 12.9 & 1.7 \\
\hline 175 & 13.5 & 13.0 & 2.0 \\
\hline 200 & 13.6 & 13.1 & 2.4 \\
\hline 225 & 13.8 & 13.2 & 2.7 \\
\hline 250 & 14.0 & 13.2 & 3.0 \\
\hline 275 & 14.2 & 13.3 & 3.4 \\
\hline 300 & 14.4 & 13.4 & 3.8 \\
\hline 325 & 14.6 & 13.5 & 4.1 \\
\hline 350 & 14.8 & 13.6 & 4.5 \\
\hline 375 & 15.0 & 13.7 & 4.9 \\
\hline 400 & 15.2 & 13.8 & 5.2 \\
\hline 425 & 15.4 & 13.9 & 5.6 \\
\hline 450 & 15.7 & 14.0 & 6.0 \\
\hline 475 & 15.9 & 14.1 & 6.4 \\
\hline 500 & 16.2 & 14.2 & 6.8 \\
\hline 525 & 16.4 & 14.3 & 7.2 \\
\hline 550 & 16.7 & 14.4 & 7.6 \\
\hline 575 & 17.0 & 14.5 & 8.0 \\
\hline 600 & 17.2 & 14.6 & 8.5 \\
\hline 625 & 17.5 & 14.7 & 8.9 \\
\hline 650 & 17.8 & 14.8 & 9.3 \\
\hline 675 & 18.1 & 15.0 & 9.8 \\
\hline 700 & 18.4 & 15.1 & 10.3 \\
\hline 725 & 18.8 & 15.2 & 10.7 \\
\hline 750 & 19.1 & 15.3 & 11.2 \\
\hline 775 & 19.4 & 15.5 & 11.7 \\
\hline 800 & 19.8 & 15.6 & 12.2 \\
\hline 825 & 20.1 & 15.7 & 12.7 \\
\hline 850 & 20.5 & 15.9 & 13.2 \\
\hline 875 & 20.8 & 16.0 & 13.7 \\
\hline 900 & 21.2 & 16.1 & 14.2 \\
\hline 925 & 21.6 & 16.3 & 14.7 \\
\hline 950 & 21.9 & 16.4 & 15.3 \\
\hline $\begin{array}{l}\text { GENERAL NOTE: } \\
\text { thermal expansion } x \\
\text { coefficient of therm } \\
20^{\circ} \mathrm{C} \text { to indicated t } \\
\text { expansion }(\mathrm{mm} / \mathrm{m}) \text { in }\end{array}$ & $\begin{array}{l}\mathrm{ent} \mathrm{A} \mathrm{i} \\
\mathrm{am} / \mathrm{mm} \\
\text { sion } \mathrm{X} \\
\text { ire. Co }\end{array}$ & $\begin{array}{l}\text { tantan } \\
\text { eefficie } \\
\mathrm{n} / \mathrm{mm} / \\
\mathrm{C} \text { is }\end{array}$ & $\begin{array}{l}\text { efficien } \\
\text { the } m \\
\text { going } \mathrm{ft} \\
\text { ar ther } \\
\text { ture. }\end{array}$ \\
\hline
\end{tabular}




\section{DRAFT FOR COMMITTEE USE ONLY}

\section{Thermal Conductivity and Thermal Diffusivity}

Table TCD

Nominal Coefficients of Thermal Conductivity (TC) and Thermal Diffusivity (TD) for Alloy 617

\begin{tabular}{ccc}
\hline & \multicolumn{2}{c}{ N06617 } \\
\cline { 2 - 3 } Temp., ${ }^{\mathbf{F}}$ & TC & TD \\
\hline 70 & 6.1 & 0.112 \\
100 & 6.3 & 0.114 \\
150 & 6.6 & 0.118 \\
200 & 6.9 & 0.122 \\
250 & 7.2 & 0.125 \\
300 & 7.5 & 0.129 \\
350 & 7.8 & 0.132 \\
400 & 8.1 & 0.136 \\
450 & 8.4 & 0.139 \\
500 & 8.7 & 0.142 \\
& & \\
550 & 9.0 & 0.145 \\
600 & 9.3 & 0.149 \\
650 & 9.5 & 0.152 \\
700 & 9.8 & 0.155 \\
750 & 10.0 & 0.158 \\
800 & 10.3 & 0.161 \\
850 & 10.5 & 0.164 \\
900 & 10.8 & 0.167 \\
950 & 11.0 & 0.171 \\
1,000 & 11.3 & 0.174 \\
1,050 & 12.1 & 0.177 \\
1,100 & 13.2 & 0.181 \\
1,150 & 14.1 & 0.184 \\
1,200 & 14.6 & 0.188 \\
1,250 & 14.9 & 0.192 \\
1,300 & 14.8 & 0.194 \\
1,350 & 14.7 & 0.191 \\
1,400 & 14.6 & 0.189 \\
1,450 & 14.5 & 0.188 \\
1,500 & 14.6 & 0.189 \\
1,550 & 14.7 & 0.191 \\
1,600 & 14.9 & 0.193 \\
1,650 & 15.1 & 0.196 \\
1,700 & 15.5 & 0.199 \\
1,750 & 15.9 & 0.203 \\
\hline & &
\end{tabular}

GENERAL NOTES:

(a) TC is the thermal conductivity, Btu/(hr-ft- $\left.{ }^{\circ} \mathrm{F}\right)$, and TD is the thermal diffusivity, $\mathrm{ft}^{2} / \mathrm{hr}$ : $\mathrm{TD}=\frac{\mathrm{TC}\left[\mathrm{Btu} / \mathrm{hr} \cdot \mathrm{ft}-{ }^{\circ} \mathrm{F}\right]}{\text { density }\left(\mathrm{lb} / \mathrm{ft}^{3}\right) \times \text { specific heat }\left(\mathrm{Btu} / \mathrm{lb}-{ }^{\circ} \mathrm{F}\right)}$

(b) Values of thermal expansion and thermal diffusivity should be used with the understanding that there is an associated $\pm 10 \%$ uncertainty. This uncertainty results from compositional variations and variables associated with original data acquisition and analysis. 


\section{DRAFT FOR COMMITTEE USE ONLY}

\begin{tabular}{|c|c|c|}
\hline Nominal Coefficients of Thermal $\mathrm{C}$ & $\begin{array}{l}\text { TCL } \\
\text { ducti } \\
\text { Alloy }\end{array}$ & TC) \\
\hline & & \\
\hline Temp.,${ }^{\circ} \mathrm{C}$ & TC & TD \\
\hline 20 & 10.5 & 2.88 \\
\hline 50 & 11.1 & 2.99 \\
\hline 75 & 11.6 & 3.08 \\
\hline 100 & 12.1 & 3.17 \\
\hline 125 & 12.6 & 3.25 \\
\hline 150 & 13.0 & 3.33 \\
\hline 175 & 13.5 & 3.41 \\
\hline 200 & 14.0 & 3.49 \\
\hline 225 & 14.4 & 3.57 \\
\hline 250 & 14.9 & 3.64 \\
\hline 275 & 15.3 & 3.71 \\
\hline 300 & 15.8 & 3.79 \\
\hline 325 & 16.2 & 3.86 \\
\hline 350 & 16.6 & 3.93 \\
\hline 375 & 17.0 & 4.01 \\
\hline 400 & 17.4 & 4.08 \\
\hline 425 & 17.8 & 4.15 \\
\hline 450 & 18.2 & 4.22 \\
\hline 475 & 18.6 & 4.30 \\
\hline 500 & 18.9 & 4.37 \\
\hline 525 & 19.3 & 4.45 \\
\hline 550 & 19.6 & 4.53 \\
\hline 575 & 21.7 & 4.60 \\
\hline 600 & 23.3 & 4.69 \\
\hline 625 & 24.5 & 4.77 \\
\hline 650 & 25.3 & 4.85 \\
\hline 675 & 25.7 & 4.94 \\
\hline 700 & 25.7 & 5.03 \\
\hline 725 & 25.4 & 4.94 \\
\hline 750 & 25.3 & 4.89 \\
\hline 775 & 25.2 & 4.86 \\
\hline 800 & 25.2 & 4.87 \\
\hline 825 & 25.3 & 4.90 \\
\hline 850 & 25.5 & 4.94 \\
\hline 875 & 25.8 & 5.00 \\
\hline 900 & 26.2 & 5.07 \\
\hline 925 & 26.7 & 5.14 \\
\hline 950 & 27.4 & 5.22 \\
\hline
\end{tabular}

GENERAL NOTES:

(a) TC is the thermal conductivity, $\mathrm{W} /\left(\mathrm{m} \cdot{ }^{\circ} \mathrm{C}\right)$, and TD is the thermal diffusivity, $10^{-6} \mathrm{~m}^{2} / \mathrm{sec}$ :

$\mathrm{TD}=\frac{\mathrm{TC}\left[\mathrm{W} /\left(\mathrm{m} \cdot{ }^{\circ} \mathrm{C}\right)\right]}{\text { density }\left(\mathrm{kg} / \mathrm{m}^{3}\right) \times \text { specific heat }\left[\mathrm{J} /\left(\mathrm{kg} \cdot{ }^{\circ} \mathrm{C}\right)\right]}$

(b) Values of thermal expansion and thermal diffusivity should be used with the understanding that there is an associated $\pm 10 \%$ uncertainty. This uncertainty results from compositional variations and variables associated with original data acquisition and analysis. 


\section{DRAFT FOR COMMITTEE USE ONLY}

\section{Modulus of Elasticity}

Table TM-4

Moduli of Elasticity $E$ of Alloy 617 for Given Temperatures

\begin{tabular}{|c|c|c|c|c|c|c|c|c|c|c|c|c|c|c|c|c|c|c|c|c|c|}
\hline \multirow[b]{2}{*}{ Material } & \multicolumn{21}{|c|}{ Modulus of Elasticity $E=$ Value Given $\times 10^{6} \mathrm{psi}$, for Temperature, ${ }^{\circ} \mathrm{F}$, of } \\
\hline & -325 & -200 & -100 & 70 & 200 & 300 & 400 & 500 & 600 & 700 & 800 & 900 & 1,000 & 1,100 & 1,200 & 1,300 & 1,400 & $\mathbf{1 , 5 0 0}$ & 1,600 & 1,700 & 1,800 \\
\hline N06617 & - & - & - & 29.2 & 28.4 & 28.0 & 27.7 & 27.4 & 27.0 & 26.5 & 26.0 & 25.5 & 24.9 & 24.3 & 23.8 & 23.2 & 22.5 & 21.8 & 21.0 & 20.2 & 19.3 \\
\hline
\end{tabular}

\section{Table TM-4 (M)}

Moduli of Elasticity $E$ of Alloy 617 for Given Temperatures

\begin{tabular}{|c|c|c|c|c|c|c|c|c|c|c|c|c|c|c|c|c|c|c|c|c|c|c|}
\hline \multirow[b]{2}{*}{ Material } & \multicolumn{22}{|c|}{ Modulus of Elasticity $E=$ Value Given $\times 10^{3} \mathrm{MPa}$, for Temperature, ${ }^{\circ} \mathrm{C}$, of } \\
\hline & -200 & -125 & -75 & 25 & 100 & 150 & 200 & 250 & 300 & 350 & 400 & 450 & 500 & 550 & 600 & 650 & 700 & 750 & 800 & 850 & 900 & 950 \\
\hline N06617 & - & - & - & 201 & 196 & 193 & 191 & 189 & 187 & 184 & 181 & 178 & 174 & 171 & 167 & 164 & 160 & 156 & 152 & 146 & 141 & 136 \\
\hline
\end{tabular}

